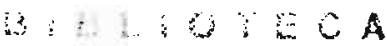

RETTUTOBE OUIMICA

Universidade de São Paulo

20.864

UNIVERSIDADE DE SÃO PAULO

INSTITUTO DE QUÍMICA

DEPARTAMENTO DE QUÍMICA FUNDAMENTAL

$* * *$

\title{
Uso de Eletrodos de Diamante na Eletrooxidação de
}

\section{Etanol}

\author{
Mauro Celso Ribeiro \\ Dissertação de Mestrado \\ Orientador: Prof. Dr. Paulo Teng-An Sumodjo
}

São Paulo

Setembro - 2004 


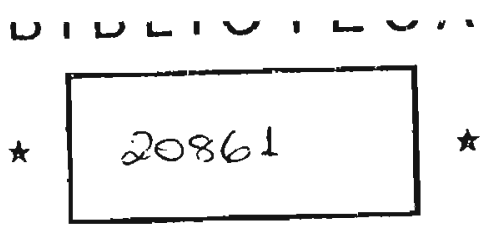

INSTITUTO DE QUIMICA UNIVERSIDADE DE SĀO PAULO

\section{Ficha Catalográfica}

Elaborada pela Divisão de Biblioteca e

Documentação do Conjunto das Químicas da USP.

\section{Ribeiro, Mauro Celso}

R484u Uso de eletrodos de diamante na eletrooxidação de etanol / Mauro Celso Ribeiro. .. São Paulo, 2004. $102 p$.

Dissertação (mestrado) - Instituto de Química da Universidade de Sào Paulo. Departamento de Química Fundamental.

Orientador: Sumodjo. Paulo Teng-An

1. Eletrodo: Fisico-quimica J. T. II. Sumodjo, Paulo Teng-An, orientador. 


\section{"Uso de eletrodos de diamante na eletrooxidação de etanol"}

\section{MAVRO CELSO RIBEIRO}

Dissertação de Mestrado submetida ao Instituto de Química da Universidade de São Paulo como parte dos requisitos necessários à obtenção do grau de Mestre em Química - Área: Físico-Química.

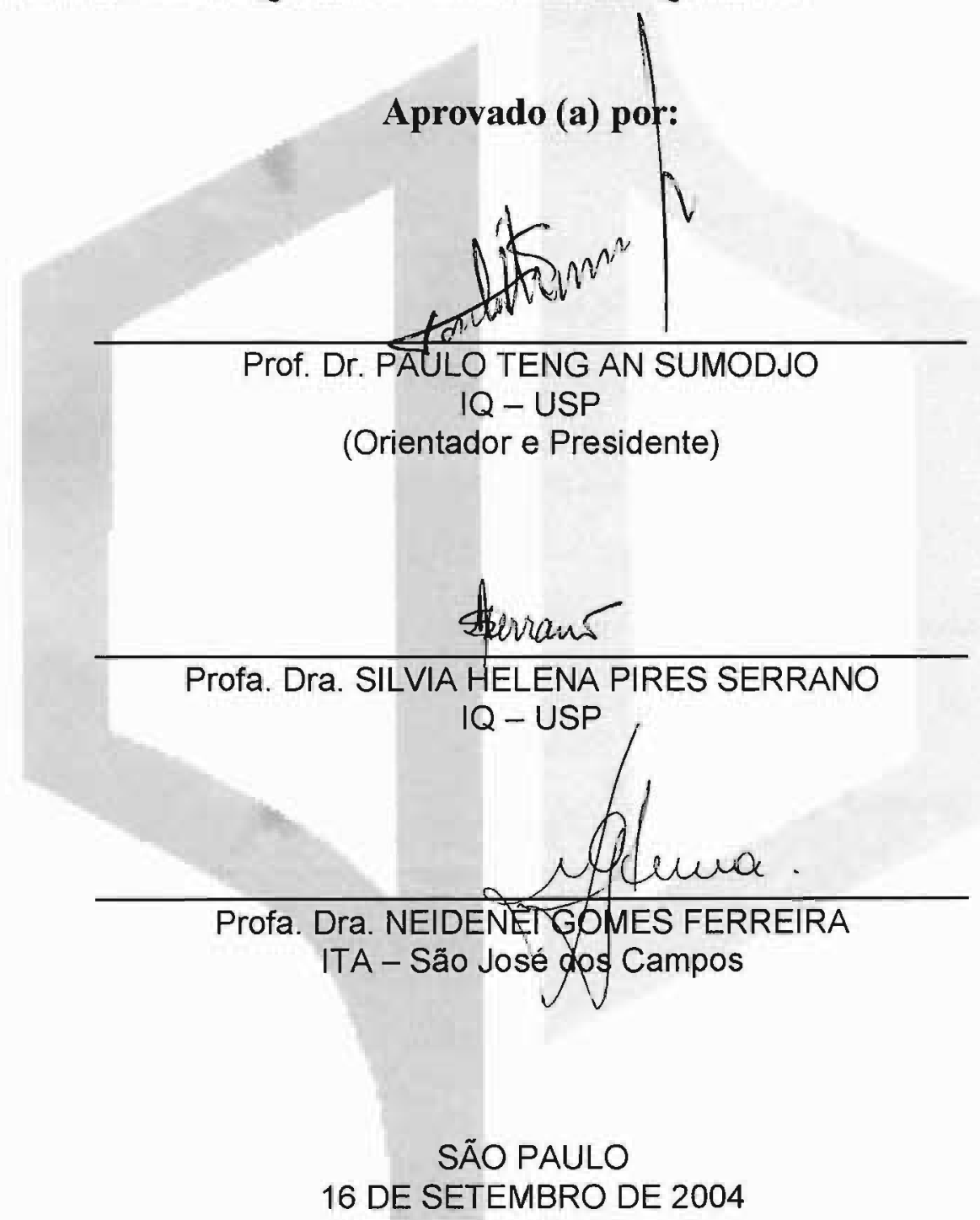


Dedicada:

A Deus:

porque dEle, e para Ele são todas as coisas...

À Mirtha,

o amor da minha vida.

Aos meus pais, João e Sônia:

Uma parte do trabalho é semear e cuidar da plantação com muito suor, DIA APÓS DIA.

A outra é colher os frutos.

Muito obrigado por terem tido a NOBREZA e a FÉ de fazer a primeira parte do trabalho... 


\section{Agradecimentos,}

- Ao Prof. Dr. Paulo T. Sumodjo pela acolhida em seu grupo de pesquisa, pelo seu estilo "dê-a-vara-e-não-o-peixe-ao-homem" de orientar e por toda confiança em mim depositada.

- À Dra. Leide L. Gonçalves por todo apoio dado, pelas injeções de ânimo e pelas discussões valiosas.

- Ao Prof. Evaldo J. Corat do Grupo de Diamantes do LAS/INPE pelas facilidades na obtenção dos filmes de Diamante.

- Aos meus companheiros do laboratório, Rodrigo e Marcos, e Luís, da Universidade São Francisco, pelo apoio informático, pelas discussões valiosas, e pelas amostras de diamante.

- Aos meus amigos e companheiros da Igreja UBF pelo apoio moral, espiritual e até financeiro. Vocês fizeram seus os meus problemas. Com isso, eu aprendi o que eu devo fazer por um amigo.

-À Universidade de São Paulo pela excelente infra-estrutura e ótimas condições de trabalho.

- Ao CNPq pela bolsa de estudos concedida, mantendo a seriedade de um compromisso mesmo em tempos de crise. Ela representa o Brasil que o Brasil tem que conhecer: sério e de ampla visão para o futuro. 


\section{Resumo}

Nesta dissertação discutem-se os resultados do estudo do efeito da modificação superficial de filmes de diamante dopados com boro (DDB) com partículas de Pt depositadas eletroquimicamente, sobre a reação de oxidação anódica de etanol em meio ácido. Foram investigadas a influência do potencial de deposição, da carga de deposição e do pré-tratamento eletroquímico em potenciais de reação de geração de $\mathrm{H}_{2}(\mathrm{RGH})$ e de $\mathrm{O}_{2}$ (RGO) no grau de dispersão da Pt e na eficiência do eletrodo de BDD-Pt para a reação de oxidação anódica de etanol. Pré-tratamentos catódicos tendem a aumentar a atividade do eletrodo para a RGO, embora este efeito não seja permanente e só seja observado em filmes novos. Polarizações anódicas contribuem para o aumento do sobrepotencial de $\mathrm{RGO}$, assim como causam a diminuição da eficiência de corrente para a deposição de Pt, embora surpreendentemente origine depósitos de Pt com maior área superficial e maior atividade para a oxidação anódica do etanol. Um modelo baseado em interações entre a superfície do diamante e o íon complexo de Pt é proposto para explicar a influência destes parâmetros nas características dos depósitos. 


\begin{abstract}
The results from the study of the surfacial modification of boron doped diamond (BDD) films with electrodeposited Pt particles for the anodic oxidation of ethanol in acidic media are discussed. It was investigated the influence of deposition potential, catalyst loading and electrochemical pre-treatment at $\mathrm{H}_{2}$ or $\mathrm{O}_{2}$ evolution reaction (HER and OER, respectively) potentials made prior to catalyst deposition, on the dispersion degree and electrode efficiency for ethanol anodic oxidation. HER polarizations tend to increase the film activity for the OER reaction, though this effect was not found to be permanent and was only observed in recently prepared BDD films. Anodic polarizations on the BDD contribute to the increase of OER overpotential as well as for the decreasing of the current efficiency for the Pt deposition, though it surprisingly resulted in more dispersed (higher surfacial area), more ethanol oxidation active Pt deposits. A tentative model based on interactions between $\mathrm{Pt}$ complex ion and $\mathrm{O}$ (or $\mathrm{H}$ ) terminated BDD surfaces is presented.
\end{abstract}




\section{Lista de abreviaturas}

DDB - Diamante Dopado com Boro.

TEM - Transmission Electron Microscopy (Microscopia de Transmissão Eletrônica).

MEV - Microscopia Eletrônica de Varredura.

STM - Scanning Transmission Microscopy (Microscopia de Varredura de Transmissão).

RGH - Reação de Geração de Hidrogênio.

RGO - Reação de Geração de Oxigênio.

HFCVD - Hot Filament Chemical Vapour Deposition (Deposição química a partir da fase vapor assistida por filamento quente).

MWCVD - Microwave Chemical Vapour Deposition (Deposição química a partir da fase vapor assistida por plasma de microondas).

EDS - Energy Dispersive Spectroscopy (Espectroscopia de energia dispersa).

XPS - X-ray Photoelectron Spectroscopy (Espectroscopia de Raios-X fotoeletrônicos).

SIMS - Secondary Ion Mass Spectrometry (Espectrometria de massas de íons secundários).

UPD - Under Potential Deposition, Deposição em regime sub-potencial. 
Índice

1. Introdução geral

2. Aspectos Gerais

2.1 - Características e síntese de diamantes .............................................................. 12

2.2 - A Eletroquímica da Platina em Meio Ácido ................................. 20

2.3 - Voltametria cíclica ............................................................................................. 21

2.4 - Técnicas eletrônicas.......................................................................................... 22

2.4.1 - Microscopia eletrônica de varredura (MEV)..................................... 22

2.4.2- Espectroscopia de energia dispersa (EDS) ...................................... 23

3. Revisão Bibliográfica 25

3.1 - Diamante dopado com boro (DDB) em Eletroquímica .............................. 25

3.2 - Modificação com Platina ................................................................................... 31

3.2.1 - Mecanismo de Eletrodeposição de Pt sobre eletrodos inertes .......... 32

3.2.2 - Natureza e pré-tratamento do substrato ............................................... 35

3.3 - Deposição de metais e de óxidos metálicos sobre DDB ............................... 41

3.3.1 - Deposição de metais .......................................................................... 41

3.3.2 - Deposição de óxidos metálicos ............................................................ 44

3.3.3 - Deposição de metais e de óxidos metálicos para reações não- 45 eletroquímicas

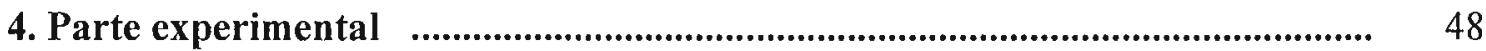

4.1 - Reagentes e Soluções ..................................................................................... 48

4.2 - Célula Eletroquímica ..................................................................................... 49

4.2.1 - Eletrodo de Trabalho ......................................................................... 49

4.3 - Metodologia .............................................................................................. 50

4.4 - Instrumentação ............................................................................................ 51

5. Resultados e Discussão …........................................................................... 52

5.1 - Caracterização Eletroquímica ........................................................................ 52

5.1.1 - Estudos Preliminares ....................................................................... 52

5.1.2 - Pré-tratamentos eletroquímicos ............................................................. 56 
5.2 - Modificação com Platina .................................................................................. 65

5.2.1 - Eletrodeposição de Pt: Estudos Preliminares ................................... 65

5.2.2 - Influência do potencial de eletrodeposição e da quantidade de Pt. 66

5.2.3 - Eletrodeposição de Pt: Efeito do tratamento superficial do 77 substrato

5.2.3.1 - Area eletroquímica dos depósitos de Pt

85

5.2.3.2 - Área eletroquímica e cargas de oxidação de etanol........ 88

6. Conclusões ...

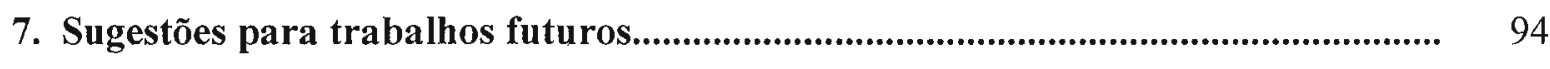

8. Referências Bibliográficas 95

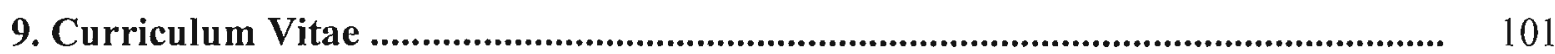




\section{INTRODUÇÃO GERAL}

O crescimento populacional e a modernização dos meios de comunicação vêm fazendo com que o Homem se dê conta de que vive em um ambiente cujos recursos naturais são finitos. Por isso, ao contrário do que ocorria nas etapas iniciais da Revolução Industrial, desde a última metade do século passado tem sido observada uma crescente preocupação com o Meio Ambiente. Entretanto, o fato de a matriz energética do mundo inteiro ainda ser baseada na combustão de petróleo, carvão e gás natural, torna apenas paliativo qualquer esforço no sentido da diminuição do impacto ambiental causado pelo uso destes combustíveis fósseis. Paralelamente, a degradação do Meio Ambiente causada pelo uso de pesticidas, fertilizantes e de processos industriais ambientalmente agressivos tem também motivado fortemente a procura por novos processos industriais e de métodos mais eficientes de tratamento de efluentes.

Nesse contexto, a Eletroquímica pode dar uma grande contribuição, tanto para a obtenção de energia limpa, quanto na área do tratamento eletroquímico de efluentes.

Energia limpa, ou seja, energia obtida com mais baixas emissões de poluentes pode ser obtida eletroquimicamente através de dispositivos chamados de pilhas ${ }^{\prime}$. Nas pilhas primárias (não recarregáveis) todo o material oxidável ou redutível se encontra na pilha e não pode ser substituído quando a pilha se descarrega. As pilhas secundárias, ou baterias, apresentam vida útil mais longa por serem recarregáveis, mas esse processo necessita de eletricidade, que é cara. Além desses problemas, há também o fato de que essas pilhas apresentam em sua composição substâncias nocivas ao Meio Ambiente, tais como óxidos de manganês, chumbo, cádmio ou lítio. As pilhas a combustível (ou pilhas terciárias) também podem ter em sua composição substâncias tóxicas tais como ácido fosfórico e níquel. Entretanto, sua vantagem está no tempo de vida útil mais longo, visto que se pode renovar o combustível, e a possibilidade de utilizar combustíveis mais simples e provenientes de fontes renováveis $\left(\mathrm{H}_{2}\right.$ ou metanol). Nestas pilhas, o combustível é oxidado no anodo, segundo a reação:

$$
\mathrm{H}_{2} \longrightarrow 2 \mathrm{H}^{+}+2 \mathrm{e}^{-}
$$

se o combustível for $\mathrm{H}_{2}$ ou 


$$
\mathrm{CH}_{3} \mathrm{OH}+3 \mathrm{H}_{2} \mathrm{O} \longrightarrow \mathrm{CO}_{2}+6 \mathrm{H}^{+}+6 \mathrm{e}^{-}
$$

se o combustível for metanol.

No catodo, $\mathrm{o} \mathrm{O}_{2}$, puro ou proveniente do ar, é reduzido segundo a reação:

$$
\mathrm{O}_{2}+4 \mathrm{H}^{+}+4 \mathrm{e}^{-} \longrightarrow 2 \mathrm{H}_{2} \mathrm{O}
$$

É sabido que estas reações ocorrem com uma etapa de adsorção de espécies intermediárias à superfície do eletrodo'. Quando o material de eletrodo contribui de alguma forma (seja por adsorção de intermediários à sua superfície, ou não) para o aumento da velocidade da reação, diz-se que ele é um eletrocatalisador. Alguns metais de transição e seus óxidos, ligas e complexos apresentam atividade eletrocatalítica para diferentes tipos de reações importantes. Contudo, sabe-se que a platina é o material que apresenta melhor desempenho para as reações existentes nas pilhas a combustível, justamente por apresentar melhores condições de adsorção e decomposição de intermediários sobre a sua superfície.

Para o funcionamento destas pilhas a combustível, fatores tais como a geometria da célula, a temperatura, a relação energia/peso do dispositivo são parâmetros importantes. Contudo, em se falando do material de eletrodo, o mesmo deve apresentar as seguintes características:

- Baixo custo;

- Ampla área eletroquímica;

- Mínima ocorrência de reações colaterais;

- Mínima geração de espécies que possam inibir as reações sobre o eletrodo;

- Estabilidade química.

Para se conseguir preencher os dois primeiros pré-requisitos, existem eletrodos em que partículas nanométricas de um metal eletrocatalisador são dispersas em um meio inerte, que na maioria das aplicações é carbono altamente particulado.

Entretanto, estes eletrodos apresentam muitos problemas. Dentre eles:

- O bloqueio de sítios ativos do catalisador por intermediários de oxidação do combustível fortemente adsorvidos do combustível, ou seja, o envenenamento do catalisador ${ }^{1}$. 
- Por serem muito pequenas, as partículas nanométricas do catalisador metálico (diâmetro: $3-10 \mathrm{~nm}$ ) tendem a aglutinar-se nas temperaturas de funcionamento do dispositivo. Isso causa diminuição do grau de dispersão do metal e, portanto há a queda da sua atividade catalítica ${ }^{1}$.

- Corrosão e erosão do suporte carbonoso do catalisador ${ }^{2-4}$.

Para minimizar estes problemas, várias abordagens têm sido propostas. Visando a diminuição do fenômeno de envenenamento do eletrocatalisador, é proposta a utilização de ligas metálicas como material eletrocatalisador ${ }^{1}$. Deve-se dizer, entretanto que estas ligas apresentam diminuição progressiva da atividade eletroquímica devida principalmente à dissolução do metal associado à platina.

Vários tipos de combustíveis são utilizados ou estudados nestes dispositivos eletroquímicos, tais como $\mathrm{H}_{2}$, hidrazina, etileno, etano, etanol e metanol. Dentre estes, os combustíveis provenientes da Biomassa são interessantes, visto que seu uso não resulta em um aumento líquido nos níveis atmosféricos de $\mathrm{CO}_{2}$. Dentre estes, o mais estudado e utilizado é o metanol, por apresentar uma cinética mais rápida de oxidação, embora apresente alta toxicidade. Por outro lado, o etanol embora apresente uma cinética de oxidação mais lenta, apresenta-se como uma boa alternativa, especialmente no Brasil, que possui uma ampla rede de produção e de distribuição deste combustível.

Além da geração de energia, um outro importante campo de aplicação da Eletroquímica é o tratamento de efluentes. No tratamento de efluentes podem ser empregados principalmente três métodos: o método biológico, o método químico e o método eletroquímico. $\mathrm{O}$ método biológico consiste no uso de microorganismos que degradam poluentes, transformando-os em resíduos menos agressivos ao Meio Ambiente. No método químico, busca-se alcançar o mesmo objetivo, mas com a utilização de substâncias químicas no tratamento dos resíduos poluentes. O primeiro tem como vantagens sobre o segundo, o seu relativamente baixo custo operacional, já que não há a necessidade de adição de grandes quantidades de reagentes químicos com a posterior geração de mais resíduos. A grande desvantagem entretanto, do método biológico, é que não é possível a decomposição de alguns resíduos inorgânicos, tais como cianetos, nem de moléculas orgânicas mais estáveis que correspondem às que têm sistemas aromáticos em sua estrutura. $\mathrm{O}$ tratamento químico pode reduzir a concentração destes poluentes, 
embora isso resulte em um outro problema, que é o da necessidade de remoção dos produtos da reação do meio. Além disso, deve-se dizer também que a maioria dos processos inseridos nas categorias acima citadas, não elimina quantitativamente os poluentes. O método eletroquímico é uma boa alternativa quando se busca a obtenção de baixas concentrações ou a remoção total de um certo resíduo. Nestes dispositivos, o efluente (orgânico ou inorgânico) é oxidado eletroquimicamente gerando uma substância menos tóxica. No caso de resíduos orgânicos, a oxidação leva a gás $\mathrm{CO}_{2}$. Contudo, devese dizer que nestes dispositivos, da mesma forma que nas células a combustível, os eletrodos também sofrem acentuada erosão e corrosão.

Neste contexto, eletrodos de filme de diamante dopado com boro (DDB) encontram grande possibilidade de aplicação, já que suas principais características são a boa condutividade e a resistência à corrosão e à erosão. Isso faz com que este material seja excelente candidato ao uso como meio dispersante (suporte) para eletrocatalisadores, em substituição ao carbono particulado como material de suporte para catalisadores em células a combustível, bem como para o uso como material de eletrodo em eletrolisadores.

Nesta dissertação, com o intuito de se estabelecer uma visão geral sobre as potencialidades do diamante, é apresentada inicialmente uma rápida introdução sobre as técnicas de síntese, principais características de filmes de diamante e suas aplicações. Em seguida, há uma revisão bibliográfica versando sobre o estudo e caracterização deste material como eletrodo na ausência e na presença de partículas de eletrocatalisador na sua superfície. Devido ao fato de ainda haverem poucos trabalhos versando sobre a deposição de Pt sobre DDB para fins eletrocatalíticos, são também relacionados alguns trabalhos de modificação superficial de grafite com Pt à guisa de comparação com o sistema DDB/Pt. Neste capítulo ainda, por ser o diamante um material relativamente novo e intensamente explorado, há também uma pequena revisão bibliográfica sobre aplicações de diamante particulado com substrato para catalisadores (não eletroquímicos) para reações importantes.

Em vista do que foi discutido neste item, o objetivo deste trabalho é estudar a aplicação de eletrodos de filmes de DDB como material de suporte para a deposição de platina e subseqüente oxidação anódica de etanol. Para tanto, no item Resultados $e$ 
Discussão são apresentados e discutidos primeiramente os resultados obtidos durante o estudo da estabilidade estrutural e eletroquímica do $\mathrm{DDB}$ em meio ácido $\left(\mathrm{H}_{2} \mathrm{SO}_{4} 0,5 \mathrm{M}\right)$, com ênfase nos efeitos de polarizações exaustivas em potenciais de reação de geração de $\mathrm{O}_{2}$ (RGO) e de $\mathrm{H}_{2}(\mathrm{RGH})$ sobre a resposta eletroquímica de filmes de DDB. Posteriormente, trata-se da influência destes pré-tratamentos de RGH e de RGO na eletrodeposição de Pt sobre eletrodos de filme de diamante (BDD/Pt) e são discutidos os resultados do estudo da reação de oxidação anódica de etanol em meio de $\mathrm{H}_{2} \mathrm{SO}_{4} \quad 0,5 \mathrm{M}$ utilizando estes eletrodos de BDD-Pt.

Avaliaram-se, portanto, os efeitos do potencial utilizado para eletrodeposição da Pt e do tipo de pré-tratamento eletroquímico, ao qual o filme de diamante foi submetido antes da deposição da $\mathrm{Pt}$, na atividade eletroquímica apresentada pelo mesmo na oxidação do etanol.

\section{2- ASPECTOS GERAIS}

\section{1 - Características e Síntese de Diamantes ${ }^{5,6}$}

O diamante apresenta propriedades fisico-químicas especiais (Tabela 2.1). Sua dureza e condutividade térmica são maiores do que qualquer outro material. Estas características aliadas à sua baixa reatividade química (o que redunda em resistência à corrosão), fazem do diamante um material com múltiplas aplicações, tais como:

- revestimento de ferramentas abrasivas (corte, furação, desbaste);

- materiais de eletrodo para meios quimicamente agressivos ${ }^{7}$;

- meio de dispersão para catalisadores em processos a altas temperaturas e pressões ${ }^{8}$. 
Há atualmente dois métodos para obtenção de diamantes. O método HPHT e o método CVD. Pelo método HPHT "High Pressure, High Temperature" são obtidos diamantes em forma de pequenos cristais ou pós. Pelo método CVD "Chemical Vapour Deposition", ou "deposição química a partir da fase vapor", que será discutido a seguir, são obtidos filmes policristalinos de diamantes, sendo que o tamanho dos cristais é da ordem de micrometros.

As pesquisas sobre a síntese e a aplicação de filmes de diamante CVD tiveram início ainda nos anos 50. A primeira aplicação proposta foi a de revestimentos anti-corrosão de estruturas metálicas expostas à ação do tempo. Mais recentemente, surgiu também o interesse pela pesquisa do uso destes filmes de diamante como revestimento antibiorejeição em próteses clínicas e como revestimento de ferramentas de corte e abrasão, aproveitando a baixa reatividade desta substância. Entretanto, devido à grande diferença de coeficientes de dilatação entre o diamante e alguns metais (tabela 2.1), e também devido ao baixo coeficiente de difusão de carbono nestes metais, filmes crescidos sobre aço, por exemplo, apresentam problemas de aderência ao substrato. Uma alternativa muito pesquisada tem sido a deposição de diamante feita após um tratamento superficial do substrato metálico. Este processo permite a formação de um filme cujo coeficiente de dilatação térmica seja intermediário aos coeficientes do substrato metálico e do diamante, o que contribui para a minimização da tensão da interface metal / diamante. No Brasil, a pesquisa sobre o revestimento de estruturas metálicas, próteses e de ferramentas de corte com filmes de diamante policristalino tem sido intensamente desenvolvida pelo Grupo de Diamantes do Laboratório Associado de Sensores do Instituto Nacional de Pesquisas Espaciais (INPE - LAS).

Além das aplicações acima descritas, pode-se citar o emprego de filmes autosustentáveis de diamante - cujo substrato no qual o filme foi crescido é removido após tratamento químico do substrato - na confecção de protetores anti-erosão para sensores de raios $\mathrm{X}$ e de infravermelho que equipam satélites, mísseis ou aeronaves. 
TABELA 2.1: Propriedades do diamante. Adaptada da referência [5].

\begin{tabular}{|c|c|c|c|c|c|}
\hline Material & $\begin{array}{l}\text { Condutividade } \\
\text { térmica / } \mathrm{W} \mathrm{cm} \mathrm{cm}^{-1} \mathrm{C}^{-1}\end{array}$ & $\begin{array}{c}\text { Dureza / } \\
\mathrm{kg} \mathrm{mm}^{-2}(298 \mathrm{~K})\end{array}$ & $\begin{array}{c}\text { Coeficiente de } \\
\text { expansão térmica } \\
\times 10^{-6}{ }^{\circ} \mathrm{C}^{-1}\end{array}$ & $\begin{array}{c}\text { Resistividade / } \\
\text { ohm cm }\end{array}$ & $\begin{array}{c}\text { Bandgap } \\
(\mathrm{eV})\end{array}$ \\
\hline \multicolumn{6}{|c|}{ 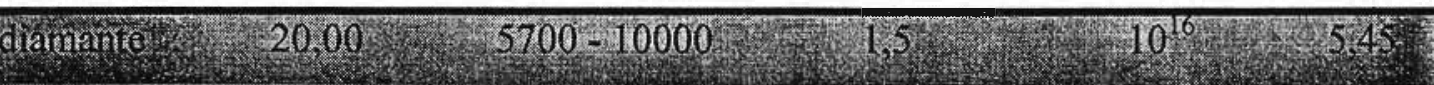 } \\
\hline DDB* & 20,00 & $5700-10000$ & 1,5 & $10^{-2}$ & -.---- \\
\hline grafite & ---- & -..-- & --.----- & $4,2 \times 10^{-2}$ & -..-- \\
\hline $\mathrm{B}_{5} \mathrm{~N}_{3}$ & 13,00 & 4500 & - & ------ & -..-- \\
\hline ferro & 0,82 & -------- & 9,1 & $10 \times 10^{-3}$ & ------ \\
\hline cobre & 3,80 & 40 & 14,1 & $1,7 \times 10^{-3}$ & $-\cdots$ \\
\hline silício & 1,45 & 1000 & 2.6 & $10^{3}$ & 1,1 \\
\hline GaAs & 0,53 & 600 & -..-- & $10^{8}$ & 1,4 \\
\hline ouro & ----.-- & --..-- & 13,2 & $2,4 \times 10^{-3}$ & ----- \\
\hline
\end{tabular}

$\mathrm{Na}$ deposição de filmes de diamante pelo processo CVD, passa pelo interior do reator um fluxo gasoso formado por uma mistura de metano (l a $5 \%$ ) e hidrogênio. Esta mistura é aquecida a altas temperaturas (acima de $2000 \mathrm{~K}$ ). O primeiro passo da deposição de diamante consiste na adsorção e difusão, até o meio do substrato, de espécies contendo carbono, até a formação de uma camada rica em carbono difundido e de carbetos, que apresentam maior resistência à difusão de carbono. A partir dessa camada de carbetos é que o filme de diamante propriamente dito começa a crescer, com taxas de nucleação e de crescimento que dependem de fatores diversos tais como:

- do pré-tratamento do substrato: maiores taxas de formação de núcleos de diamante são obtidas em substratos que são pré-tratados em ultrassom com uma suspensão de pó de diamante. Resultados ligeiramente inferiores são obtidos quando o pó de diamante é substituído por carbeto de boro ou $\mathrm{Al}_{2} \mathrm{O}_{3}$. Acredita-se que além de aumentar o número de sítios de deposição através da abrasão superficial, estes tratamentos podem inserir na superfície do substrato partículas do material em suspensão que podem servir de gérmens de cristalização para o diamante.

- do material do filamento: Foram testados vários metais de alto ponto de fusão. Destes, os mais efetivos são os de mais alto ponto de fusão (W e Ta), porque o gás $\mathrm{H}_{2}$ 
apresenta maior taxa de formação de radicais $\mathrm{H}$, em temperaturas mais altas (acima de $2000 \mathrm{~K}$ ). São necessárias altas concentrações de radicais $\mathrm{H}$ no interior do reator. Esses radicais atacam preferencialmente o carbono $\mathrm{sp}^{2}$ e amorfo, que eventualmente se formam no filme em formação, resultando no crescimento de um filme de diamante (carbono $\mathrm{sp}^{3}$ ) de alta pureza.

- - da proporção $\mathrm{H}_{2} / \mathrm{CH}_{4}$ utilizada. Foi observado que filmes de diamante de mais alta qualidade (menor teor de carbono $\mathrm{sp}^{2}$ ) são obtidos com menores concentrações de $\mathrm{CH}_{4}$ (inferiores a $1 \%$ ). Acima desta faixa de concentrações, há a formação de um filme que é uma mistura de diamante, grafite e carbono amorfo.

O processo de ativação da mistura gasosa no interior do reator (Figura 2.2) é a principal diferença entre os vários métodos de crescimento de diamante hoje disponíveis. O processo de crescimento pode ser térmico (filamento quente), por plasma de microondas de alta potência, ou por chama de combustão.

$\mathrm{Na}$ deposição química a vapor assistida por filamento quente (HFCVD), o substrato é posicionado de 1 a $10 \mathrm{~mm}$ abaixo do filamento quente e a mistura gasosa fluxa no interior do reator (figura $2.2 \mathrm{~A}$ ). Nestas condições, o hidrogênio molecular dissocia-se cataliticamente sobre a superfície do filamento quente para ativar o processo de deposição de diamante. O filamento quente pode ser de W, Mo ou Ta, usualmente aquecido a $2000-2400{ }^{\circ} \mathrm{C}$.

$\mathrm{Na}$ deposição química a vapor assistida por microondas (MWCVD), a ação de microondas de alta potência faz com que os elétrons contidos na mistura gasosa sejam excitados ao ponto de chocarem-se contra as moléculas do gás, resultando na formação de uma bola de plasma, constituída por hidrogênio atômico e por espécies ativadas de carbono. Nestas condições, no substrato normalmente colocado próximo à bola de plasma, há a formação do filme de diamante (figura $2.2 \mathrm{~B}$ ).

Deposição em plasma de combustão ${ }^{5,6}$, processo pelo qual a ativação do hidrocarboneto é feita através da sua combustão incompleta no interior do reator, sendo o substrato posicionado próximo à chama formada. As misturas geralmente utilizadas são: $\mathrm{C}_{2} \mathrm{H}_{2} / \mathrm{H}_{2} / \mathrm{O}_{2}, \mathrm{C}_{2} \mathrm{H}_{2} / \mathrm{O}_{2}, \mathrm{C}_{2} \mathrm{H}_{4} / \mathrm{O}_{2}$ e $\mathrm{C}_{3} \mathrm{H}_{6} / \mathrm{O}_{2}$.

Entretanto, qualquer que seja o processo de ativação empregado, pode haver no interior do reator a formação de carbono $\mathrm{sp}^{2}$ (não-diamante) no filme em crescimento. 
Mas a alta concentração de radicais $\mathrm{H}$ no ambiente faz com que esta forma mais reativa de carbono volte ao plasma na forma de algum radical hidrogenado de carbono (Fig. 2.1).

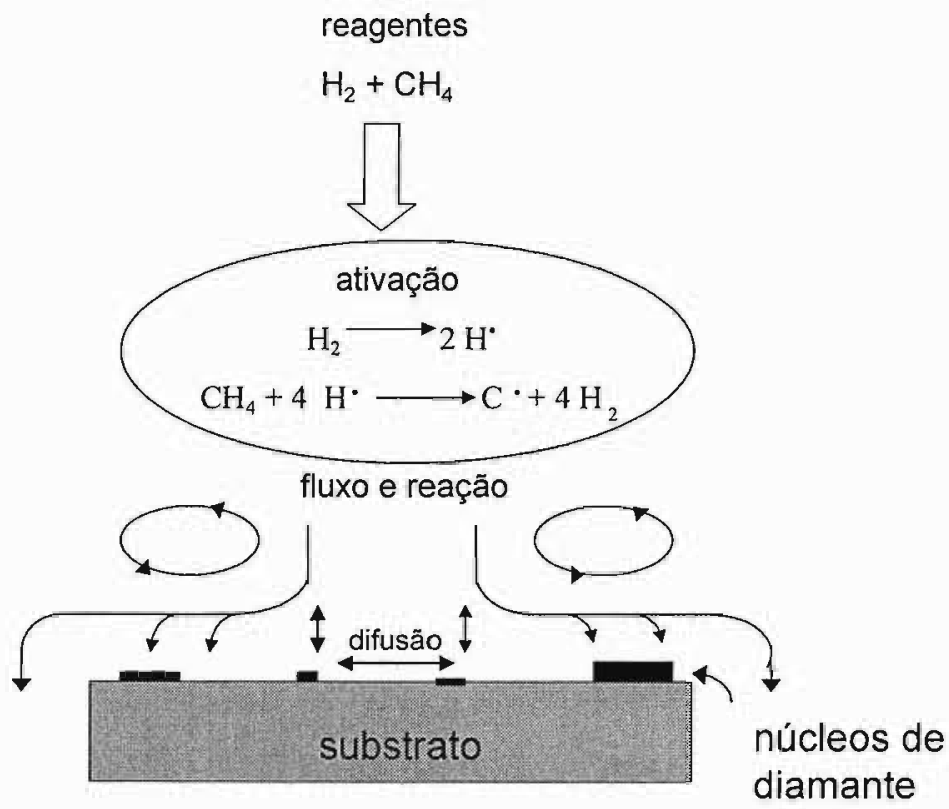

FIGURA 2.1: Representação esquemática dos processos químicos que ocorrem em um reator de diamante CVD. Adaptado da referência [5].
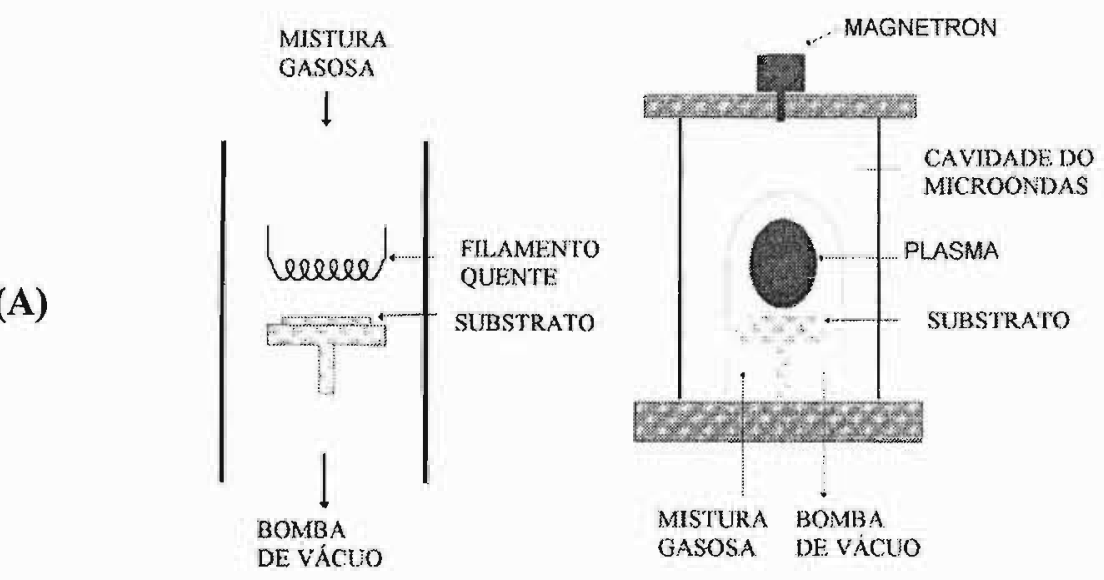

(B)

FIGURA 2.2: Principais tipos de reatores para fabricação de filmes de diamante CVD. (A) - Reator a filamento quente. (B) - Reator a plasma de microondas. Esquema reproduzido da referência [9]. 
De acordo com o diagrama de fases do carbono (Figura 2.3), nas condições usualmente empregadas na síntese de filmes de diamante CVD $\left(700{ }^{\circ} \mathrm{C}\right.$ e $\left.0,1 \mathrm{~atm}\right)$, a forma termodinamicamente mais estável é o grafite. No entanto, as altas concentrações de espécies radicais de carbono e de hidrogênio tornam cineticamente possível a existência de diamante, ou seja, o diamante nestas condições é uma forma metaestável.

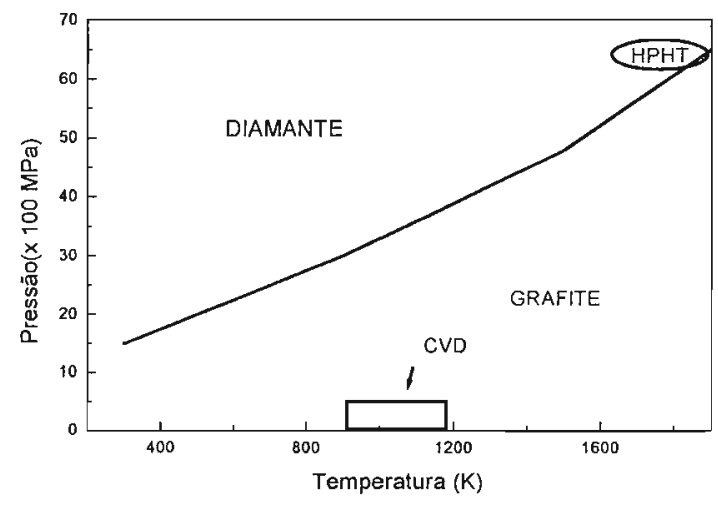

FIGURA 2.3:- Diagrama de fases do carbono. Reproduzido da referência [9].

Quando os átomos estão arranjados em uma rede cristalina, seus campos elétricos exercem influência mútua. Como resultado, os níveis energéticos, preferencialmente dos elétrons de valência dos átomos que compõem esse cristal, distribuem-se em duas regiões de alta densidade de níveis de energia, chamadas de bandas ${ }^{10}$, separadas por um intervalo de densidade nula de níveis de energia, chamado de bandgap, ou espaçamento entre bandas. A banda de menor energia é chamada de banda de valência e a banda de energia mais alta é denominada banda de condução. Um dada substância sólida conduz eletricidade sempre quando há a ocupação incompleta tanto da banda de valência, como da banda de condução. Nesse sentido, os metais são bons condutores porque apresentam níveis incompletos na banda de valência ou, em muitos casos, praticamente não há separação entre a banda de valência e a banda de condução (figura 2.4). Entretanto, nos semicondutores ou isolantes, há um espaçamento considerável entre a banda de valência, sempre completa e a banda de condução, fazendo com que a condução seja possível somente quando há a transferência eletrônica da banda de valência para a de condução por energia térmica ou por ação da luz. 


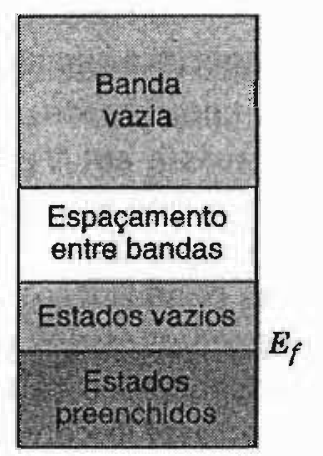

(a)

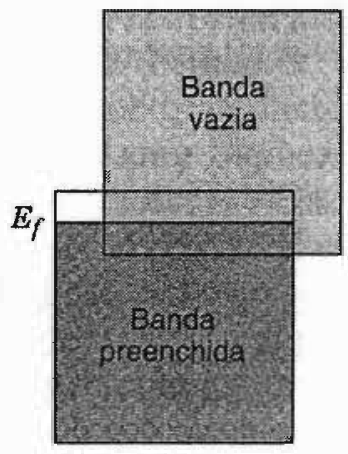

(b)

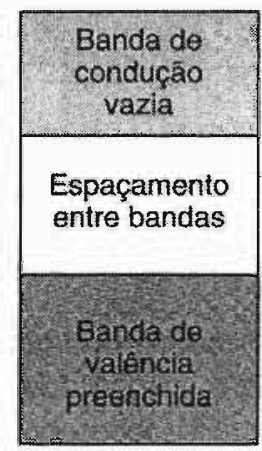

(c)

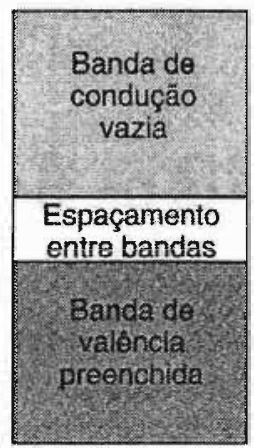

(d)

FIGURA 2.4: Diagramas de bandas de energia de (a) e (b) metais, (c) isolantes e (d) semicondutores. Reproduzido da referência [10].

A adição de determinadas impurezas a um semicondutor ou isolante contribui para o aumento da sua condutividade. Quando essa impureza (dopante) é um átomo de um elemento com mais elétrons de valência do que os dos átomos que compõem o semicondutor, o semicondutor recebe uma dopagem do tipo $n$, pela qual elétrons livres são inseridos no retículo, ou na linguagem da Teoria das Bandas, são inseridos níveis energéticos próximos à banda de condução (figura 2.5). Pelo contrário, se é adicionado um dopante com menor número de elétrons de valência, é inserido no retículo uma lacuna, ou a falta de elétrons. Neste tipo de dopagem, chamado de tipo $\mathrm{p}$, o portador de carga será uma lacuna e não mais um elétron como na dopagem do tipo n. Isso equivale à inserção de um nível de energia no bandgap do semicondutor, próxima à banda de valência (figura 2.6).

O diamante puro é um isolante elétrico (bandgap $\cong 5.5 \mathrm{eV}$ ). Para aumentar a sua condutividade, é necessária a dopagem com boro (tipo p), nitrogênio, fósforo e enxofre (tipo $\mathrm{n}$ ), embora tentativas de dopagem do tipo $\mathrm{n}$ não tenham ainda resultado em resultados confiáveis ${ }^{11}$. Os principais métodos de dopagem estudados ${ }^{5}$ são a difusão térmica, a implantação de íons de alta energia e a dopagem durante o processo de crescimento. A difusão térmica apresenta como vantagens a eliminação do risco de contaminação do reator CVD visto que a dopagem é efetuada após o crescimento do filme de diamante. A implantação iônica oferece como vantagem a possibilidade do controle do gradiente de dopagem em função da profundidade do filme. Na dopagem feita durante o crescimento do filme, uma substância que contém em sua composição o 
elemento que se quer inserir é adicionada junto à fase gasosa precursora do crescimento do filme. As principais fontes de $\mathrm{B}, \mathrm{N}$ e $\mathrm{S}$ são, respectivamente, $\mathrm{B}_{2} \mathrm{O}_{3}$ dissolvido em metanol, $\mathrm{NH}_{3}$ e $\mathrm{H}_{2} \mathrm{~S}$. Esta técnica se apresenta como uma boa alternativa quando se deseja uma distribuição uniforme de dopante pelo filme. Neste caso, entretanto, há o inconveniente da contaminação das paredes do reator pelo dopante.
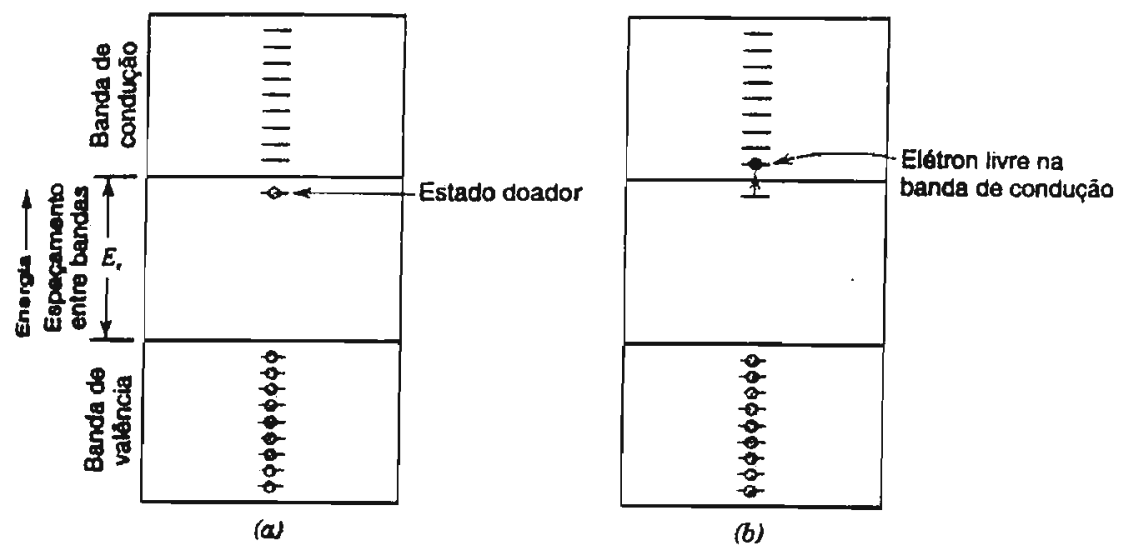

FIGURA 2.5: Diagramas de bandas de energia em um semicondutor representando a dopagem do tipo $\mathrm{n}$ antes (a) e após (b) a transferência eletrônica por energia térmica ou por ação da luz. Reproduzido da referência [10].
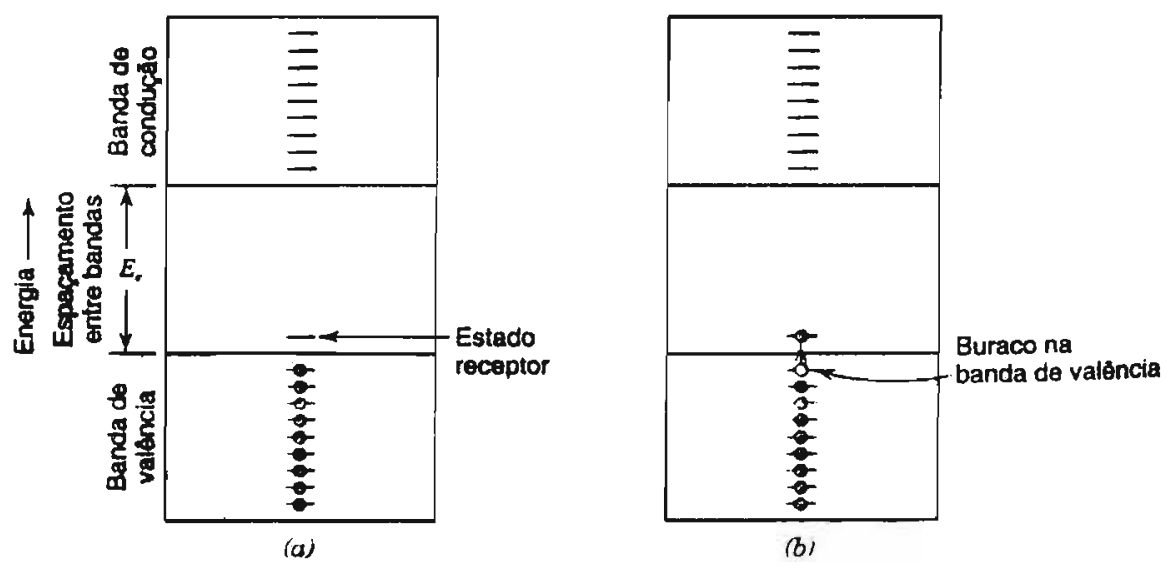

FIGURA 2.6: Diagramas de bandas de energia em um semicondutor representando a dopagem do tipo $\mathrm{p}$ antes (a) e após (b) a transferência eletrônica por energia térmica ou por ação da luz. Reproduzido da referência [10]. 


\section{2 - A Eletroquímica da Platina em Meio Ácido}

O comportamento eletroquímico da Pt em meio ácido é há algum tempo bem conhecido e há excelentes revisões sobre esse aspecto na Literatura ${ }^{12,13}$. Na Figura 2.7 é apresentado um voltamograma típico de um eletrodo de platina policristalina em solução de $\mathrm{H}_{2} \mathrm{SO}_{4}$ 0,5 M. No voltamograma da platina podemos ver claramente três regiões bem distintas. No intervalo de potenciais entre 0,8 e $1,5 \mathrm{~V}$, pode-se ver a região anódica correspondente ao complexo processo de adsorção de água, com a formação de um filme de óxidos. Em potenciais acima de 1,5 V, a RGO começa a tomar parte. Na varredura contrária de potenciais, há a segunda região localizada entre c.a $1,0 \mathrm{~V}$, e $0,5 \mathrm{~V}$, representada por um largo pico catódico que é correspondente à redução dos óxidos anteriormente formados sobre a Pt na varredura no sentido crescente de potenciais. A terceira região é representada por um conjunto de picos anódicos e catódicos de intensidade relativamente baixa localizados na região imediatamente anterior à $\mathrm{RGH}$ e representa a adsorção reversível de íons $\mathrm{H}^{+}$sobre a platina.

Sabe-se que a carga de adsorção de íons $\mathrm{H}^{+}$, que é obtida da integração da região do voltamograma da Platina representada na Figura 2.7 (b), é proporcional à área superficial do eletrodo ${ }^{12}$. sendo que a carga necessária à formação de uma monocamada de hidrogênio adsorvido sobre uma superfície policristalina de platina é de $210 \mu \mathrm{C} \mathrm{cm}$ [14].

Na região de adsorção de oxigênio sobre o eletrodo de platina, há a formação de uma monocamada de óxidos, cuja proporção é de aproximadamente 2 átomos de oxigênio para $1 \mathrm{de} \mathrm{Pt}(\mathrm{O} / \mathrm{Pt}=2)$. Em potenciais imediatamente próximos à $\mathrm{RGO}$, essa proporção atinge um máximo de $\mathrm{O} / \mathrm{Pt}=2,6$, indicando haver a oxidação do metal em camadas mais profundas $^{12,13,14}$. De qualquer forma, pode-se estimar a área eletroquímica da Pt também em função sua carga de redução ou de formação de óxidos, considerando que para a formação de uma monocamada de oxigênio sejam necessários aproximadamente $420 \mu \mathrm{C}$ $\mathrm{cm}^{-2}$, ou seja, o dobro da carga de formação de uma monocamada de hidrogênio. 

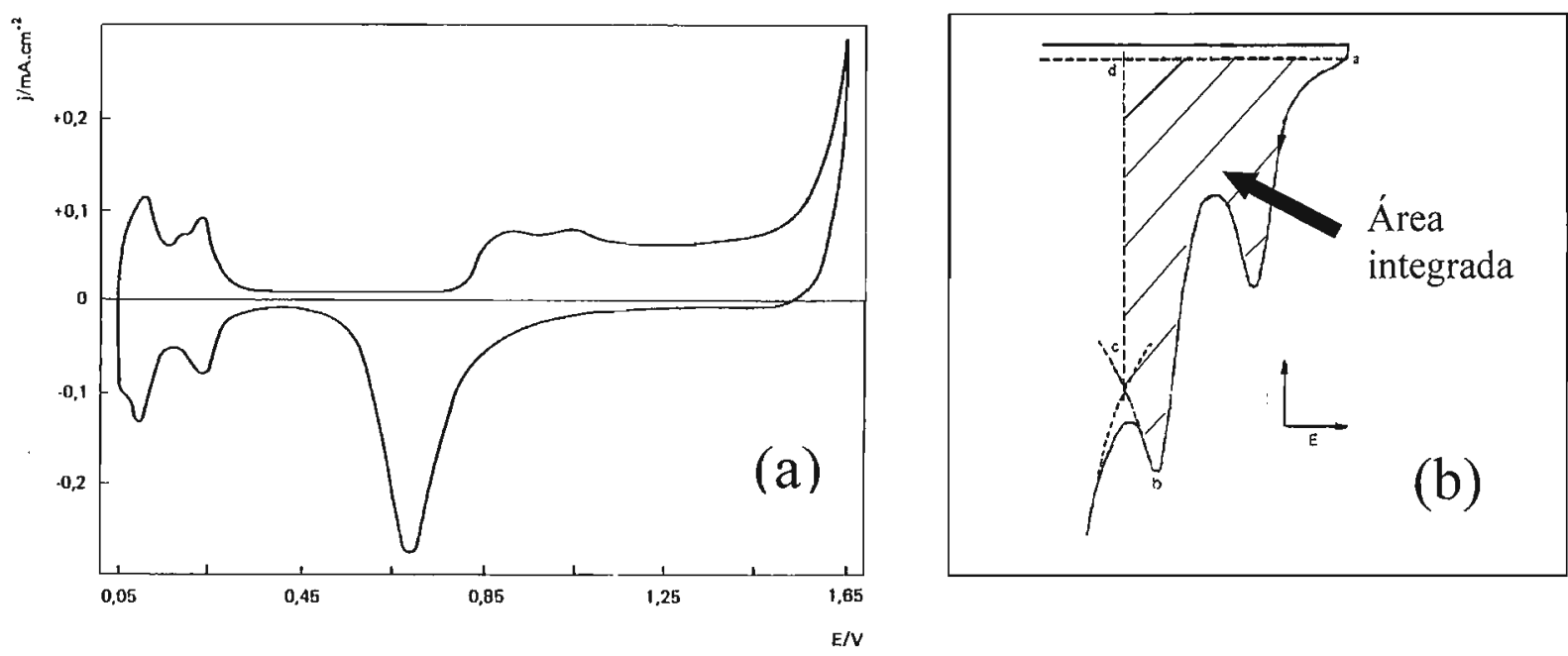

FIGURA 2.7: (a) - Voltamograma cíclico típico de um eletrodo de platina policristalina em meio de $\mathrm{H}_{2} \mathrm{SO}_{4}$ 0,5 M. (b) - Região de adsorção de íons $\mathrm{H}^{+}$em meio ácido evidenciando a região do voltamograma (c.a $0,05 \mathrm{~V}$ a $0,3 \mathrm{~V}$, na Figura 5.13 (a)) que é integrada para o cálculo da área superficial da Platina. Reproduzido da referência [15].

\section{3- Voltametria Cíclica ${ }^{16,17}$}

A Voltametria Cíclica é uma técnica amplamente empregada em estudos eletroquímicos. Ela consiste na aplicação de um programa de perturbação no qual o potencial aplicado ao sistema é variado linearmente até um valor pré-estabelecido e depois retorna ao valor inicial (Figura 2.8). Quando é atingido um potencial onde há uma reação eletroquímica, a resposta é um aumento de corrente até um valor que é proporcional à concentração da espécie eletroativa junto à superfície do eletrodo e à velocidade da reação. Se o experimento é realizado em condições estacionárias (sem agitação), a concentração da espécie eletroativa que está sofrendo processo eletroquímico tende a diminuir, uma vez que a velocidade de difusão de espécies eletroativas do interior da solução para a interface solução/eletrodo é menor do que a velocidade de consumo desta espécie junto à superfície do eletrodo. Há neste caso a queda da corrente que passa pela célula. Portanto, em condições estacionárias, a resposta voltamétrica é um pico de corrente em uma região próxima ao potencial em que acontece a reação eletroquímica.

Em muitos casos, pode haver a formação de uma espécie intermediária que seja eletroativa, por exemplo, a formação de uma espécie parcialmente reduzida na deposição de um metal ou a oxidação de uma molécula orgânica. Por isso, dependendo da velocidade com que o potencial é variado em uma varredura cíclica, pode-se detectar a 
presença desta espécie intermediária. Desta forma, a Voltametria Cíclica é uma boa ferramenta para o estudo de mecanismo de processos eletroquímicos.

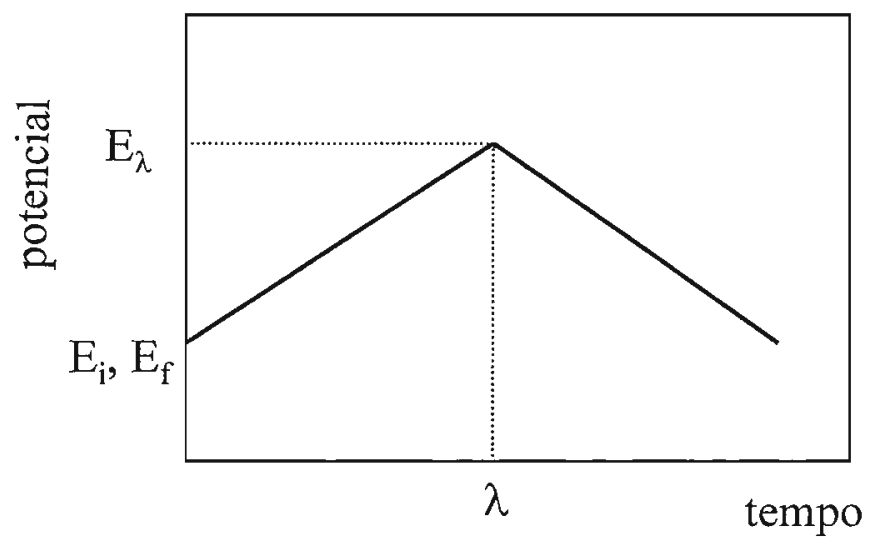

FIGURA 2.8 - Exemplo de diagrama potencial-tempo empregado na voltametria cíclica.

\section{4- Técnicas eletrônicas}

\subsection{1- Microscopia eletrônica de Varredura (MEV) ${ }^{18}$}

$\mathrm{O}$ principio de funcionamento da MEV consiste na incidência de um feixe de elétrons que varre toda a superfície da amostra. Em conseqüência, a superfície emite algum tipo de radiação: elétrons, fótons na região do visível, calor ou som. Os elétrons emitidos pela amostra, que normalmente são detectados e transformados em uma imagem, são de dois tipos: os refletidos (backscattered) e os elétrons secundários . Geralmente, 20 a $40 \%$ dos elétrons incididos são espalhados no interior da amostra e refletidos. Uma outra parcela dos elétrons emitidos, chamados de elétrons secundários é proveniente de processos dispersivos inelásticos cuja baixa energia (4 eV, independentemente da energia do feixe incidente) faz com que elétrons provenientes do interior da amostra não tenham energia o suficiente para escapar da amostra e atingir o detector. Dessa forma, somente elétrons provenientes da superfície da amostra é que 
atingem o detector, e por isso esse tipo de emissão é a mais comumente utilizada para a formação de imagens que revelam a morfologia superficial da amostra.

\subsection{2 - Espectroscopia de Energia Dispersa ${ }^{19}$}

Quando a amostra é bombardeada pelo feixe de elétrons do aparelho do MEV, elétrons são ejetados dos átomos, deixando a superfície da amostra. A vacância então produzida é preenchida por elétrons de uma camada mais externa, e neste processo, um raio $\mathrm{X}$ é emitido para compensar a queda de energia do elétron neste processo. O detector conta o número de raios $\mathrm{X}$ emitidos em função da sua energia, que é característica de cada elemento do qual o raio $X$ é proveniente. Um espectro da energia em função do número de contagens relativo a um padrão é obtido e usado tanto para análises quantitativas como qualitativas, dos elementos presentes na superfície. A esta técnica dá se o nome de EED - Espectroscopia de Energia Dispersa (mais conhecida como EDS Energy Dispersive Spectroscopy).

Esta técnica não é aplicável para os elementos $\mathrm{H}$ e He, visto que, como eles apresentam elétrons apenas no primeiro nível (1s), é impossível a emissão de raios-X pelo mecanismo de relaxamento eletrônico apresentado anteriormente. Além destes, há problemas de detecção com os elementos leves do primeiro período da tabela periódica, visto que emitem raios $X$ de muito baixa energia para a sua deteç̧ão quantitativa. Os elementos de Boro a Flúor têm limites de detecção de $10 \%$ em massa e no caso em que estes elementos estejam presentes em somente algumas monocamadas na superfície da amostra, a sensibilidade do detector fica ainda mais comprometida. Neste sentido, a EDS, sobretudo no caso da determinação de concentrações de elementos localizados na superfície da amostra, é mais indicada para elementos mais pesados que o sódio.

Para o cálculo da concentração de um dado elemento em nível superficial faz-se uso de uma curva de calibração e de brancos compatíveis que eliminem a contribuição de outros fatores para a leitura obtida da amostra. Existem também rotinas analíticoestatísticas que são incorporadas ao próprio software do equipamento de aquisição de dados. Dentre estas, o método mais usual é o método ZAF, que leva em conta os fatores de correção do número atômico do elemento $(Z)$, da absorbância $(A)$ e da fluorescência (F). O computador faz então cálculos comparativos levando em conta estes três fatores 
de correção tanto para a amostra quanto para o padrão. O resultado final é um fator de correção que é implementado à leitura do aparelho da seguinte forma:

$$
C_{x}=C_{p} \cdot k \cdot Z \cdot A \cdot F
$$

Onde $C_{x}$ é a concentração do elemento $x, C_{p}$ é concentração do elemento $x$ no padrão, $\mathrm{k}$ é a intensidade dos picos relativos ao elemento $\mathrm{x}$ tanto na amostra quanto no padrão, Z, A e F são respectivamente os fatores de correção para o número atômico, para a absorbância e F para a fluorescência. Neste caso, vemos que uma medida é tanto mais confiável quanto mais próxima de 1 for o valor do fator ZAF. 


\section{3 - REVISÃO BIBLIOGRÁFICA}

\section{1 - Filmes de Diamante em Eletroquímica}

O primeiro trabalho sobre a eletroquímica deste material foi publicado em 1987, por Pleskov e col. ${ }^{20}$ que estudaram o comportamento fotoeletroquímico de filmes policristalinos de diamantes dopados com boro com o objetivo de se desenvolver materiais de eletrodo para células fotoeletroquímicas mais resistentes à corrosão. Neste trabalho, o potencial do eletrodo foi variado ciclicamente desde potenciais de geração de $\mathrm{O}_{2}$ até potenciais de geração de $\mathrm{H}_{2}$, com o eletrodo sendo simultaneamente irradiado com luz de frequências desde o visível $(600-400 \mathrm{~nm})$ até o UV $(400-200 \mathrm{~nm})$. O material apresentava um máximo de fotocorrente de geração de $\mathrm{H}_{2}$ quando irradiado com luz UV de alta energia ( $290 \mathrm{~nm})$. Uma vez que o diamante apresenta um band-gap de 5,5 eV, seria necessária uma radiação com menor comprimento de onda $(165 \mathrm{~nm})$ para promover transições interbandas. Para explicar esses resultados inesperados foi proposto que a condução ocorresse através de transições eletrônicas pelos níveis intermediários às bandas de valência e de condução, introduzidos via dopagem. Embora o artigo não esclareça as condições experimentais em que foram empregados, tratamentos anódicos, realizados em soluções neutras de $\mathrm{KCl} 0,1 \mathrm{M}$, deslocavam para valores mais negativos o potencial de início da reação de geração de hidrogênio (RGH). O abaixamento do pH provocava a drástica diminuição da fotocorrente tanto anódica quanto catódica. Os autores não propuseram uma explicação para estes fatos. De qualquer forma, a grande contribuição deste primeiro trabalho foi mostrar que o diamante não é um material tão inerte, mas que algumas de suas propriedades intrínsecas e superficiais (principalmente sua reatividade) podem ser alterados por tratamentos eletroquímicos.

Mais tarde, em 1999, ainda estudando a fotoeletroquímica de filmes de diamante, Yagi e col. ${ }^{21}$ compararam o comportamento de filmes de diamante (dopados com boro) recém-depositados com filmes submetidos a dois tipos de pré-tratamento oxidativo: eletroquímico e por plasma. Foi observado, em experimentos potenciostáticos, que a oxidação da superfície tanto por pré-tratamento anódico como por plasma de $\mathrm{O}_{2}$ fazia a fotocorrente de geração de $\mathrm{H}_{2}$ atingir valores mais negativos, em comparação com o filme recém-depositado quando o mesmo era submetido a um potencial catódico e 
irradiado com luz U.V. (193 nm). Um fato interessante foi a observação de que um severo tratamento catódico (em solução de eletrólito neutro), resultou na recuperação do comportamento fotoeletroquímico somente daquela amostra que havia sido oxidada eletroquimicamente, embora a relação $\mathrm{O} / \mathrm{C}$ (relação entre as concentrações superficiais de oxigênio e de carbono, determinadas por espectroscopia fotoeletrônica de raios X - XPS) não tenha diminuído consideravelmente com o tratamento catódico. A especulação dos autores foi de que o tratamento por plasma de oxigênio, além de retirar o hidrogênio contido na camada subsuperficial do filme $e^{22,23}$, alteraria de alguma forma a estrutura daquela região de modo a dificultar a nova inserção de hidrogênio na camada subsuperficial, durante o tratamento catódico. O tratamento anódico, apesar de também oxidar a superfície, não exerce o mesmo efeito que o observado com o tratamento com plasma de $\mathrm{O}_{2}$, na concentração de hidrogênio subsuperficial do diamante.

Estudando características elétricas de filmes policristalinos de diamante, Swain e col. $^{24}$, observaram o aumento da resistividade do filme de diamante com o tratamento térmico em atmosfera inerte. Eles atribuíram o fato à perda ou rearranjo estrutural de hidrogênio sub-superficial. Da mesma forma, foi demonstrado que a condutividade e a reatividade do filme de diamante é sensivelmente influenciada por tratamentos químicos, anódicos e por plasmas de $\mathrm{O}_{2}, \mathrm{H}_{2}$ e de gases inertes ${ }^{25-27}$.

Nishikawa e col. $^{23}$ investigaram a natureza desta camada subsuperficial de hidrogênio. Através de medidas de espectroscopia de massas de íons secundários (SIMS), verificaram que a maior parte do hidrogênio contido no diamante CVD encontra-se na superfície e a aproximadamente $20 \mathrm{~nm}$ abaixo da superfície. Baseados nestes dados, os autores propuseram que o filme de diamante, em camadas próximas à superfície tem descontinuidades, regiões intergranulares, completadas por fracas ligações C-H (Figura 3.1). Essa observação pode explicar o comportamento do filme observado pelos autores nos trabalhos comentados anteriormente. Essa camada descontínua de diamante (Fig. 3.1) é removida integralmente no tratamento por plasma de $\mathrm{O}_{2}$, enquanto que apenas o hidrogênio e parte desta camada são removidas no tratamento anódico. Quando o eletrodo é severamente catodizado, em potenciais de geração de $\mathrm{H}_{2}$, o comportamento inicial do filme é recuperado só no caso do eletrodo pré-tratado anodicamente, porque nestas 
condições, a camada descontínua de diamante não é destruída e hidrogênio pode ser reinserido portanto, nesta região do filme.

Torresi e col. ${ }^{28}$ observaram a diminuição de resistividade, seguida de aumento da quantidade de portadores de carga em filmes de $\mathrm{TiO}_{2}$ submetidos a severo tratamento catódico em potenciais de geração intensa de $\mathrm{H}_{2}$ (meio de $\mathrm{H}_{2} \mathrm{SO}_{4}$ 0,5 M). Kang e col. ${ }^{29}$, trabalhando com filmes de $\mathrm{ZnO}$ sintetizados por sputtering de alta freqüência, em atmosfera de $\mathrm{H}_{2}$, também obtiveram nestes filmes maior condutividade e um maior número de portadores de carga. Vemos que tanto pelo método eletroquímico como pelo método físico, hidrogênio pôde ser incorporado na estrutura destes óxidos, o que causou aumento de condutividade dos mesmos. Como explicação tentativa para o aumento de condutividade observado nos filmes hidrogenados de $\mathrm{ZnO}$, os autores propuseram a formação de pontes $\mathrm{O}-\mathrm{H}-\mathrm{O}$ entre diferentes grãos, possibilitando assim a comunicação entre os mesmos. Embora os filmes de diamante apresentem uma estrutura diferente da destes óxidos, pode-se imaginar que em um filme recém-depositado, a alta concentração de hidrogênio nos vazios intergranulares possa desempenhar o mesmo papel na comunicação nos interstícios das camadas subsuperficiais, aumentando a condutividade do filme. Os tratamentos térmicos, realizados em atmosfera inerte $\left(\mathrm{N}_{2}\right.$ ou $\left.\mathrm{Ar}\right)$, fariam com que estas ligações $\mathrm{C}-\mathrm{H}$ se rompessem, liberando $\mathrm{H}_{2}$ e formando insaturações superficiais (Figura 3.1), com diminuição da condutividade do material. Embora existam trabalhos que atestem falta de re-hidrogenação ${ }^{30}$ e até a oxidação da superfície do diamante em tratamento catódicos ${ }^{25}$, o mecanismo de geração de $\mathrm{H}_{2}$ parece passar por uma etapa de hidrogenação superficial ${ }^{31,32}$. Por outro lado, Pleskov e col. ${ }^{33}$ em condições mais severas de recozimento observaram o aumento da condutividade de filmes de diamante nãodopados, isso já devido à grafitização superficial do material.

Vários autores ${ }^{24-26,34}$ observaram a existência de correntes de baixa intensidade anteriores à da geração de $\mathrm{O}_{2}$, as quais não seriam resultantes de processos meramente capacitivos, visto que a corrente naquela região de potenciais diminui com o número de varreduras de potenciais, o que seria esperado para uma superfície que vai sendo irreversivelmente oxidada a cada ciclo voltamétrico.

Considerando-se os trabalhos acima citados, há um certo consenso de que as modificações na resistividade e reatividade dos filmes de diamante possam ser atribuídas 
a alteração na concentração de hidrogênio subsuperficial. Contudo, existem também evidências de modificação destas propriedades por oxidação de sítios ativos superficiais no filme de diamante, como veremos a seguir.

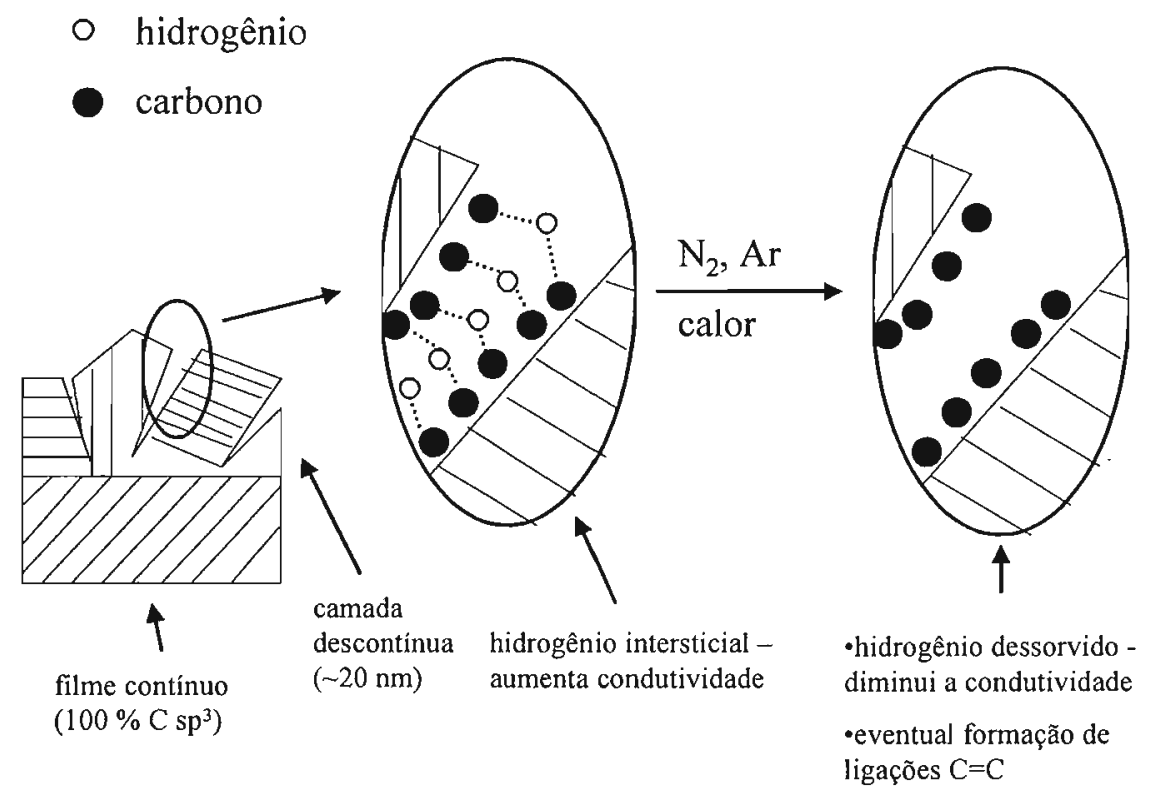

FIGURA 3.1: Perfil de um filme de diamante CVD e reações superficiais durante o recozimento em atmosfera inerte.

Ando e col. ${ }^{35-37}$, através da espectroscopia de infra-vermelho, estudaram a natureza das espécies formadas na superfície do diamante expondo amostras de pó de diamante ao tratamento térmico em atmosfera de $\mathrm{O}_{2}$. Foi observado que, ao mesmo tempo em que os picos de estiramento $\mathrm{C}-\mathrm{H}$ diminuíam de intensidade, a partir da temperatura de $300{ }^{\circ} \mathrm{C}$ foi observada a presença de picos associados a ligações do grupamento C-O-C. Aumentando-se progressivamente a temperatura, surgiram picos atribuídos a cetonas, lactonas e, a temperaturas mais altas $\left(550^{\circ} \mathrm{C}\right)$, ésteres anidridos. Tratou-se a amostra de pó de diamantes oxidada a $500{ }^{\circ} \mathrm{C}$ com solução $0,1 \mathrm{M}$ de $\mathrm{NaOH}$ e a espectroscopia no infravermelho revelou o aparecimento de picos correspondentes a grupos carboxílicos. Em vista destes dados, os autores propuseram um mecanismo de oxidação superficial do diamante no qual formam-se grupos $\mathrm{C}=\mathrm{O}$ ou $\mathrm{C}-\mathrm{O}-\mathrm{C}$, com eliminação de hidrogênio ou água e posterior formação de ésteres anidridos e desprendimento de $\mathrm{CO}_{2}$ (Figura 3.2). 
Embora a oxidação não tenha sido eletroquímica, os resultados deste estudo fornecem informações importantes sobre os possiveis tipos de espécies oxigenadas e a ordem de facilidade com que estas se formariam sobre a superfície do diamante.

Fujishima e colaboradores publicaram uma interessante série de resultados de estudos sobre a natureza das espécies oxigenadas geradas através de tratamentos anódicos e por plasma de $\mathrm{O}_{2}$. Eles reportam que (Figura 3.3):

- Oxidações anódicas e tratamentos por plasma de $\mathrm{O}_{2}$ aumentam a relação $\mathrm{O} / \mathrm{C}^{38,39}$. Este tipo de tratamento também torna mais lenta a cinética de transferência de carga de pares redox aniônicos $\left(\left[\mathrm{Fe}(\mathrm{CN})_{6}\right]^{3-14-},\left[\operatorname{IrCl}_{6}{ }^{12-13-}\right)\right.$ e aceleram a cinética de transferência de carga de pares redox catiônicos $\left(\mathrm{Fe}^{2+/ 3+}\right)^{31}$. Outros autores também obtiveram resultados similares ${ }^{40,41}$.

- Tratamentos anódicos em meio neutro inibem a eletrodeposição de cobre ${ }^{42}$.

Os autores propuseram como explicação para os resultados acima citados, uma possível interação eletrostática que ocorre entre os íons em solução e a camada de óxidos superficiais. Entretanto, essa explicação é inconsistente, visto que seria esperado que uma camada de óxidos (de caráter negativo) deveria atrair ions $\mathrm{Cu}^{2+}$ para superfície do eletrodo. Um argumento mais plausível seria o simples impedimento estérico que a camada de óxidos sobre a superfície do eletrodo poderia imprimir. Isso contribuiria para o aumento da distância entre a superfície do eletrodo e o íon, diminuindo a taxa de transferência eletrônica. Por outro lado, poder-se-ia pensar que a oxidação superficial do filme causasse simplesmente a queda na condutividade do material, entretanto, isso não explicaria a aceleração da cinética de transferência de carga para íons positivos (Figura 3.3).

- Através do uso de reagentes que capturam seletivamente certas espécies superficiais, foi demonstrado que formam-se ligações $\mathrm{C}=\mathrm{O}$ e $\mathrm{C}-\mathrm{O}-\mathrm{H}$ na superfície do eletrodo quando o mesmo é submetido ao tratamento anódico em meio ácido ${ }^{44,45}$.

Realizando experimentos de voltametria cíclica com íons de $\left[\mathrm{Fe}(\mathrm{CN})_{6}\right]^{3-14-}$ em filmes de diamante dopado com boro submetidos a tratamento anódico, Granger ${ }^{40}$ observou que a reversibilidade da reação redox daquele íon diminui com o tratamento anódico. Neste caso, o tratamento anódico poderia causar dois tipos de alteração superficial: a) bloqueio 
de sítios ativos por espécies oxigenadas, b) impedimento eletrostático, causado pelo efeito de repulsão entre a superfície oxigenada do eletrodo e o ânion. Diante deste resultado, os autores variaram o $\mathrm{pH}$ do meio (intervalo de 1,8 a 7,2) e observaram que a reversibilidade do sistema aumentava em $\mathrm{pH}$ baixo. Isso os levou a concluir que na superfície se formavam carboxilas, que em $\mathrm{pH}$ baixo eram protonadas, diminuindo o efeito de repulsão superfície-ion.

Assim, pode-se concluir que o diamante não é um material tão inerte quanto se podia esperar e que a sua modificação superficial, seja por oxidação ou hidrogenação, imprime alterações fundamentais no seu comportamento eletroquímico.

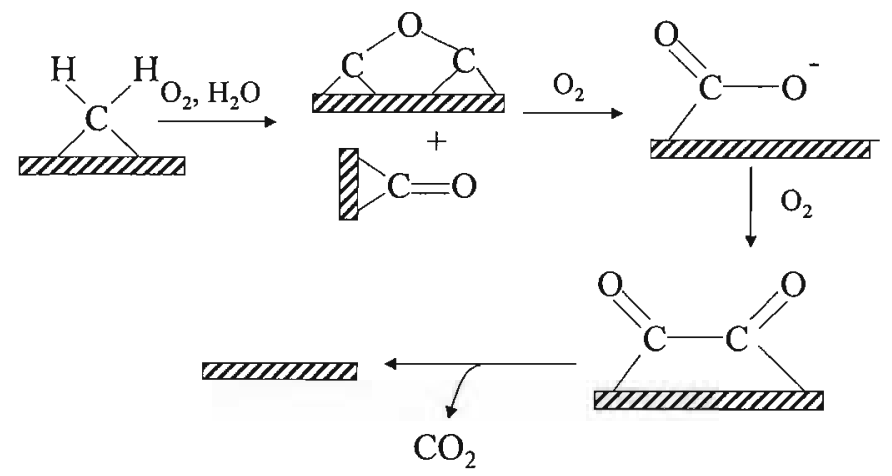

FIGURA 3.2 - Mecanismo proposto de oxidação superficial do diamante. Adaptado da referência [35].

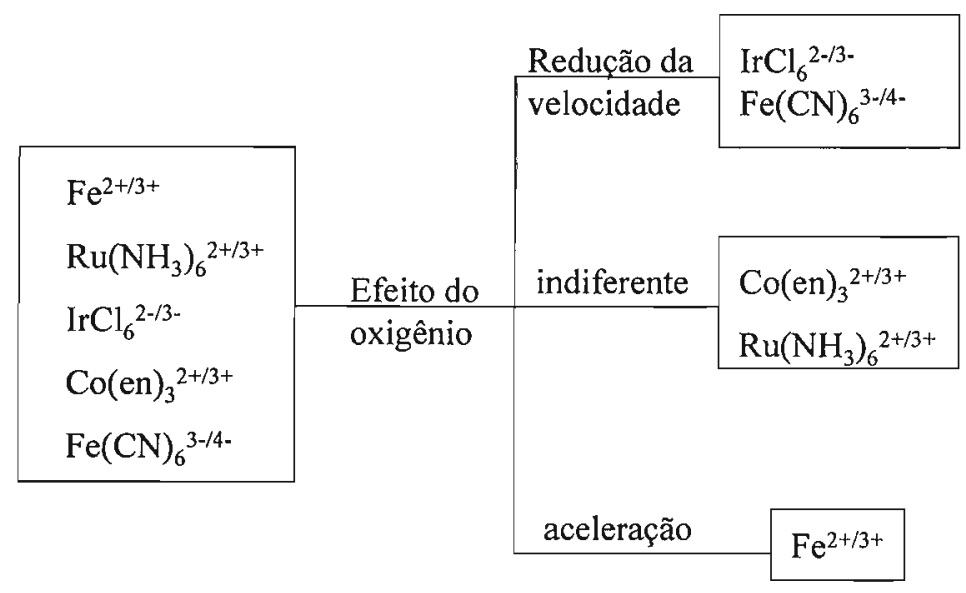

FIGURA 3.3: Classificação dos pares redox para eletrodos de diamante. Adaptado da referência [38]. 


\section{2 - Modificação com Platina}

A modificação superficial de eletrodos com partículas de catalisadores é uma alternativa interessante tanto para a diminuição de custos, quanto para o aumento da atividade química do catalisador. Esse aumento de atividade é devido, dentre outros fatores, ao aumento da área eletroquímica do catalisador. Sobre este assunto, há uma literatura extensa, e as mais diversas combinações de substrato/catalisador foram estudadas e propostas ${ }^{46-52}$. No entanto, deve-se dizer que a literatura versando sobre a modificação superficial de eletrodos de diamante ainda é relativamente limitada, comparando-se com outros substratos não metálicos, tais como grafite e silício ${ }^{53,54}$.

No caso da eletrodeposição de metais sobre grafite, dada a sua disponibilidade e características tais como alta condutividade e condições relativamente simples de prétratamento, a maioria dos trabalhos publicados tratam do estudo básico dos fenômenos de nucleação e crescimento de uma fase metálica sobre a sua superfície. Outra razão para o extenso emprego deste material em estudos de eletrodeposição de catalisadores é o fato de que se pode simular o sistema carbono altamente particulado/catalisador encontrado em alguns tipos de células a combustível.

Os trabalhos publicados sobre a eletrodeposição de metais sobre silício objetivam o desenvolvimento de dispositivos fotoeletroquímicos úteis para a fotoeletrólise da água ${ }^{53,54}$.

No caso do diamante, como já foi mencionado anteriormente, relativamente poucos trabalhos de eletrodeposição de metais ou eletrocatalisadores foram publicados. Isso se deve em grande parte ao recente domínio da síntese de filmes condutivos de diamante. De qualquer forma, alguns trabalhos visam o emprego de dispersões de metais em diamante para oxidação de álcoois, substâncias orgânicas poluentes, redução de $\mathrm{CO}_{2}$ e de $\mathrm{O}_{2}$. Para uma análise dos métodos utilizados e das principais observações encontradas na literatura, segue uma revisão bibliográfica versando sobre a eletrodeposição de platina não só sobre diamante, mas também sobre outros substratos inertes.

Há muitos parâmetros que podem exercer influência sobre as características da dispersão de um catalisador sobre uma superfície eletródica. Dentre eles, o potencial ou corrente de deposição, condições de banho ( $\mathrm{pH}$, força iônica, concentração), natureza e pré-tratamento do substrato. Paralelamente, é de suma importância o conhecimento do 
mecanismo de deposição de um catalisador. Na literatura há um número extenso de estudos, nos quais são discutidos estes parâmetros. Na revisão aqui apresentada discute-se apenas os seguintes parâmetros, que são pertinentes ao presente trabalho:

1. Mecanismo de eletrodeposição de catalisador;

2. A natureza e pré-tratamento do substrato;

\subsection{1-Mecanismo de Eletrodeposição de Platina sobre eletrodos inertes}

Para utilização em processos catalíticos ou eletrocatalíticos, sobretudo de reações eletroquímicas usuais em células a combustível, a dispersão de Pt é geralmente efetuada sobre carbono altamente particulado. Dispersões de Pt sobre materiais semicondutores tais como n-Si, n-GaAs, n-InP, $\mathrm{TiO}_{2}, \mathrm{SnO}_{2}$, também encontram uma aplicação importante para fins fotoeletrocatalíticos. Estas dispersões podem ser feitas via química, física ou eletroquímica. Na via química, uma solução de um sal deste metal é aspergida (ou misturada, no caso de o substrato ser particulado), sobre a superfície. O solvente é evaporado e a superfície é tratada em atmosfera redutora de $\mathrm{H}_{2}$, a quente. Na via física, ou implantação iônica por sputtering, a dispersão de Pt é obtida quando partículas carregadas deste metal são eletricamente aceleradas contra a superfície a ser alterada. Todavia, estes são processos muito caros e as características do depósito (tamanho e a distribuição das partículas) são difíceis de serem controladas. Por isso, muitos esforços têm sido dirigidos para o estudo da deposição via eletroquímica. Neste contexto, justificase o interesse pelo estudo do mecanismo de eletrodeposição, visando a otimização da dispersão deste catalisador, através do controle de parâmetros do banho, tais como potencial, densidade de corrente, $\mathrm{pH}$ e concentração. Por razões práticas são usualmente empregados nestes estudos eletrodos-modelo de carbono, cujos mais utilizados são o carbono vítreo $(\mathrm{CV})$ e o grafite pirolítico altamente ordenado (HOPG - High Ordered Pyrolytic Graphite).

$\mathrm{Na}$ redução de íons $\mathrm{PtCl}_{6}{ }^{2-}$ sobre $\mathrm{CV}$ em meio de $\mathrm{H}_{2} \mathrm{SO}_{4} 0,5 \mathrm{M}$, Shimazu e col. ${ }^{55}$ observaram através de voltametria cíclica a presença de dois picos catódicos em c.a. $0,2 \mathrm{~V}$ e em - 0,18 V (vs. Ag/AgCl). O pico catódico localizado em c.a. 0,2 V apresentouse duplicado na amostra de carbono vítreo pré-tratada com aquecimento ao ar. Os autores não tentaram explicar este comportamento. Todavia, comparando-se a relação do número 
de elétrons trocados em cada um dos picos observados, foi concluído que no primeiro pico (em 0,2 V) houve a redução de íons Pt (IV) a Pt (II) (etapa I). Como foi detectada por microscopia eletrônica de varredura, a presença de Pt metálica no tratamento do eletrodo em $0,2 \mathrm{~V}$, foi deduzido que haja também uma etapa de desproporcionamento químico de Pt (II), dando Pt metálico (etapa II, no esquema abaixo). O segundo pico, localizado em $-0,18 \mathrm{~V}$ foi considerado como a redução de Pt (IV) a Pt (0) (etapa III).

$$
\begin{aligned}
& \mathrm{Pt}(\mathrm{IV})+2 \mathrm{e}^{-} \longrightarrow \operatorname{Pt}(\mathrm{II}) \quad \text { (eletroquímica / 0,2 V) } \\
& 2 \mathrm{Pt}(\mathrm{II}) \quad \longrightarrow \operatorname{Pt}(0)+\operatorname{Pt}(\mathrm{IV}) \quad \text { (química) } \\
& \operatorname{Pt}(\mathrm{IV})+4 \mathrm{e}^{-} \longrightarrow \operatorname{Pt}(0) \quad \text { (eletroquímica / -0,18) }
\end{aligned}
$$

Os autores também observaram que o tratamento superficial do substrato influenciava o comportamento do pico catódico observado em $0,2 \mathrm{~V}$, sendo que este pico praticamente desaparecia quando o eletrodo era anodicamente tratado ( $15 \mathrm{~min}$. em $1,8 \mathrm{~V} \mathrm{em}_{2} \mathrm{SO}_{4} 0,5$ M). Entretanto, o pico localizado em c.a. - 0,18 não sofreu qualquer alteração com os pré-tratamentos empregados. Isso mostrou que o pré-tratamento do substrato pode alterar sensivelmente o mecanismo de deposição de platina.

Ainda estudando os estágios iniciais da deposição de Pt sobre HOPG em meio de $\mathrm{HCl}$ $1,0 \mathrm{M}$, Zubimendi e col. ${ }^{56}$ associaram dados de experimentos de cinética eletroquímica com informações sobre a topografia de tais depósitos de Pt. Da mesma forma e nas mesmas condições experimentais que o encontrado por Shimazu e col. ${ }^{55}$, foram observados três picos catódicos localizados na região próxima à reação de geração de hidrogênio. Baseando-se em resultados já obtidos por outros autores, eles atribuíram ao pico localizado no sobrepotencial mais alto o processo de redução de Pt (IV) a Pt (0), com geração paralela de $\mathrm{H}_{2}$. O pico intermediário, menos intenso representava a redução de íons Pt (IV) a Pt (0) e Pt (II) a Pt (0). Todavia, os autores focalizaram seu trabalho na elucidação do mecanismo de deposição deste metal no pico de corrente de menor sobrepotencial. Na deposição em um potencial mais baixo e em baixas cargas, observouse por MEV e por STM de baixa resolução a formação de aglomerados de $\mathrm{Pt}$, separados por extensões do substrato aparentemente sem cobertura de Pt. Entretanto, a análise por STM de alta resolução efetuada nestas regiões aparentemente com cobertura de Pt, 
mostrou a existência de partículas de Pt de 2 a $3 \mathrm{~nm}$, que se dispunham na superfície do HOPG em um padrão, que seguia a orientação cristalina do substrato. Como eles depositaram o catalisador a partir de um banho de $\mathrm{H}_{2} \mathrm{PtCl}_{6}$, atribuíram o primeiro pico, menos intenso, à redução, de Pt (IV) a Pt (II), assim como proposto por Shimazu ${ }^{48}$. Como a deposição efetuada neste potencial originou também a formação de depósitos de Pt, os autores admitiram a redução de Pt (IV) a Pt (III), seguida de uma reação de desproporcionamento:

$$
2 \mathrm{Pt}(\mathrm{III}) \longrightarrow 0,5 \mathrm{Pt}(0)+1,5 \mathrm{Pt}(\mathrm{IV})
$$

Bindra e Yeager $^{57}$ estudaram o mecanismo de eletrodeposição de platina em meio ácido $\left(\mathrm{H}_{2} \mathrm{SO}_{4} 1 \mathrm{M}\right)$ sobre HOPG em potenciais de formação de dupla camada elétrica e de co-geração de $\mathrm{H}_{2}$. Analisando os transientes de corrente para a eletrodeposição de $\mathrm{Pt}$, os autores observaram que em potenciais distantes da co-geração de $\mathrm{H}_{2}$, a deposição de Pt se dá com nucleação progressiva de centros de crescimento tridimensionais, cujo crescimento subseqüiente é controlado por difusão dos íons $\mathrm{PtCl}_{6}{ }^{2-}$ para a superficie do eletrodo. Em potenciais de geração de $\mathrm{H}_{2}$, há a nucleação instantânea de centros de $\mathrm{Pt}$, cuja taxa de crescimento é diminuída pela adsorção e geração de $\mathrm{H}_{2}$. Dessa forma, o crescimento dos núcleos torna-se a etapa determinante do processo, resultando em grãos de orientação cristalográfica bem definida. Essa análise foi corroborada por imagens de microscopia eletrônica de transmissão, que mostraram a formação de núcleos hexagonais. Por experimentos de varredura de potenciais na região de adsorção de íons $\mathrm{H}^{+}$, observouse que a orientação cristalográfica predominante é $<111\rangle$, visto que a forma do voltamograma da $\mathrm{Pt}$ na região imediatamente anterior à $\mathrm{RGH}$ é um indicador da orientação cristalográfica predominante da superfície da $\mathrm{Pt}^{58}$.

Allongue e Souteyrand ${ }^{59}$ estudaram o mecanismo dos primeiros estágios de deposição de $\mathrm{Pt}$ em n-GaAs através de cronoamperometria e de observações de TEM. Tendo proposto um método de deconvolução da corrente de co-geração de $\mathrm{H}_{2}$ da resposta cronoamperométrica, foi possível estudar a deposição de $\mathrm{Pt}$ em potenciais mais negativos e em $\mathrm{pH}=0$, condições em que há significativa co-geração de $\mathrm{H}_{2}$. Foi observado que em condições de geração intensa de $\mathrm{H}_{2}$, há a formação de um maior número de núcleos por 
área, sendo que estes apresentam menores dimensões, que os obtidos em potenciais ou $\mathrm{pH}$ mais altos.

Até aqui vimos então que o grau de dispersão de um eletrocatalisador metálico sobre um substrato eletródico inerte pode ser controlado através do $\mathrm{pH}$ e do potencial de deposição, sendo que maiores dispersões de Pt (menores partículas em maior número por unidade de área do substrato) de Pt podem ser obtidas quando este metal é eletrodepositado em potenciais de co-geração de $\mathrm{H}_{2}$ e em meio ácido $(\mathrm{pH}=0)$. $\mathrm{A}$ atividade catalítica é proporcional à área superficial do eletrocatalisador. Como a área superficial é tanto maior quanto mais disperso ele for, conclui-se que as melhores condições para deposição de Pt sobre um substrato inerte são meio ácido e deposição do metal em potenciais de co-geração de $\mathrm{H}_{2}$. Entretanto, do ponto de vista operacional, nestas condições é difícil a avaliação do rendimento da deposição, ou seja, a quantidade de Pt efetivamente depositada, por unidade de carga.

\subsection{2- Natureza e pré-tratamento do substrato}

Nestes estudos, diferentes substratos têm sido empregados: metais, semicondutores e polímeros condutores. Resultados interessantes têm sido obtidos em alguns sistemas, devido, em alguns casos, principalmente a uma espécie de ação sinérgica entre a platina e o substrato, e à influência do pré-tratamento do substrato no grau de dispersão das micropartículas de catalisador. Devido ao enorme número de trabalhos e à existência de revisões mais detalhadas sobre o tópico em questão ${ }^{53}$ esta revisão bibliográfica visará apenas avaliar as tendências abordadas na literatura, através da correlação de alguns trabalhos mais significativos e pertinentes à metodologia empregada no estudo dos filmes de diamante descrito nesta Dissertação, não sendo portanto exaustiva.

Lin-Cai e col. $^{46}$ estudaram a influência do tipo de substrato na atividade eletrocatalítica de dispersões de platina. Foram comparados substratos de carbono vítreo e de ouro. Os autores observaram que depósitos feitos sobre carbono vítreo não apresentavam a curva voltamétrica característica de adsorção de $\mathrm{H}^{+}$, que consiste em dois picos catódicos de baixa intensidade ${ }^{12,13}$, mas somente em altas quantidades de Pt depositada. Entretanto, na platina depositada sobre ouro, mesmo em baixas quantidades de $\mathrm{Pt}$ já proporciona o comportamento normal de adsorção de íons $\mathrm{H}^{+}$, com dois picos de 
adsorção. Além disso, microdepósitos de Pt em ouro mostraram-se muito ativos para a oxidação de ácido fórmico, em comparação à atividade catalítica dos microdepósitos efetuados sobre carbono vítreo. $\mathrm{O}$ autores atribuem essa diferença de atividade a alguma característica especial adquirida pelos depósitos de Pt e que dependem do tipo de substrato. Entretanto, pode-se dizer também que esse comportamento é indício da mera diferença de condutividade entre o ouro - um metal altamente condutivo - e o grafite, que é bem menos condutivo (ver tabela 2.1 no item Aspectos Gerais). Da mesma forma, como não foram realizadas análises da Pt depositada, não se sabe se a correlação entre carga elétrica de deposição de Pt e massa de catalisador depositada (eficiência de corrente) é igual para ambos.

Palanker e $\mathrm{col}^{47}$, examinando propriedades eletrocatalíticas de microdepósitos de platina em grafite pirolítico e ouro, mostraram que a atividade eletrocatalítica específica (corrente por área eletroquímica) de tais microdepósitos é maior que em platina lisa para reações de geração de $\mathrm{H}_{2}$ e de oxidação de ácido fórmico. Este efeito foi tanto mais intenso quanto menor foi a quantidade de catalisador depositada. No caso da reação de oxidação de metanol, foi observado que as densidades de corrente de oxidação do álcool foram mais baixas do que em platina lisa, mesmo para grandes quantidades de platina. Adicionalmente, a velocidade de adsorção de metanol é sensivelmente reduzida com a diminuição do tamanho médio das partículas de $\mathrm{Pt}$, embora esta tendência não tenha sido observada para a adsorção de ácido fórmico. Estes resultados motivaram esse grupo à publicação de uma interessante série de artigos (Skundin e col. ${ }^{48-52}$ ), correlacionando a atividade eletrocatalítica de dispersões de platina com a natureza do substrato empregado. Foram utilizados diferentes substratos: grafite pirolítico Ti, Ta, Zr e Nb. As reações estudadas foram a adsorção reversível de íons $\mathrm{H}^{+}$e de adsorção/dessorção de oxigênio. Os autores chegaram à conclusão de que as nanopartículas de platina depositada sobre substratos que têm funções-trabalho mais baixas que a da platina têm a sua densidade eletrônica aumentada, o que contribui para o aumento da atividade eletrocatalítica deste metal. Este efeito é tanto mais intenso quanto menores forem as dimensões da partícula (da ordem de alguns $\AA$ ).

Shimazu e col. ${ }^{55}$ estudaram a influência do pré-tratamento do substrato na eletrodeposição e atividade catalítica de dispersões de platina sobre carbono vítreo. $\mathrm{O}$ 
tratamento térmico do eletrodo em atmosfera inerte, feito anteriormente à eletrodeposição de Pt aumentou consideravelmente a atividade do depósito frente à reação de geração de $\mathrm{H}_{2}$. Os autores acreditam que o pré-tratamento remove o material microparticulado que normalmente se forma quando o eletrodo é lixado, gerando uma superfície lisa, cujos microdepósitos de platina tenham melhor contato elétrico com a superfície.

Uma classe de substratos para eletrocatalisadores bastante estudada é a dos polímeros eletroativos, dada a sua boa condutividade, relativa estabilidade química (quesitos necessários para aplicação em células à combustível), e a capacidade de formar membranas tridimensionais porosas com considerável área superficial. Dentre os polímeros mais freqüentemente estudados estão o politetrafluoroetileno sulfonado $\left(\right.$ Nafion $\left.{ }^{\circledR}\right)$ e a polianilina (PANI), em diversos tipos de reações (eletrooxidação de metanol, formaldeído e de $\mathrm{H}_{2}$ e redução de $\mathrm{O}_{2}$ ). Uma revisão interessante sobre este aspecto foi publicada por Malinauskas ${ }^{61}$.

Maksimov e col. ${ }^{62}$ comparando dispersões de platina em filmes de $\mathrm{Nafion} \circledast$ e de Polivinilpiridina, observaram que a região de adsorção reversível de íons $\mathrm{H}^{+}$apresentava comportamento diferente, segundo o polímero utilizado como substrato. No caso do Nafion, mesmo em pequenas quantidades de platina foram observados os característicos dois picos catódicos de adsorção de $\mathrm{H}^{+}$. No caso da Polivinilpiridina só foi observado um pico largo, típico do que é geralmente observado em dispersões de platina em substratos inertes $^{46}$. Baseados no fato de que o perfil voltamétrico da região de adsorção reversível de íons $\mathrm{H}^{+}$em platina é muito sensível às características morfológicas e eletrônicas do catalisador, os autores concluíram que o tipo de substrato polimérico utilizado exercia influência preponderante no grau de dispersão e no diâmetro médio das partículas.

Mikhaylova e col. ${ }^{63}$ estudaram a influência do substrato polimérico de Nafion ${ }^{\circledR}(\mathrm{Nf})$, na reação de oxidação de metanol (catalisada por micropartículas de Pt dispersas), em comparação com o carbono vítreo $(\mathrm{CV})$ e a platina $(\mathrm{Pt})$ como substratos para a Platina. Neste estudo, foram mostrados dois aspectos diferentes:

1- Em maiores quantidades de platina, as atividades específicas (densidade de corrente/massa de catalisador) do $\mathrm{Pt} / \mathrm{CV}, \mathrm{Pt} / \mathrm{Nf} / \mathrm{CV}$ e de $\mathrm{Pt} / \mathrm{Pt}$ eram parecidas.

2- Em menores quantidades de platina $\left(10-30 \mu \mathrm{g} \cdot \mathrm{cm}^{-2}\right)$, assumindo eficiência de corrente de deposição $100 \%$, foi observado no sistema $\mathrm{Pt} / \mathrm{Nf} / \mathrm{CV}$ um sensível decréscimo 
no grau de cobertura de espécies fortemente adsorvidas de metanol sobre as micropartículas de Pt (envenenamento do catalisador). Por outro lado, nestas condições houve também a diminuição da atividade catalítica específica do eletrodo. Os autores propuseram que estes efeitos foram devidos à diminuição do tamanho das partículas dispersas no polímero.

Dispersões de platina em substratos poliméricos apresentam grande área eletroquímica dada a tridimensionalidade do substrato. Nesse sentido, as características eletroquímicas destas dispersões são diferentes das dispersões de platina em diamante devido ao fato de que as primeiras tratam-se de dispersões tridimensionais. Todavia, é interessante notar que a atividade eletrocatalítica da platina pode ser influenciada pelo tipo de substrato utilizado, sendo esta influência tanto mais pronunciada quanto menores forem os diâmetros médios das partículas. Outro fato digno de nota é de que, não importando o método de deposição utilizado, pode-se observar que geralmente dispersões com menores diâmetros médios são conseguidas em substratos poliméricos (da ordem de 1 a $10 \mathrm{~nm}$ ), enquanto que em outros substratos (diamante, outros materiais carbonáceos e metais), o diâmetro médio das partículas apresenta-se no intervalo entre 10 e $400 \mathrm{~nm}$.

A influência do pré-tratamento superficial do substrato nas características da dispersão de catalisador é objeto de constante estudo, sendo que a totalidade destes estudos enfoca o pré-tratamento oxidativo (não eletroquímico) de substratos de carbono particulado, com vistas ao controle da atividade catalítica destes sistemas. Apesar das evidentes diferenças estruturais entre o diamante e o carbono particulado, há alguma similaridade na química superficial destes materiais. No diamante, já vimos que sua superfície é composta por átomos de $\mathrm{C}$ e de $\mathrm{H}$. Quando o filme é de alguma forma oxidado, há formação de grupamentos oxigenados na sua superfície, dentre eles, carbonilas $^{44,45}$. No carbono particulado, há átomos de carbono, ligados uns aos outros através de ligações em sua maioria insaturadas. Em amostras oxidadas, onde podem haver grupamentos oxigenados na superfície (carbonilas, álcoois, carboxilas e cetonas) ${ }^{64}$. Essas características fazem com que seja esperado que ambos os materiais apresentem comportamento eletroquímico similar, a despeito da maior estabilidade química e da menor carga capacitiva apresentada por eletrodos de filme de diamante. Deve-se dizer também que há poucos trabalhos tratando deste assunto em substratos de diamante BDD. 
Por essas razões, justifica-se a investigação crítica de alguns resultados relevantes no campo da alteração superficial de substratos de carbono particulado.

Yang e col. ${ }^{65}$ observaram que o grau de dispersão de partículas de $\mathrm{Ag}$ e a atividade eletrocatalítica para a reação de redução de $\mathrm{O}_{2}$ em meio básico aumentava com o nível de oxidação do substrato de carvão ativado (efetuada em solução de $50 \%$ de $\mathrm{HNO}_{3}$, a quente). Contudo, em maiores tempos de pré-tratamento oxidativo, obtiveram-se depósitos menos dispersos e pouco aderentes ao substrato. Prado-Burguete e col. ${ }^{66}$ publicaram resultados correlacionando a variação da concentração de espécies oxigenadas na superfície do substrato (grupos $\mathrm{C}=\mathrm{O}$ e $\mathrm{COOH}$ ) com o grau de dispersão de Pt. Embora o método de pré-tratamento tenha diferido deste $\left(48 \mathrm{~h}, \mathrm{H}_{2} \mathrm{O}_{2}, 4 \mathrm{M}\right)$ para o trabalho de Yang e col. ${ }^{65}$, os resultados corroboram entre si, no sentido de que eles também observaram que o tratamento oxidativo do carvão ativado contribui para o aumento do grau de dispersão das partículas de $\mathrm{Pt}$ depositadas quimicamente. O diferencial apresentado por este trabalho entretanto, está no fato de que os autores puderam propor mais precisamente quais grupamentos oxigenados são responsáveis por este efeito. Através de medidas de Espectroscopia no Infra-Vermelho com Transformadas de Fourier, eles mostraram que havia uma correlação direta entre o grau de dispersão de Pt e a concentração superficial de grupos $\mathrm{C}=\mathrm{O}$. Baseados nestes resultados, os autores propuseram como explicação dois fatores que exerceriam influência no grau de dispersão das partículas de catalisador:

1- A oxidação do substrato fornece uma superfície hidrofílica na qual há melhor penetração da solução de complexo de Pt no material;

2- Os ânions complexos de Pt podem interagir com os grupamentos superficiais (principalmente $\mathrm{C}=\mathrm{O}$, dado o seu caráter relativamente básico), dificultando a redistribuição ou aglomeração das micropartículas na etapa da redução destes ânions, que nestes experimentos, foi feita a $393 \mathrm{~K}$.

Amine e col. ${ }^{67}$ observaram que a presença de grupamentos $\mathrm{COOH}$, inseridos no substrato de carvão ativo com tratamento oxidativo contribuía para o aumento do grau de dispersão das partículas de Pt. Entretanto este efeito só era observado quando era usado um complexo catiônico de $\mathrm{Pt}\left(\left[\mathrm{Pt}\left(\mathrm{NH}_{3}\right)_{4}\right]^{2+}\right)$. Utilizando-se como fonte de $\mathrm{Pt}$ o ânion $\mathrm{PtCl}_{6}{ }^{2-}$ obtiveram-se aglomerações não-cristalinas de Pt de menor grau de dispersão, após 
o processo de redução. Esse trabalho não pode ser comparado com os citados anteriormente, uma vez que neste caso, os autores não comparam o grau de dispersão das partículas de Pt depositadas sobre substrato não-oxidado com o oxidado. Entretanto, sua conclusão concorda com a dos outros autores citados. Segundo ele, uma das etapas da formação de núcleos de Pt sobre o substrato passaria pela captura da Pt via formação de um complexo entre o íon metálico e grupos carboxilas presentes na superfície, ao mesmo tempo em que estes grupos dificultavam a migração e coalescência de espécies intermediárias de Pt sobre a superfície do substrato.

Em relação aos filmes de diamantes, alguns estudos sobre o pré-tratamento eletroquímico na eletrodeposição de metais sobre filmes de diamantes condutivos foram efetuados envolvendo a deposição de cobre. Yoshihara e col. ${ }^{30,43}$ descobriram que a geração de $\mathrm{H}_{2}(-0,25 \mathrm{~V}$, vs. ECS) sobre um eletrodo de diamante dopado com boro, sob irradiação de luz ultravioleta, gerava depósitos de cobre (efetuados em meio de $\mathrm{H}_{2} \mathrm{SO}_{4}$ $0,5 \mathrm{M})$ mais uniformes e dispersos. Investigando a causa deste fenômeno, os autores observaram que a fotoeletrogeração de $\mathrm{H}_{2}$ sobre o eletrodo feita a $-0,25 \mathrm{~V}$ diminuía a concentração de espécies oxigenadas localizadas na superfície do filme, bem como aumentava a sua condutividade superficial. Este mesmo tratamento realizado em $-0,50 \mathrm{~V}$ não alterava a composição superficial do filme. Disso, os autores concluíram que somente o $\mathrm{H}_{2}$ gerado a partir de processos fotoeletroquímicos $(\mathrm{a}-0,25 \mathrm{~V})$ e não devido a processos eletroquímicos $(\mathrm{a}-0,50 \mathrm{~V})$ no filme, contribuía para a redução da sua superfície e/ou para a inserção de hidrogênio subsuperficial do filme $\mathrm{e}^{23,24}$, o que facilitava a dispersão uniforme das partículas de cobre. Em um trabalho anterior a este, Bouamrane e col. ${ }^{68}$ observaram a deposição em regime de deposição sub-potencial (under potential deposition - UPD), em filmes de diamante, que era intensificada quando os eletrodos eram pré-tratados em potenciais de geração de $\mathrm{H}_{2}$. O pico UPD de deposição de cobre era reprimido quando o substrato era bombardeado com íons $\mathrm{Ar}^{+}$de baixa energia. Os autores propuseram que a deposição UPD do metal se deu sobre núcleos de carbono $\mathrm{sp}^{2}$, o que não era mais possível quando estes núcleos grafíticos eram supostamente removidos por conta do tratamento com ions $\mathrm{Ar}^{+}$. Entretanto, outros autores obtiveram justamente a

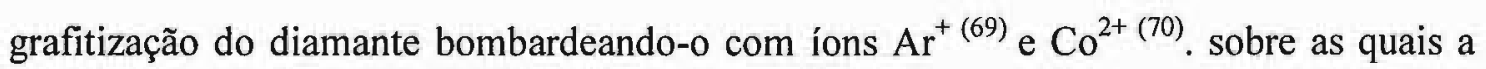
eletrodeposição de metais mostrou-se preferivel ${ }^{70}$. Em vista destes últimos resultados 
aparentemente conflitantes, pode-se dizer que a deposição UPD tenha se dado possivelmente por conta da hidrogenação (superficial ou sub-superficial) do eletrodo, superfície sobre a qual o cobre é preferencialmente depositado ${ }^{30,43}$. Em relação a este último trabalho comentado, deve-se ressaltar, entretanto, que a deposição UPD de algum metal sobre o eletrodo de diamante dopado com boro não foi reportada em nenhum outro trabalho.

Ohta e col. ${ }^{42}$ observaram que o pré-tratamento anódico do eletrodo de filme diamante condutivo em pH 7 dificultava a deposição de íons $\mathrm{Cu}^{2+}$. Entretanto, um pesquisador do mesmo grupo (Nakabayashi e col. ${ }^{71}$ ) relatou no mesmo ano e nas mesmas condições experimentais que em [42], que íons $\mathrm{Cu}^{2+}$ sofriam redução à superfície do diamante sem qualquer tipo de pré-tratamento, sem contudo haver a deposição do mesmo. Provavelmente este segundo autor tenha trabalhado com amostras de diamante com alta concentração de oxigênio superficial, que reconhecidamente inibe a deposição de metais.

\section{3- Deposição de metais e de óxidos metálicos sobre o DDB}

Com o intuito de se aumentar a atividade eletroquímica do diamante, aproveitando a sua resistência à corrosão, alguns grupos têm se dedicado a estudar a eletrodeposição de partículas de eletrocatalisador sobre filmes condutivos de diamante, sejam elas metálicas ou de óxidos metálicos.

\subsection{1- Deposição de metais}

Superfícies de diamante são conhecidas pela baixa concentração de sítios ativos para adsorção de espécies. Com o objetivo de se estudar os possíveis sítios preferenciais de eletrodeposição de metais, Enea e col. ${ }^{72}$ estudaram utilizando AFM e STM a eletrodeposição de Pt sobre filmes de diamante, submetidos previamente a tratamento anódico em solução $\mathrm{H}_{2} \mathrm{SO}_{4}$ 0,5 M. Os autores observaram a formação de nanodepósitos circulares de Pt de diâmetro na faixa de 200-600 nm, cuja altura desses não ultrapassava a 25-30\% da dimensão do diâmetro, distribuindo-se uniformemente pela superfície do filme. Não foram observadas regiões preferenciais de crescimento dos nanodepósitos. Os autores propuseram que as regiões propícias à nucleação destes nanocristais situavam-se 
nos pontos do filme onde havia maior condução elétrica, ou seja, maior concentração de dopante.

Zhang e col. ${ }^{73}$ estudaram a redução de $\mathrm{O}_{2}$ em dispersões de ouro eletrodepositado sobre eletrodos de diamante dopado com boro. Foram obtidas dispersões nanométricas de partículas, uniformemente distribuídas pela superfície do eletrodo. Convém ressaltar aqui que as amostras de diamante eram de filmes auto-sustentados. O filme de diamante foi crescido sobre um substrato de silício que foi totalmente removido a partir de um ataque químico com uma mistura de $\mathrm{HF} / \mathrm{HNO}_{3}$ (1:2, em volume) após o crescimento do filme. As dispersões de $\mathrm{Au}$ apresentaram altas densidades de corrente de redução de $\mathrm{O}_{2}$ em baixas coberturas de catalisador. A densidade de corrente por massa de metal depositado, sofreu diminuição à medida em que a cobertura aumentava. A eficiência catalítica do $\mathrm{Au}$ depositado no eletrodo de diamante com uma área superficial de $\mathrm{Au}$ dividida pela área total do eletrodo de 0,06 , que foi aproximadamente 20 vezes maior do que em um eletrodo de ouro policristalino. De uma maneira geral, os eletrodos de diamante com ouro eletrodepositado apresentaram maior atividade eletroquímica do que a do eletrodo de ouro policristalino. Entretanto, Holt e col. ${ }^{74}$, estudando a viabilidade do uso de eletrodos de diamante para aplicações em análise de quantidades-traço de ouro, observaram que o tratamento anódico em água régia dificultava a deposição de ouro à superfície do filme, proporcionando a formação de Au coloidal. Inversamente, foi observado por esse grupo que o tratamento catódico do filme (também em água régia) redundava em diminuição da concentração superficial de oxigênio e no aumento da quantidade de ouro depositado à superfície do filme.

A aparente discordância dos dados de comportamento do filme submetido a prétratamentos anódicos mostra que o mecanismo de deposição de metais sobre este material é complexo e que ainda pouco se conhece a respeito das reais condições de controle destes depósitos.

Vemos então que no campo do estudo da atividade catalítica de dispersões de metais sobre eletrodos de filmes de diamante, alguns trabalhos têm sido publicados. Na maioria desses estudos, a abordagem empregada é o estudo da influência da quantidade de metal depositado na sua atividade eletrocatalítica. Não foram encontrados trabalhos nos quais eram comparadas as características dos filmes de diamante, com outros materiais 
carbonosos, sob uma mesma condição experimental. Swain e col. publicaram trabalhos $^{75,76}$ tratando da deposição de partículas de Pt por eletrodeposicão e por sputtering. Posteriormente à deposição, as amostras foram submetidas a um novo processo de crescimento de uma fina camada de diamante. Dessa forma, foram obtidas partículas de platina ancoradas no substrato de diamante (Figura 3.4), com excelente estabilidade, mesmo em tratamentos em meio de $\mathrm{H}_{3} \mathrm{PO}_{4} 85 \%, 170{ }^{\circ} \mathrm{C}$ e $0,1 \mathrm{~A} / \mathrm{cm}^{2(74)}$. Os autores observam também que a eletrodeposição galvanostática é vantajosa em relação à deposição por sputtering, uma vez que foi possivel obter um melhor controle do tamanho e da distribuição das nanopartículas de Pt (30 a $300 \mathrm{~nm}$ ), que ocorreu tanto nas regiões intercristalinas quanto nas faces dos microcristais do substrato. No caso da deposição de Pt por sputtering, foram obtidas partículas de 10 a $500 \mathrm{~nm}$ de diâmetro, distribuídas principalmente nas regiões intergranulares de diamante.

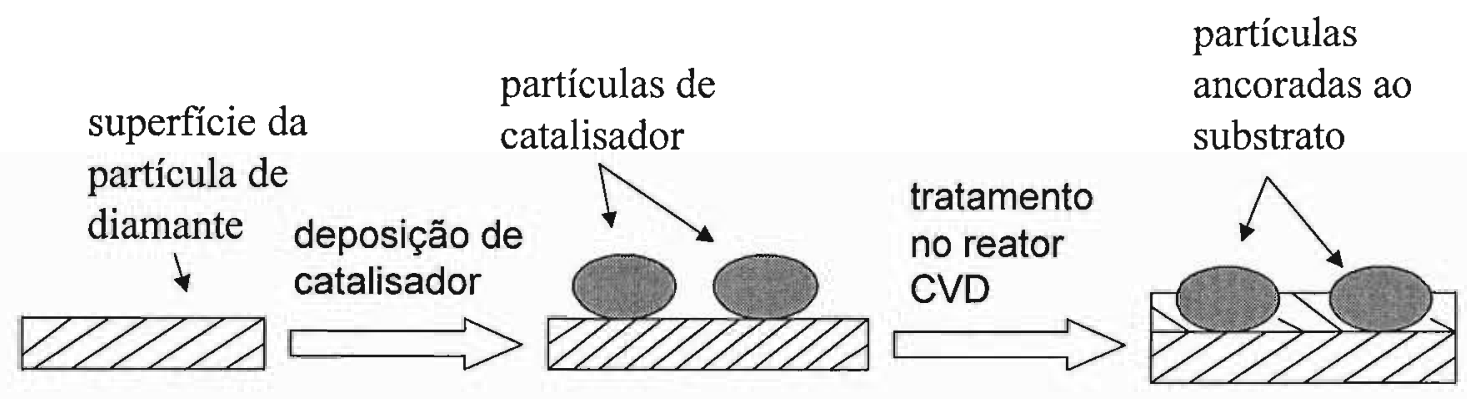

FIGURA 3.4: Esquema de ancoragem de partículas de catalisador à superfície de diamante BDD.

Honda e col. ${ }^{77}$ depositaram quimicamente Pt sobre filmes nanoporosos de diamante para a oxidação de metanol, etanol e isopropanol e para a redução de $\mathrm{O}_{2}$. Foram obtidas superfícies com área superficial aumentada, em relação à dispersão de Pt em filmes de diamante comuns, com partículas de Pt da ordem de 10 a $150 \mathrm{~nm}$ de diâmetro. Foi observado que o potencial de eletrooxidação do álcoois aumentava no sentido metanol / etanol / isopropanol, sendo que esse aumento não era proporcional às diferenças de coeficientes de difusão destes álcoois. A explicação proposta pelos autores foi de que os nanoporos dificultam a difusão de moléculas maiores de álcool até a Pt depositada em maiores profundidades no poro. Outro aspecto interessante observado pelos autores foi 
que as dispersões de $\mathrm{Pt}$ em diamantes nanoporosos por eles obtidas apresentaram atividade eletrocatalítca para a reação de redução de $\mathrm{O}_{2}$, cerca de $40 \%$ mais baixa do que em eletrodos de Pt policristalina. A caracterização dessas dispersões por difração de raios $\mathrm{X}$ mostrou que as orientações cristalográficas predominantes eram (111) e (100), que são reconhecidamente menos ativas para esse tipo de reação ${ }^{78}$.

Deve-se mencionar que são relativamente poucos os estudos da influência de prétratamentos (químicos ou eletroquímicos) de filmes de diamante sobre as características dos depósitos metálicos formados. Fujishima e colaboradores ${ }^{42}$ observaram que tratamentos do filme de diamante em potenciais de geração de $\mathrm{O}_{2}$ inibiam a eletrodeposição de cobre. Como explicação, foi proposta a influência de interações eletrostáticas de repulsão entre o íon $\mathrm{Cu}^{2+}$ e a superfície oxidada do eletrodo. Entretanto, como já comentado no item 3.1 - Filmes de Diamante em Eletroquímica, devido à inconsistência dessa explicação, a oxidação superficial do filme parece exercer impedimento estérico à aproximação do íon metálico.

\subsection{2- Deposição de óxidos metálicos}

É bem conhecida a atividade eletrocatalítica de alguns óxidos metálicos, tais como $\mathrm{Co}_{2} \mathrm{O}_{3}, \mathrm{RuO}_{2}$ e $\mathrm{IrO}_{2}$, para reações de geração de $\mathrm{H}_{2}, \mathrm{O}_{2}, \mathrm{Cl}_{2}$, para a oxidação de pequenas moléculas orgânicas (álcoois simples, formaldeído e cetaldeído) e para a oxidação de substâncias, tais como $\mathrm{H}_{2} \mathrm{O}_{2}{ }^{79}$. Essa classe de óxidos é também conhecida como anodos dimensionalmente estáveis (DSA ${ }^{\circledR}$ ). Dessa forma, a deposição de alguns óxidos metálicos foi estudada, utilizando-se diferentes condições de deposição e de pré-tratamento do substrato.

Utilizando o método de deposição química, Duo e col. ${ }^{80}$ modificaram eletrodos de diamante com partículas de $\mathrm{IrO}_{2}$ e observaram grande aumento da atividade do eletrodo para a reação de geração de $\mathrm{O}_{2}$. A oxidação de metanol, ácido fórmico e isopropanol só foi observada em potenciais de decomposição anódica da água. Neste trabalho, não foi caracterizada a morfologia das partículas; todavia ele é digno de nota, já que se trata de um dos primeiros trabalhos publicados sobre a modificação superficial de eletrodos de diamante com óxidos metálicos. 
Terashima e col. ${ }^{81}$ depositaram filmes de $\mathrm{IrO}_{2}$ sobre eletrodos de diamante com intuito de propor a aplicação deste material como substrato para sensores analíticos. Depósitos estáveis deste óxido foram preferencialmente obtidos quando o substrato foi submetido ao tratamento anódico e quando a deposição potenciostática foi feita em potenciais próximos à redução da água. Em baixas quantidades superficiais de $\operatorname{IrO}_{\mathrm{x}}$, foram obtidos filmes descontínuos e estáveis com alta atividade eletrocatalítica para a oxidação anódica de $\mathrm{H}_{2} \mathrm{O}_{2}$. Por outro lado, foram também obtidos filmes contínuos de óxido de irídio que apresentaram excelente resposta ao $\mathrm{pH}$ em um largo intervalo de pH's. É importante ressaltar o fato de que no trabalho destes autores foram obtidas dispersões de partículas nanométricas $(\sim 30 \mathrm{~nm})$, que apresentaram distribuição sobre o substrato tanto mais regular quanto menores eram os grãos do substrato.

Em se tratando da modificação superficial de eletrodos de diamante com óxido de rutênio, dois trabalhos foram publicados de maneira relativamente simultânea. Em um dos trabalhos, Ferro e col. ${ }^{82}$ propõem o uso de eletrodos de diamante modificados com partículas de $\mathrm{RuO}_{2}$ para a geração de $\mathrm{Cl}_{2}$, em meio ácido.

McKenzie e col. ${ }^{83}$ depositaram quimicamente partículas de $\mathrm{RuO}_{2}$ sobre eletrodos polidos de diamante. Quando foi empregada água como solvente para o banho de deposição de $\mathrm{RuO}_{2}$, foram obtidas partículas da ordem de 8 a $14 \mathrm{~nm}$. Quando foi utilizado etanol como solvente, foram obtidas partículas de apenas 1 a $2 \mathrm{~nm}$, que apresentaram entretanto bem menor atividade eletroquímica para geração de $\mathrm{H}_{2}$. A grande vantagem prática deste eletrodo destacada pelos autores é de que ele apresentou uma resposta linear de sensibilidade ao $\mathrm{pH}$ bem maior do que eletrodos de $\mathrm{RuO}_{2}$ usualmente depositados sobre ITO, por exemplo, o que o faz um bom candidato a sensor de $\mathrm{pH}$. Todavia os autores não esboçaram nesse trabalho nenhuma tentativa de explicação do porquê deste comportamento diferenciado.

Com o intuito desenvolver um material eletrocatalisador para as reações de geração e de redução de $\mathrm{O}_{2}$, Spataru e col. ${ }^{84}$ estudaram a eletrodeposição anódica de $\mathrm{Co}_{2} \mathrm{O}_{3}$ sobre eletrodos de diamante dopados com boro. Foram obtidos depósitos em escala nanométrica com alta atividade eletroquímica para geração de $\mathrm{O}_{2}$ em meio alcalino, cujo mecanismo foi similar ao obtido em dispersões deste óxido sobre outros substratos em meio básico. 


\subsection{3-Deposição de metais e de óxidos metálicos para reações não-eletroquímicas}

Não é só no campo da Eletroquímica que o diamante vem encontrando aplicações. É intensa a pesquisa sobre a sua utilização como material de suporte para catalisadores, sobretudo para reações em altas temperaturas. Isso porque devido à sua alta condutividade térmica (ver Tabela 2.1 - item Aspectos Gerais), este material evita a formação de ilhas de calor. Essas ilhas de calor ocorrem quando o suporte do catalisador não é bom condutor de calor. Dessa forma, na partícula do suporte, a temperatura permanece bem mais alta do que no resto do reator, fornecendo condições para a geração de outros produtos inesperados. Como para estes fins, o diamante não precisa ser dopado, utiliza-se amostras em pós de alta área superficial, obtidos quase sempre pelo método HTHP (alta temperatura / alta pressão), ou como subprodutos da lapidação de pepitas. É interessante a citação de alguns trabalhos desenvolvidos neste sentido, pelo fato de que são propostas aplicações para os mais variados tipos e condições reacionais. Além disso, pode-se observar que tipos de pré-tratamentos são empregados para obtenção de uma melhor aderência da partícula catalisadora sobre o substrato de diamante. Nestes trabalhos, é unânime a observação de que uma melhor aderência da partícula de catalisador sobre o substrato é obtida quando se submete o mesmo a tratamento oxidativo, que tem por objetivo substituir o hidrogênio, por uma camada de espécies oxigenadas sobre a superfície da partícula de diamante. Neste sentido, foi proposta a deposição química de vários metais $(\mathrm{Zn}, \mathrm{Fe}, \mathrm{Mn}, \mathrm{Ce}, \mathrm{Ga}, \mathrm{Mo}, \mathrm{V}, \mathrm{Cr}$ ) e de seus óxidos sobre pó de diamante ${ }^{85}$. O procedimento geral empregado nesta deposição era a mistura de pó de diamante (já oxidado) a uma solução destes metais, seguida pela evaporação do solvente e exposição da mistura à uma atmosfera de $\mathrm{H}_{2}$ em alta temperatura, para a redução dos íons aos seus respectivos metais. Estas dispersões foram testadas para a desidrogenação catalítica de etano em presença de $\mathrm{CO}_{2}$ como oxidante. De todos estes, o sistema diamante $/ \mathrm{Cr}_{2} \mathrm{O}_{3}$ foi o que apresentou maior eficiência e seletividade para a produção da olefina correspondente.

Yuan e col. ${ }^{86}$ estudaram a atividade catalítica de dispersões de zirconoceno em UDDBP para a polimerização de etileno. O UDDBP (Ultra Dispersed Diamond Black Powder) é o produto da detonação de explosivos contendo carbono em sua composição, em um ambiente deficiente de oxigênio. O produto desta reação é um pó altamente 
disperso de grafite com 25 a $30 \%$ de diamante nanoparticulado (5-15 nm). Os suportes usuais para esta classe de catalisador são a alumina e a sílica. Entretanto, o zirconoceno apresentou maior eficiência catalítica sobre o UDDBP do que sobre $\mathrm{Al}_{2} \mathrm{O}_{3}$, fato que os autores creditaram à presença de grupos funcionais oxigenados na superfície das partículas do material carbonoso. Embora se espere que este material seja quimicamente bem diferente do pó de diamante de pureza $100 \%$, é importante destacar-se a importância de grupamentos superficiais oxigenados no grau de dispersão de catalisador sobre o substrato. 


\section{4 - PARTE EXPERIMENTAL}

\section{1 - Reagentes e Soluções}

Todos os reagentes utilizados nos experimentos são de pureza analítica, foram utilizados sem pré-purificação e a origem destes encontram-se na Tabela 3. Todas as soluções empregadas neste trabalho foram preparadas com água deionizada.

TABELA 4.1 - Procedência e pureza dos reagentes utilizados

\begin{tabular}{|c|c|c|}
\hline Material & Procedência & Pureza / \% \\
\hline Ácido Sulfúrico & Merck & $95,0-97,0$ \\
\hline Cloreto de Potássio & Nuclear & 99 \\
\hline Etanol (padrão cromatográfico) & Merck & 99,0 \\
\hline Ferrocianeto de Potássio & Ecibra & 99,0 \\
\hline Ácido Hexacloroplatínico & Carlo Erba & 99,0 \\
\hline Hidróxido de Potássio & Merck & 99 \\
\hline
\end{tabular}

A solução de $\mathrm{H}_{2} \mathrm{SO}_{4}$ 0,5 $\mathrm{M}$ foi preparada a partir da diluição de $27,7 \mathrm{~mL}$ de $\mathrm{H}_{2} \mathrm{SO}_{4}$ (densidade $1,84 \mathrm{~g} / \mathrm{mL}$ ) com água deionizada até o volume de $500 \mathrm{~mL}$.

Foi preparada uma solução-estoque de ácido hexacloroplatínico pela dissolução do sólido com uma solução de $\mathrm{KCl}$ 0,1 M até o volume de $100 \mathrm{ml}$ (concentração de 2,3 $\times 10^{-2} \mathrm{M}$ ). As demais soluções deste ácido foram preparadas por diluição a partir desta. $\mathrm{O}$ pH da solução foi acertado em pH 3,4 por meio de adição de solução diluída de $\mathrm{KOH}$.

Para evitar possíveis flutuações na concentração de etanol por evaporação ou por oxidação em presença do ar, não foi preparada solução estoque de etanol. Desta forma, antes de cada experimento, a solução de etanol $0,1 \mathrm{M}$ era preparada a partir da diluição de $0,56 \mathrm{ml}$ etanol anidro (densidade $0,81 \mathrm{~g} / \mathrm{mL}$ ) com solução de $\mathrm{H}_{2} \mathrm{SO}_{4} 0,5 \mathrm{M}$, em um balão volumétrico, até completar o volume de $100 \mathrm{ml}$.

Todo o material utilizado (balões volumétricos, espátulas, béqueres, etc), passou por um procedimento de limpeza com o intuito de assegurar a ausência de quaisquer resíduos orgânicos. Para isso foi utilizado ácido sulfúrico concentrado e posterior lavagem com água destilada. 


\section{2 - Célula Eletroquímica}

Utilizou-se uma célula de vidro Pyrex de compartimento único, com capacidade para $200 \mathrm{ml}$, equipada com tampa em Teflon contendo orifícios para o posicionamento dos eletrodos e da linha de nitrogênio ultra-puro, utilizado na desoxigenação da solução. $O$ eletrodo de referência utilizado foi o de $\mathrm{Ag} / \mathrm{AgCl} 3 \mathrm{M}$ adaptado em um capilar de Luggin que foi posicionado a uma distância de aproximadamente $3 \mathrm{~cm}$ do eletrodo de trabalho. $\mathrm{O}$ contra-eletrodo foi um fio de platina platinizada.

\subsection{1 - Eletrodo de trabalho}

O eletrodo de trabalho foi composto de um filme de diamante montado sobre um suporte de latão e o sistema todo revestido por Teflon. As amostras de filmes de diamantes provenientes do Grupo de Diamantes do Laboratório Associado de Sensores do Instituto Nacional de Pesquisas Espaciais (LAS-INPE) e do Laboratório de Diamantes da Universidade São Francisco. Tais amostras foram depositadas pelo método HFCVD (deposição a vapor químico assistido por filamento quente) ${ }^{9}$.

Nos experimentos de caracterização do eletrodo em solução de $\mathrm{H}_{2} \mathrm{SO}_{4} 0,5 \mathrm{M}$, o filme era mantido junto ao eletrodo por meio de uma cola vedante de silicone. Por motivos de irreprodutibilidade causada por infiltração de solução entre o filme e a camada de cola, adotou-se a seguinte configuração, como está esquematizado na Figura 4.1. As amostras de filmes de diamante foram arranjadas em um sistema de latão recoberto por Teflon, cuja vedação era feita com um anel de borracha, o-ring. Nesta configuração, a área geométrica exposta do eletrodo foi de $0,07 \mathrm{~cm}^{2}$ e de $0,19 \mathrm{~cm}^{2}$ em alguns experimentos. $O$ contato elétrico foi feito diretamente com o filme de diamante sobre o latão, pressionando-se o filme sobre o latão, através da tampa rosqueada do eletrodo. 


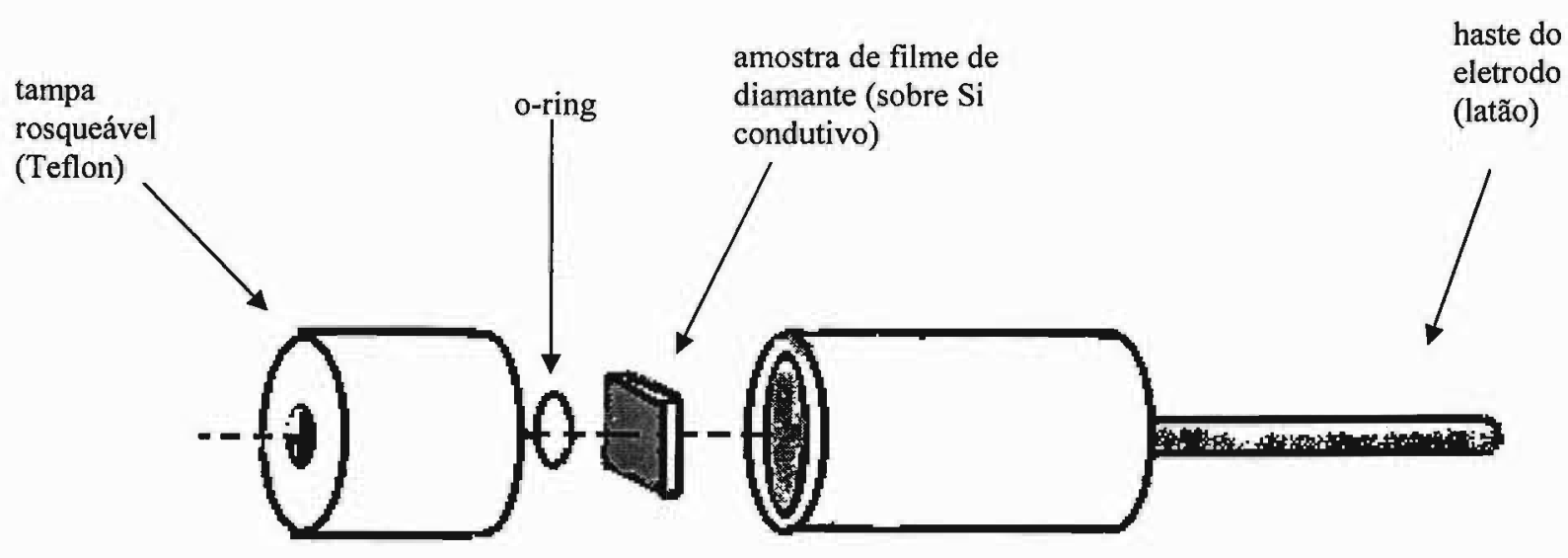

FIGURA 4.1- Esquema de montagem do eletrodo de trabalho.

\section{3 - Metodologia}

Foram realizados experimentos de voltametria cíclica em soluções de $\mathrm{H}_{2} \mathrm{SO}_{4} \quad 0,5 \mathrm{M}$ e de $\mathrm{H}_{2} \mathrm{PtCl}_{6}$ 3,9 mM. Os experimentos de voltametria cíclica foram feitos em diferentes velocidades de varredura, dependendo do experimento, no intervalo de estabilidade da água $(-0,5 \mathrm{~V}$ a $2,0 \mathrm{~V}$, vs. $\mathrm{Ag} / \mathrm{AgCl})$. Entre cada experimento, borbulhou-se $\mathrm{N}_{2}$ ultrapuro por 2 minutos a fim de se eliminar possíveis produtos gasosos gerados durante o experimento anterior $\left(\mathrm{H}_{2}, \mathrm{O}_{2}\right.$ ou $\left.\mathrm{CO}_{2}\right)$ dissolvidos e, após deixar a solução em repouso por 1 minuto, era iniciado o experimento voltamétrico. No caso dos experimentos em solução ácida de etanol $0,1 \mathrm{M}$, a solução era renovada a cada dois experimentos para se evitar problemas de variações de concentração de etanol ou de interferência de intermediários de oxidação deste álcool nos experimentos.

Nos experimentos de eletrodeposição de platina, as amostras de filmes de diamante foram platinizadas a partir de uma solução de $3,9 \mathrm{mM}$ de $\mathrm{H}_{2} \mathrm{PtCl}_{6}$ tendo como eletrólitosuporte $\mathrm{KCl}$ 0,1 M. O pH foi ajustado em 3,4 gotejando-se soluções de $\mathrm{HCl}$ ou de $\mathrm{KOH}$, ambos diluídos em solução de eletrólito-suporte. 
As eletrodeposições foram realizadas potenciostaticamente $(-0,2 \mathrm{~V}$ e $-0,9 \mathrm{~V})$, variando-se o tempo de eletrodeposição. As cargas de eletrodeposição foram calculadas a partir da integração das áreas dos cronoamperogramas obtidos, levando-se em conta que não houve considerável geração catódica de $\mathrm{H}_{2}$

Sempre com uma mesma amostra, quantidades crescentes de platina eram depositadas potenciostaticamente e, logo após cada eletrodeposição, o eletrodo era retirado do banho de $\mathrm{H}_{2} \mathrm{PtCl}_{6} 3,9 \mathrm{mM}$, lavado cuidadosamente com água destilada e imerso em solução de $\mathrm{H}_{2} \mathrm{SO}_{4} 0,5 \mathrm{M}$ e de etanol $0,1 \mathrm{M}+\mathrm{H}_{2} \mathrm{SO}_{4} 0,5 \mathrm{M}$ para se fazerem as medidas de atividade eletroquímica do eletrodo modificado. Antes de serem registrados os voltamogramas cíclicos obtidos tanto em solução de $\mathrm{H}_{2} \mathrm{SO}_{4} \quad 0,5 \mathrm{M}$ quanto em solução de etanol $0,1 \mathrm{M}$ foram feitos vários ciclos potenciodinâmicos nestas soluções até a obtenção de resposta reprodutível.

\section{4 - Instrumentação}

Para as medidas eletroquímicas foi utilizado o potenciostato / galvanostato, EG\&G modelo 273A acoplado a um microcomputador dotado do programa PARC M-270. Os resultados da MEV e de EDS foram obtidos em um microscópio eletrônico JEOL Pioneer, com energia dos feixes de elétrons correspondentes a $20 \mathrm{keV}$ e $10 \mathrm{keV}$, respectivamente. 


\section{5 - RESULTADOS E DISCUSSÃO}

\section{1- Caracterização eletroquímica}

\subsection{1 - Estudos preliminares}

Nesta etapa foram realizados estudos voltamétricos em solução de $\mathrm{H}_{2} \mathrm{SO}_{4} 0,5 \mathrm{M}$ com um eletrodo de diamante recém-depositado dopado com $5000 \mathrm{ppm}$ de boro a uma velocidade de varredura de $100 \mathrm{mV} \mathrm{s}^{-1}$. Foi realizada uma varredura no intervalo de potenciais de $-0,6 \mathrm{~V}$ a $1,4 \mathrm{~V}$. No voltamograma resultante deste experimento, mostrado na Figura 5.1, pode-se observar que a corrente, aproximadamente nula no intervalo de potenciais que vai de $-0,5 \mathrm{~V}$ a $0,0 \mathrm{~V}$, apresenta picos de baixa intensidade até a partir de $0,1 \mathrm{~V}$ até $0,9 \mathrm{~V}$. Em potenciais superiores a $0,9 \mathrm{~V}$, surge uma intensa corrente anódica correspondente à RGO. Na varredura no sentido decrescente de potenciais, observa-se uma região de corrente catódica de baixa intensidade (entre $0,1 \mathrm{e}-0,5 \mathrm{~V}$ ), anterior à corrente de $\mathrm{RGH}(\mathrm{em} \mathrm{E}<-0,5 \mathrm{~V})$. Alguns autores relacionam esse sinal à redução de $\mathrm{O}_{2}$, que no diamante segue uma cinética lenta ${ }^{87}$.

Os experimentos voltamétricos seguintes foram realizados utilizando a mesma amostra de DDB. Com a mesma velocidade de varredura $\left(100 \mathrm{mV} \mathrm{s}^{-1}\right)$, o potencial foi variado de $-0,6 \mathrm{~V}$ a apenas $1,0 \mathrm{~V}$, para evitar excessiva geração de $\mathrm{O}_{2}$. Os voltamogramas referentes a estes experimentos são mostrados na figura 5.1, nos quais, ao contrário do que foi visto na primeira varredura, não se observam os picos catódicos ou anódicos de baixa intensidade no intervalo de estabilidade da água. Além disso, observase que a RGO é inibida com o número de ciclos voltamétricos a que o eletrodo é submetido. Este comportamento foi observado por alguns autores ${ }^{24,26,34}$ que relataram a diminuição da atividade do filme de diamante (apassivação) devida à oxidação superficial do eletrodo, que tende a alterar os potenciais de oxidação de várias substâncias sobre o eletrodo de diamante ${ }^{88,89}$.

$\mathrm{O}$ fato de que o intervalo de estabilidade da água observado nestes voltamogramas feitos no filme novo foi de aproximadamente $1,5 \mathrm{~V}$, bem menor do que o encontrado na 
literatura (entre 3,0 V e 4,0 V). Entretanto, como veremos depois (seção 5.1.2), serão apresentados voltamogramas com maior intervalo de estabilidade da água, que correspondem a amostras já várias vezes cicladas voltametricamente em meio ácido. Alguns autores creditam esse comportamento dos eletrodos novos de DDB a sítios ativos formados por carbono $\mathrm{sp}^{2}$ (grafítico ou amorfo) localizados na superfície do filme $\mathrm{e}^{26}$, embora não tenha sido detectada a presença de impurezas de grafite nestas amostras por Espectroscopia Raman ${ }^{9}$. Todavia, se há a presença destas impurezas de carbono $\mathrm{sp}^{2}$, elas sofrem um processo de decomposição à medida em que o eletrodo vai sendo ciclado voltametricamente em meio ácido, restando apenas a superfície pouco reativa de diamante.

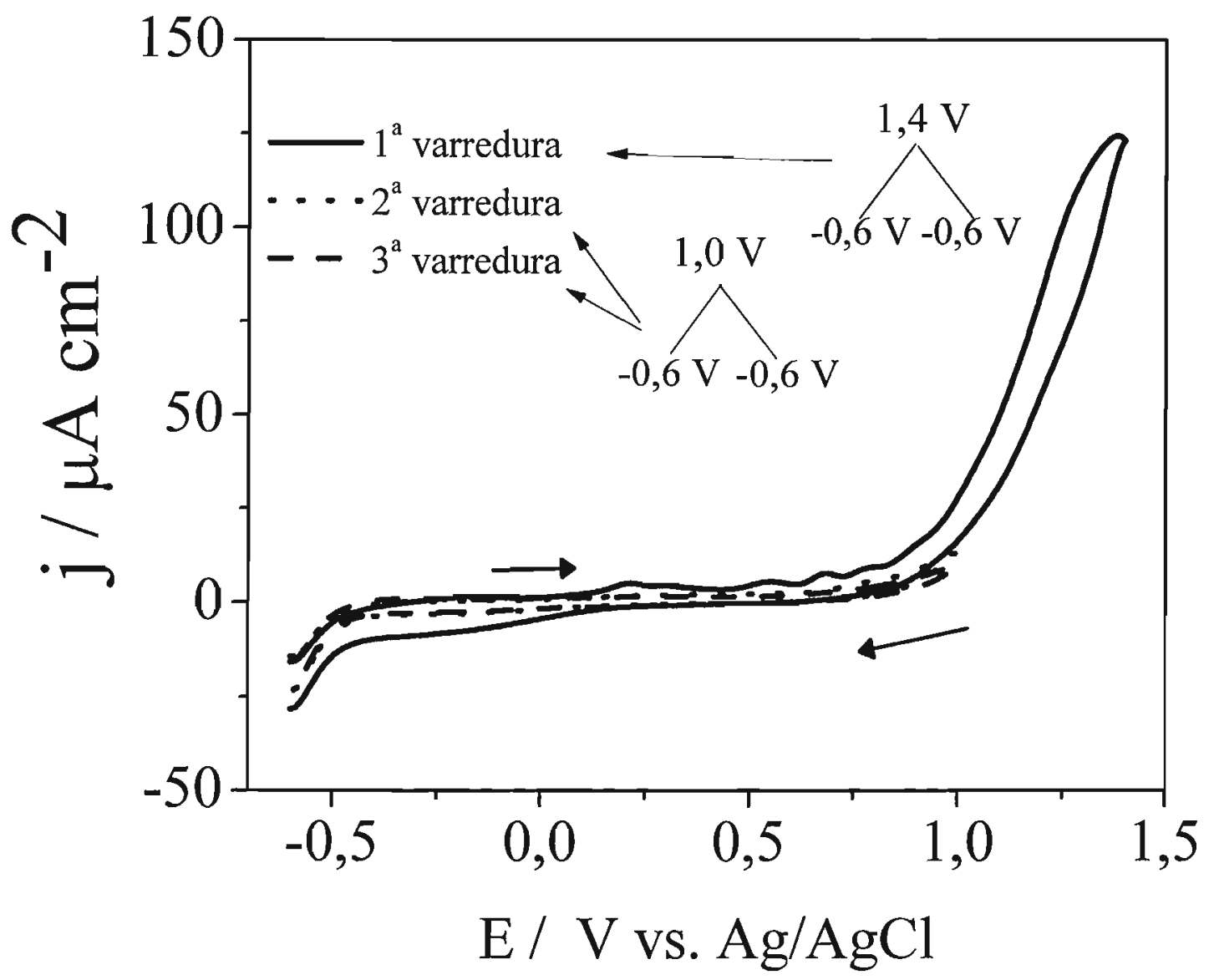

FIGURA 5.1- Três primeiros voltamogramas cíclicos de um eletrodo de diamante novo. Meio de $\mathrm{H}_{2} \mathrm{SO}_{4}$ 0,5 M, velocidade de varredura: $100 \mathrm{mV} / \mathrm{s}$. Nível de dopagem do eletrodo: $5000 \mathrm{ppm}, \mathrm{B} / \mathrm{C}$. Área geométrica do eletrodo: $0,19 \mathrm{~cm}^{2}$. 
Utilizando uma outra amostra de DDB, foram feitos três experimentos. Primeiramente foi efetuada uma varredura cíclica no eletrólito-suporte no intervalo de $-0,6 \mathrm{~V}$ a $1,0 \mathrm{~V}$ com velocidade de varredura igual a $100 \mathrm{mV} \mathrm{s}^{-1}$. Na Figura 5.2 pode-se observar o voltamograma cíclico obtido neste experimento no qual o intervalo de estabilidade da água é similar ao obtido no experimento anterior. A região catódica localizada próxima ao início da RGH é também similar ao experimento anterior. Entretanto, neste experimento, não foram observados os picos de baixa intensidade localizados anteriormente à RGO. Após este experimento, o foi efetuado um prétratamento constituído por 15 varreduras cíclicas em potenciais de $\mathrm{RGH}$ (de $-1,6 \mathrm{~V}$ a $0,0 \mathrm{~V}$, velocidade de varredura de $100 \mathrm{mV} \mathrm{s}^{-1}$ ) e após 2 minutos borbulhando $\mathrm{N}_{2}$, foi efetuada uma voltametria cíclica do eletrodo utilizando o mesmo programa empregado no primeiro experimento utilizando esta amostra. Pode-se ver que com o tratamento em potenciais de $\mathrm{RGH}$, houve o aparecimento de um pico anódico intenso em c.a 0,2 V, seguido de uma região anódica que se prolongou até o início da $\mathrm{RGO}$ em c.a 0,8 V. Após isso, o eletrodo foi submetido a um pré-tratamento que constituído por 15 ciclos entre 0,0 $\mathrm{V}$ e $1,8 \mathrm{~V}$ (tratamento anódico), com velocidade de varredura de $100 \mathrm{mV} \mathrm{s}^{-1}$, e após 2 minutos borbulhando $\mathrm{N}_{2}$ foi realizada uma voltametria cíclica com o mesmo programa utilizado anteriormente. Observou-se que tanto o pico em c.a 0,2 V quanto a densidade de corrente de RGO diminuíram sensivelmente.

Um pico anódico em c.a. $0,11 \mathrm{~V}$ (vs. $\mathrm{Ag} / \mathrm{AgCl}$ ) foi observado por Swain e col. ${ }^{90}$. Embora não o tenham estudado detalhadamente, os autores relacionaram aquele pico a uma possível oxidação da prata proveniente do eletrodo de referência. Entretanto, esta proposta é pouco provável, visto que o pico de oxidação da prata foi observado em c.a. $0,3 \mathrm{~V}$ em eletrodos de filmes de diamante altamente condutivos ${ }^{90}$.

Um pico anódico na região de 0,0 a 0,2 V em meio ácido foi observado em filmes de diamantes de diversos níveis de dopagem ${ }^{9}$, em meio ácido. Neste trabalho, os autores concluiram que aquele pico é relacionado à adsorção de espécies oxigenadas à superfície do eletrodo. Em eletrodos de platina, a região de adsorção anódica de oxigênio surge somente em potenciais acima de c.a. $1,0 \mathrm{~V}$ (vs. $\mathrm{Ag} / \mathrm{AgCl}$ ). Em vista disso, é pouco 
provável que sendo a superfície do diamante menos reativa que a da platina, possa ocorrer um pico de oxidação da sua superfície em tão baixos potenciais.

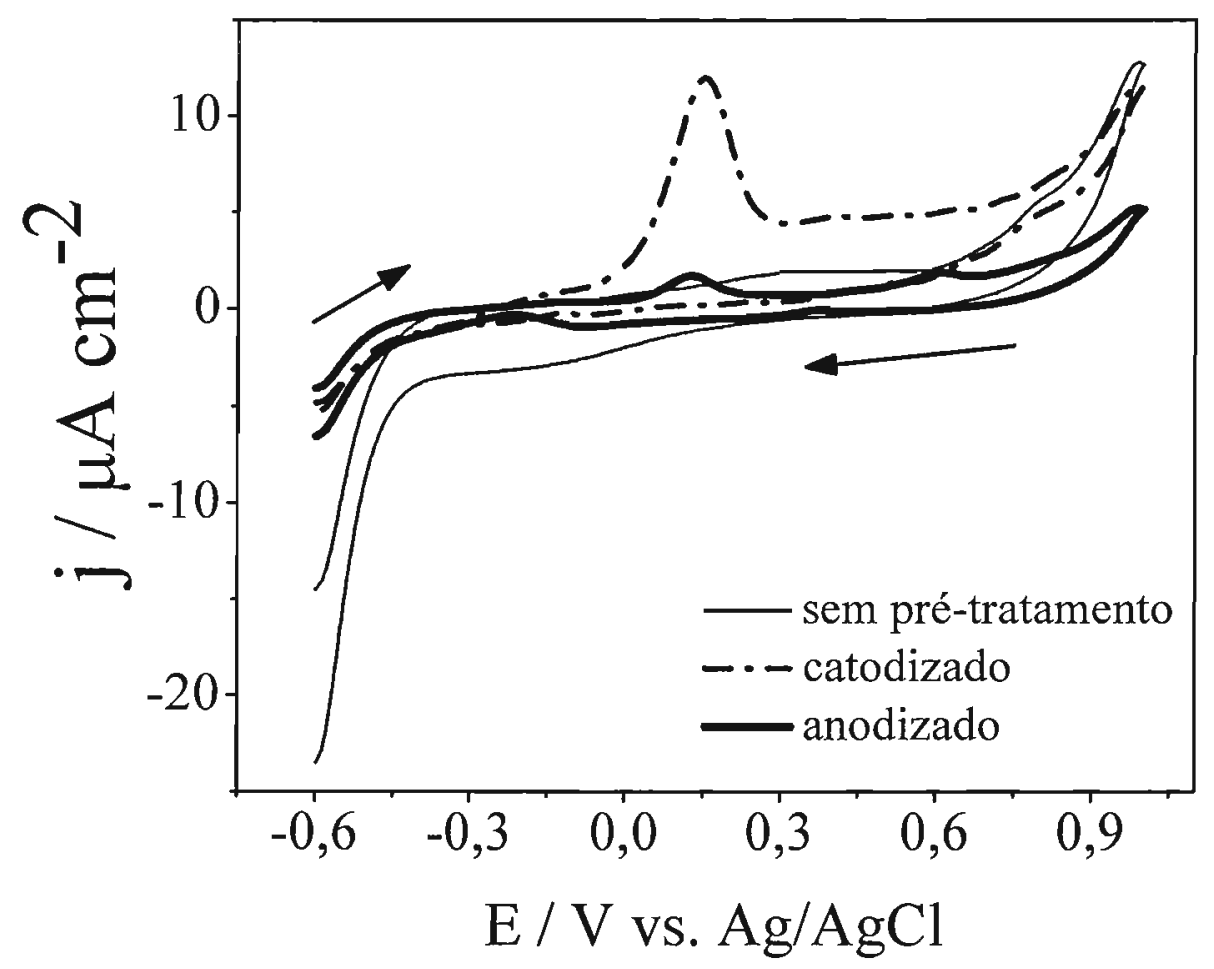

FIGURA 5.2: Efeito do tratamento catódico e anódico na resposta voltamétrica do diamante. Solução de $\mathrm{H}_{2} \mathrm{SO}_{4}$ 0,5 M. Velocidade de varredura: $100 \mathrm{mV} / \mathrm{s}$. Pré tratamento da amostra em solução de $\mathrm{H}_{2} \mathrm{SO}_{4}$ 0,5 M. Nível de dopagem do eletrodo: $5000 \mathrm{ppm}, \mathrm{B} / \mathrm{C}$. Área geométrica do eletrodo: $0,19 \mathrm{~cm}^{2}$. Tratamento catódico 15 ciclos entre $-1,6 \mathrm{e} 0,0 \mathrm{~V}$, $150 \mathrm{mV} . \mathrm{s}^{-1}$. Tratamento anódico 15 ciclos de $0,0 \mathrm{~V}$ a $1,8 \mathrm{~V}, 100 \mathrm{mV} \mathrm{s}^{-1}$.

Deve-se mencionar também que este pico anódico em c.a. $0,15 \mathrm{~V}$ diminuiu de intensidade à medida em que o eletrodo era ciclado voltametricamente até o desaparecimento total. Da mesma forma, não foi mais observada a ocorrência deste pico, mesmo após intenso tratamento catódico.

Desta etapa preliminar pôde-se observar, de um modo geral, dois aspectos do comportamento eletroquímico do eletrodo de diamante, frente a polarizações em potenciais de geração de $\mathrm{H}_{2}$ e de $\mathrm{O}_{2}$ : 
a) Em potenciais de $R G O$, a reatividade do eletrodo diminuía, aumentando o sobrepotencial de RGO.

b) Em potenciais de $R G H$, a reatividade do eletrodo para a reação de geração de $\mathrm{O}_{2}$ aumentava. Além disso, surgiu um pico em c.a. 0,15 V. Entretanto este comportamento só foi observado em filmes recém-crescidos. À medida em que o filme de diamante ia sendo usado, estes picos diminuíam, até o total desaparecimento, mesmo após tratamentos catódicos.

É relativamente bem conhecido o comportamento eletroquímico de filmes de diamante expostos a tratamentos oxidativos tanto baseados na anodização eletroquímica em potenciais de reação de geração de oxigênio ${ }^{39,41,45,93}$, quanto baseados na exposição do filme a plasmas de $\mathrm{O}_{2}{ }^{38,39,41,45}$. Contudo, há relativamente poucos trabalhos tratando da caracterização deste material frente a tratamentos catódicos, em potenciais de RGH. Fujishima e col. ${ }^{30,43}$, observaram que em baixos sobrepotenciais de geração de $\mathrm{H}_{2}$, com simultânea irradiação de luz ultravioleta (195 nm), há a diminuição da hidrofilicidade do filme com a redução da concentração de oxigênio na superfície do diamante. Destes resultados, há duas hipóteses sobre o que poderia ter acontecido neste processo: a rehidrogenação superficial ou a inserção de $\mathrm{H}_{2}$ nas camadas sub-superficiais do filme ${ }^{22,23}$, o que o torna mais condutivo e portanto mais sensível a processos que envolvem baixas intensidades de corrente. Quanto à hipótese da rehidrogenação superficial, os autores não puderam explicar, entretanto, se nas condições empregadas houve a rehidrogenação ou a simples liberação de oxigênio, com formação de insaturações $\mathrm{C}=\mathrm{C}$ na superfície do diamante. Foi também observado que a geração de $\mathrm{H}_{2}$ em potenciais mais altos e sem a irradiação do eletrodo parece não contribuir nem para o aumento da hidrofilicidade nem para a diminuição da concentração de oxigênio na superfície do filme de diamante. Contudo, há fortes indícios de que a catodização (sem irradiação de UV) do eletrodo em meio ácido leva à hidrogenação do mesmo ${ }^{31,32}$.

Com base no comportamento do eletrodo de filme de DDB frente à polarização em potenciais de decomposição da água, foi de interesse fazer um estudo mais sistemático deste material nessas condições. Segue-se por isso, a discussão dos resultados do comportamento voltamétrico do DDB frente a pré-tratamentos catódicos e anódicos. 


\subsection{2 - Pré-tratamentos eletroquímicos}

Estudou-se o comportamento do filme de diamante policristalino diante de prétratamentos baseados em múltiplos ciclos de alta velocidade de varredura (figura 5.3). Com isso, o filme seria exposto a uma condição mais severa de polarização, do que a simples polarização em potencial constante, sendo possível assim testar o comportamento do filme perante a geração intensa de $\mathrm{H}_{2}$. Inicialmente tratou-se o filme de diamante com varreduras em alta velocidade em potenciais localizados nas regiões de geração de $\mathrm{O}_{2} \mathrm{e}$ de $\mathrm{H}_{2}$. Na Figura 5.4 (a) são mostrados voltamogramas cíclicos do eletrodo exposto a prétratamentos anódicos e catódicos, em comparação com o eletrodo não exposto ao prétratamento. Pode-se observar que o tratamento catódico influencia o comportamento do eletrodo tornando a corrente anódica mais alta, confirmando os resultados dos estudos preliminares efetuados (item 5.1.1). A água é oxidada em um sobrepotencial mais baixo. Há também o surgimento de um pico de pequena intensidade em c.a. 0,25 V. Este pico mostrou-se tanto mais intenso quanto mais tempo o eletrodo era catodizado (Fig. 5.4 b) e pode ser relacionado com o pico em c.a $0,15 \mathrm{~V}$ observado no experimento anterior (Fig. 5.2), a despeito da diferença de potencial de cerca de $100 \mathrm{mV}$ entre os dois picos, uma vez que ambos apareceram quando o eletrodo foi polarizado catodicamente. Pelo que se pode inferir dos voltamogramas, o eletrodo tem a sua atividade aumentada quando exposto a pré-tratamentos catódicos. Pode-se racionalizar esse fato de duas formas: rehidrogenação superficial ${ }^{30,43}$ ou inserção de uma subcamada de hidrogênio que aumenta a condutividade superficial do material ${ }^{22,23}$.

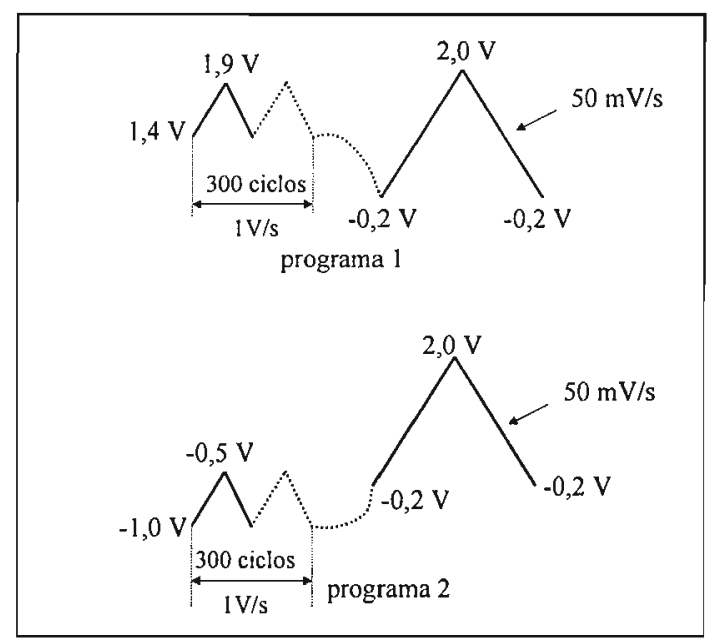

FIGURA 5.3: Programas voltamétricos do experimento apresentado da figura 5.4 

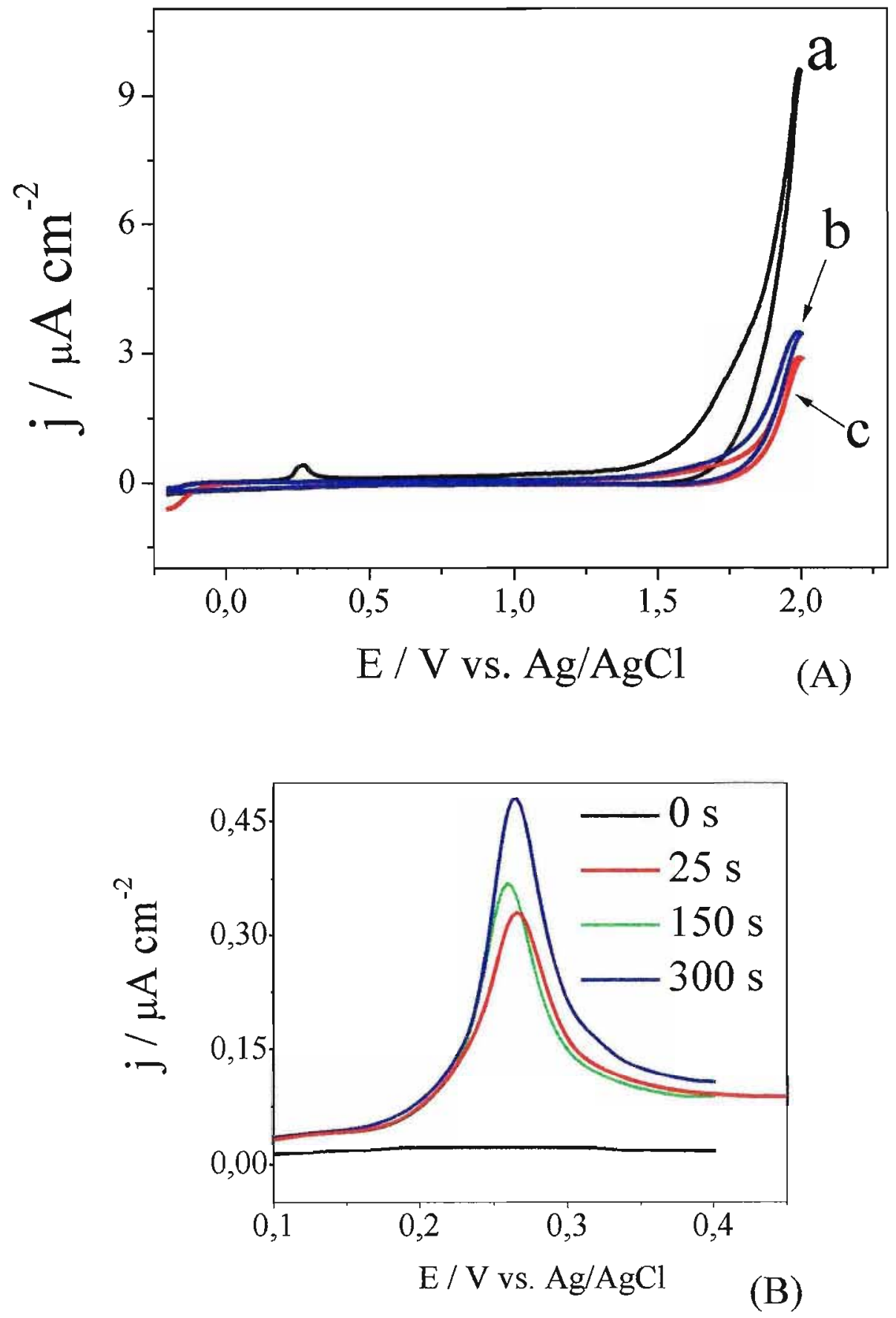

FIGURA 5.4: (A): Influência das polarizações catódica e anódica na resposta voltamétrica do eletrodo. Curva $a$ é eletrodo tratado catodicamente (prog. 2). Curva $b$ é eletrodo tratado anodicamente (programa 1). Curva $c$ é eletrodo sem tratamento. (B): é a região de 0,1 a $0,5 \mathrm{~V}$ da Figura (A), com o eletrodo submetido a diferentes tempos de ciclagem em potenciais catódicos. Solução de $\mathrm{H}_{2} \mathrm{SO}_{4} 0,5 \mathrm{M}$, velocidade de varredura: 50 $\mathrm{mV} / \mathrm{s}$. 
Com o intuito de se estudar a dependência da carga anódica com o tempo de prétratamento, o eletrodo foi pré-polarizado em $-0,4 \mathrm{~V}$ por um certo tempo e depois foram efetuadas duas varreduras cíclicas consecutivas, com potenciais variando de $-1,0 \mathrm{~V}$ a $2,0 \mathrm{~V}$ e depois voltando a $-1,0 \mathrm{~V}$ (ver esquema do programa de potenciais inserido na figura 5.5), com velocidade de varredura de $100 \mathrm{mV} / \mathrm{s}$. Este experimento foi repetido em diferentes tempos de polarização. Na figura 5.5 são apresentados os resultados de variação da carga anódica dos voltamogramas (dois ciclos) obtidos neste experimento, em função do tempo de permanência em $-0,4 \mathrm{~V}$. Nota-se que há um aumento da carga à medida em que se aumenta o tempo de pré-tratamento. Observa-se que as cargas da varredura subseqüente de potenciais são sempre mais baixas. Isso mostra que a alteração superficial do filme de diamante ocorrida na catodização do mesmo é diminuída quando o eletrodo é submetido a potenciais positivos da varredura.

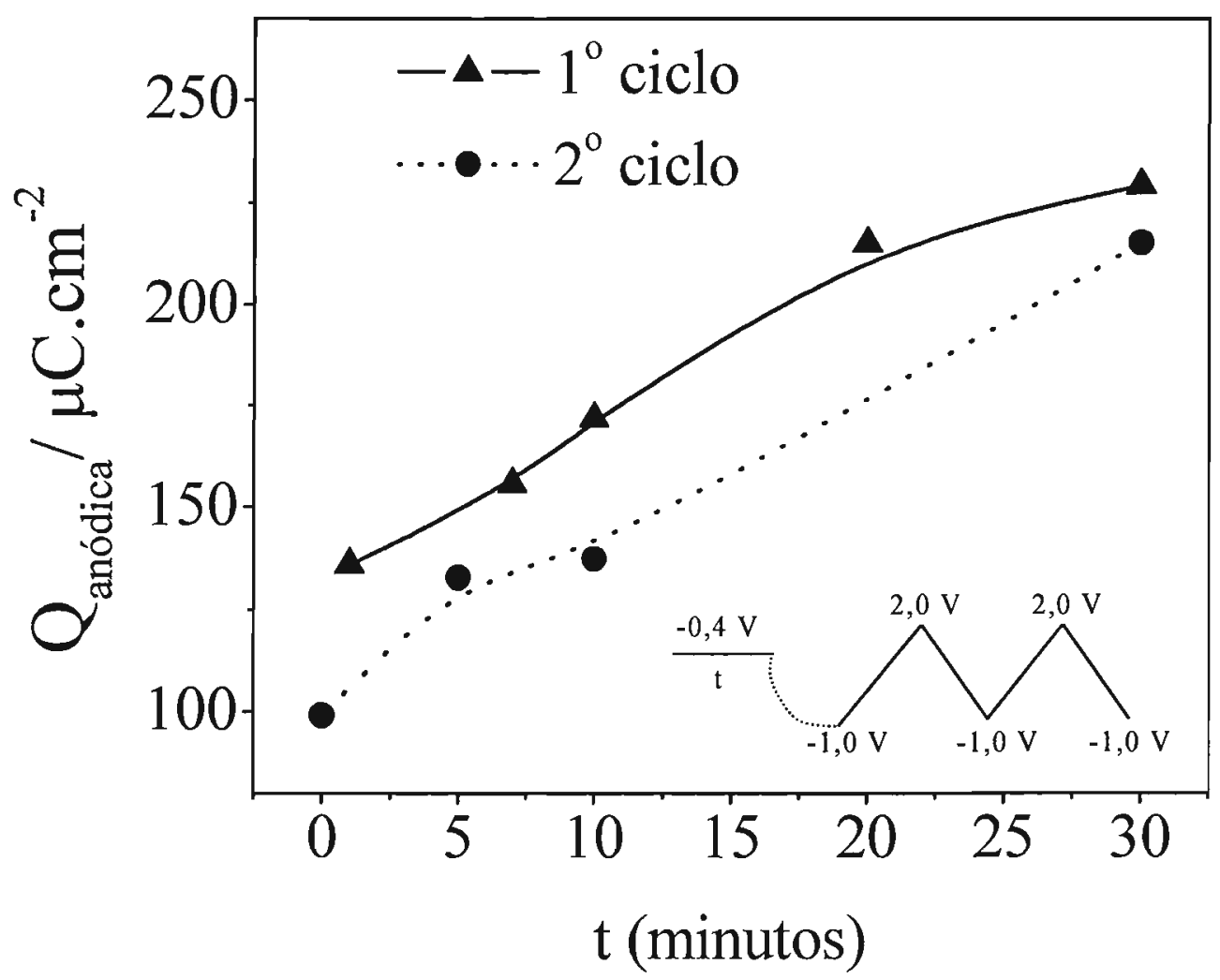

HIGUKA 5.5: (a): Largas anodıcas dos experımentos de polarızaçäo catodıca em meıo ácido $\left(\mathrm{H}_{2} \mathrm{SO}_{4} 0,5 \mathrm{M}\right),-0,4 \mathrm{~V}$. Área do eletrodo: $0,19 \mathrm{~cm}^{2}$. 
Em vista destes resultados, pode-se dizer que o eletrodo em tratamento catódico pode sofrer:

a) Rehidrogenação superficial. Por um lado, nas condições drásticas empregadas, o gás hidrogênio é gerado em grande quantidade na superfície do diamante e a geração de $\mathrm{H}_{2}$ em meio ácido pode ter um mecanismo no qual uma das etapas é a hidrogenação superficial do eletrodo ${ }^{31,32}$. Neste caso, o pico anódico observado em c.a. 0,25 V após o tratamento catódico do filme de DDB, é correspondente à eliminação de hidrogênio adsorvido na superfície do filme, com o aumento da concentração de óxidos superficiais ${ }^{26}$ ou a formação de dangling bonds, que podem se converter em insaturações superficiais, segundo a reação 5.1:

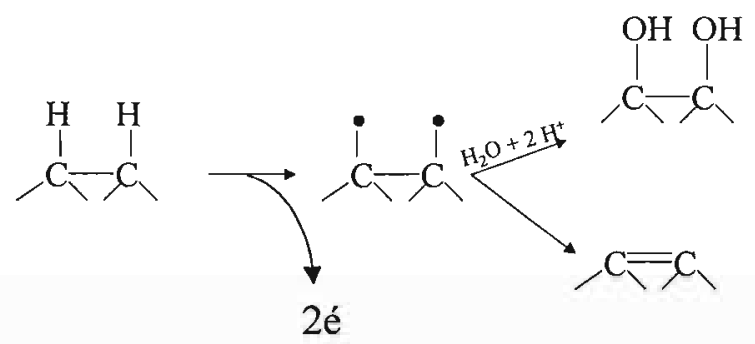

reação 5.1

b) Inserção de hidrogênio. Alguns autores observaram que a condutividade do filme de diamante é tanto maior quanto maior a concentração superficial ${ }^{24,30,93}$ e subsuperficial ${ }^{21,22}$ de hidrogênio, na forma de $\mathrm{H}_{2}$ ou de $\mathrm{H}^{+}$. Neste sentido, outra possível explicação para o aumento de reatividade para a RGO do eletrodo é que a geração de hidrogênio pode não ter-se dado apenas superficialmente e sim nos estratos imediatamente inferiores do filme. Este $\mathrm{H}_{2}$ aprisionado no interior do filme pode funcionar com dopante do tipo $\mathrm{p}$ aumentando a condutividade do filme e, por isso, diminuindo o sobrepotencial da RGO, como observado na Figura 5.3. Segundo esta abordagem, considera-se que o pico anódico localizado em c.a. $0,2 \mathrm{~V}$ corresponda à dessorção (que ocorre segundo a reação 5.1), ou à oxidação de uma pequena quantidade de hidrogênio ainda localizado à superfície ou na região subsuperficial do diamante, segundo a reação 5.2 .

$$
\mathrm{H}_{2} \longrightarrow 2 \mathrm{H}^{+}+2 \mathrm{e}^{-}
$$


O fato de que a corrente de pico não tenha aumentado até um certo ponto com o tempo de catodização indica, se a proposta acima é verdadeira, que uma quantidade fixa de hidrogênio é formada no interior do filme.

Com o intuito de estudar as alterações impostas ao comportamento voltamétrico do eletrodo em função do potencial de pré-tratamento, foram efetuados experimentos de polarização em diferentes potenciais, por um intervalo de tempo fixo (10 minutos). Estes experimentos foram realizados em meio ácido $\left(\mathrm{H}_{2} \mathrm{SO}_{4} 0,5 \mathrm{M}\right)$, utilizando uma amostra de filme de diamante dopado com $5000 \mathrm{ppm}$. Após o pré-tratamento, o eletrodo era submetido a duas varreduras cíclicas consecutivas de potenciais de $-0,2 \mathrm{~V}$ a $2,0 \mathrm{~V}$, com velocidade de varredura de $700 \mathrm{mV} / \mathrm{s}$.

Na Figura 5.6, é apresentada a variação da carga anódica com o potencial em que foi efetuado o pré-tratamento. No caso do eletrodo de diamante em meio ácido, a carga anódica é composta quase que totalmente pela carga envolvida na geração de $\mathrm{O}_{2}$ (figura 5.3). Pode-se ver que como já mostrado anteriormente, a carga anódica aumenta quando o eletrodo é pré-tratado em potenciais próximos à $\mathrm{RGH}$. Vemos também que tratamentos em potenciais próximos à RGO fazem diminuir a carga anódica do eletrodo. Contudo, esse efeito de aumento da carga anódica do voltamograma após tratamento em potenciais próximos à $\mathrm{RGH}$ só foi observado no primeiro ciclo voltamétrico. Na segunda varredura consecutiva pode-se observar que o filme não responde com a mesma intensidade ao tratamento catódico. Pode-se dizer então que qualquer alteração imposta no eletrodo em potenciais de $\mathrm{RGH}$ é anulada quando o eletrodo é polarizado em potenciais próximos à RGO, ainda na primeira varredura cíclica. 


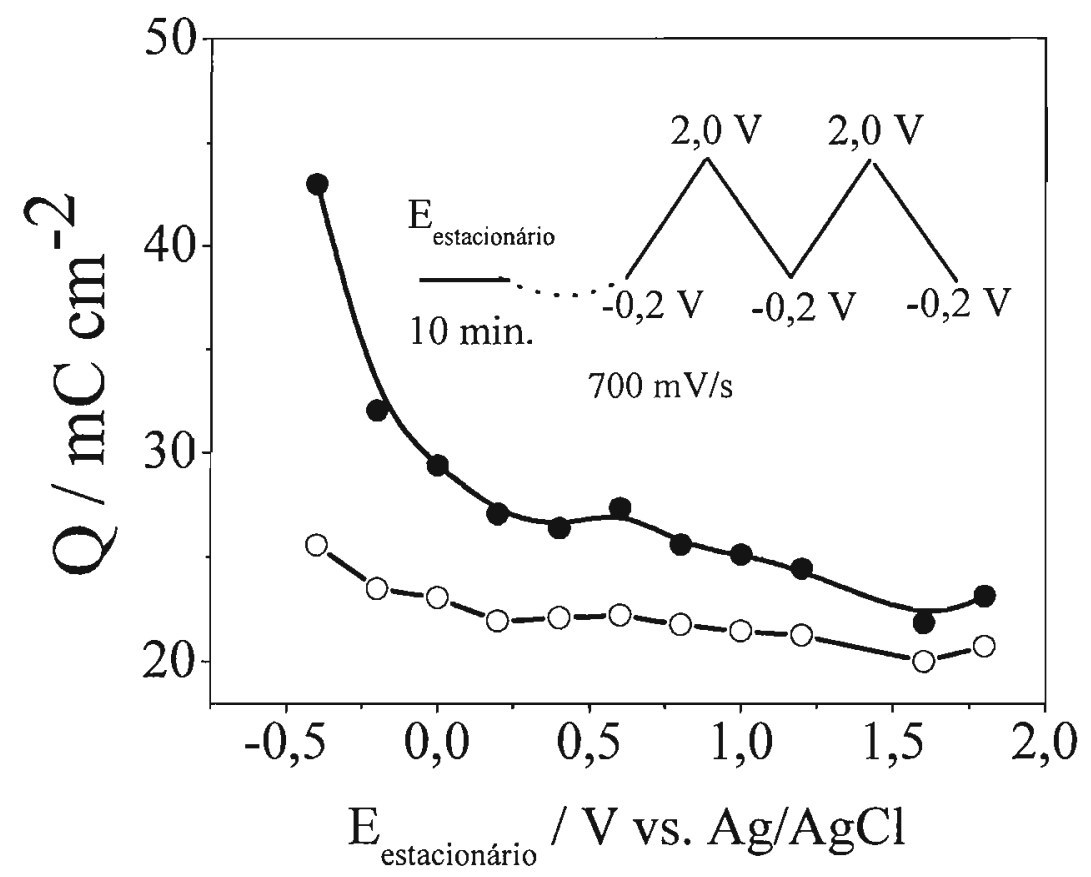

FIGURA 5.6: Influência do potencial de pré-tratamento na carga anódica do eletrodo de filme de diamante. Varreduras de potenciais a $700 \mathrm{mV} / \mathrm{s}$. Dopagem do filme de diamante: 5000 ppm. Solução de $\mathrm{H}_{2} \mathrm{SO}_{4} 0,5 \mathrm{M}$.

Fujishima obteve resultados surpreendentes ao estudar o efeito da oxidação superficial de eletrodos de filmes de DDB nas reações redox de algumas sondas eletroquímicas $^{38}$ e de substâncias tais como a dopamina ${ }^{88}$ e o ácido ascórbico ${ }^{39,88}$. Foi observado que, com o pré-tratamento oxidativo (anódico ou por plasma de $\mathrm{O}_{2}$ ), a reatividade superficial do filme diminui para reações que envolvam transferências de carga na etapa determinante da reação ou a aproximação de espécies eletroativas carregadas negativamente. Contrariamente, a velocidade de reações redox de íons positivos é acelerada por aquele tipo de pré-tratamento.

A conhecida baixa reatividade da superfície do eletrodo de diamante é evidenciada pelos altos potenciais de decomposição da água neste eletrodo. Todavia, há também evidências de que quando um eletrodo deste material recém sintetizado é polarizado anodicamente, há adsorção de espécies oxigenadas à sua superfície $e^{9,38,39,88}$. Dos experimentos anteriores, também vimos que esse processo de adsorção de espécies oxigenadas / geração de $\mathrm{O}_{2}$ sobre o eletrodo é influenciado pelo tipo de pré-tratamento 
dispensado ao eletrodo. Neste sentido, houve o interesse de se testar a atividade do eletrodo de filme de diamante em solução de etanol $+\mathrm{H}_{2} \mathrm{SO}_{4} 0,5 \mathrm{M}$, para investigar se há adsorção de etanol sobre a superfície de diamante, bem como uma possível influência de pré-tratamentos em potenciais de RGH e de RGO neste processo. Para tanto, foram realizados experimentos de voltametria cíclica (varreduras duplas) de $-1,0 \mathrm{~V}$ a $2,2 \mathrm{~V}$ em solução de eletrólito-suporte $\left(\mathrm{H}_{2} \mathrm{SO}_{4} \quad 0,5 \mathrm{M}\right)$ e de etanol $0,1 \mathrm{M}+\mathrm{H}_{2} \mathrm{SO}_{4} 0,5 \mathrm{M}$ (figura 5.7). Pode-se observar que há superposição dos voltamogramas, o que mostra que nestas condições, o eletrodo é indiferente à presença do etanol e qualquer oxidação do álcool se daria indiretamente, isto é, através da formação de espécies ativadas da água sobre o $\mathrm{DDB}$ em potenciais de $\mathrm{RGO}^{94}$.

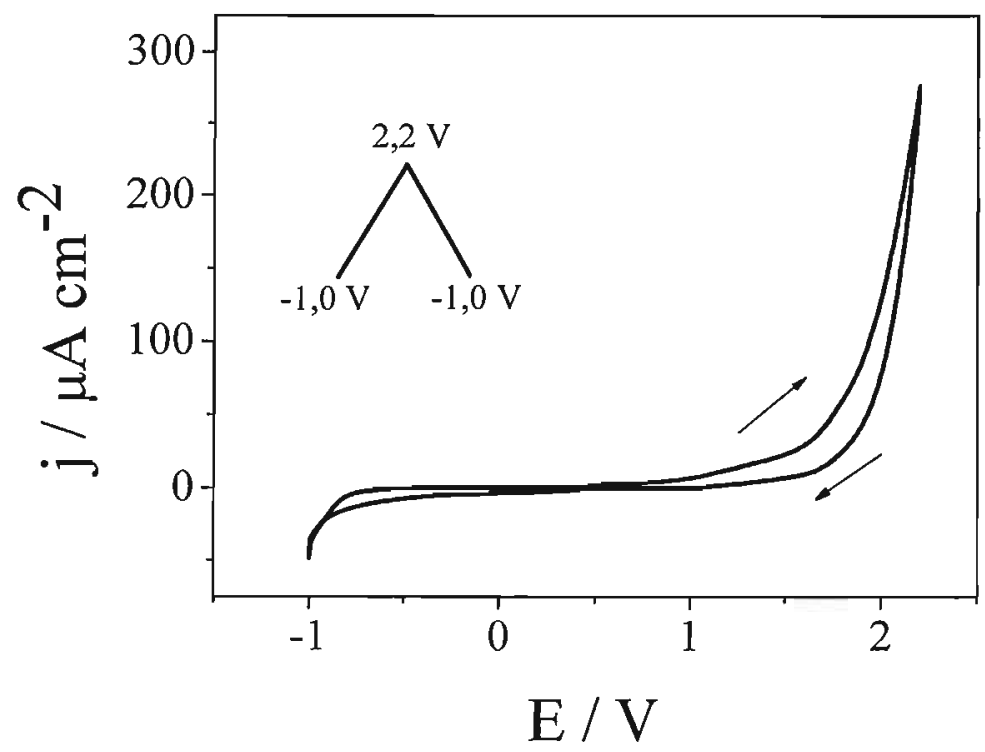

FIGURA 5.7 : Voltamogramas sobrepostos do eletrodo de diamante em solução de $\mathrm{H}_{2} \mathrm{SO}_{4} 0,5 \mathrm{M}$ e de $\mathrm{H}_{2} \mathrm{SO}_{4} 0,5 \mathrm{M}+$ etanol $0,1 \mathrm{M}$. Velocidade de varredura: $100 \mathrm{mVs}^{-1}$.

Após este experimento efetuou-se o mesmo experimento de voltametria cíclica em soluções de $\mathrm{H}_{2} \mathrm{SO}_{4}$ e de etanol $+\mathrm{H}_{2} \mathrm{SO}_{4}$ mas tratando-se o eletrodo anodicamente em 1,0 $\mathrm{V}$ por 5 minutos em solução de $\mathrm{H}_{2} \mathrm{SO}_{4} 0,5 \mathrm{M}$ antes de cada experimento. Estes mesmos experimentos foram repetidos posteriormente, mas com pré-tratamento do eletrodo em $-1,0 \mathrm{~V}$ por 5 minutos. Nas figuras 5.8 (a) e (b) são mostrados os voltamogramas do eletrodo tratado em $-1,0$, em $1,0 \mathrm{~V}$, em solução de $\mathrm{H}_{2} \mathrm{SO}_{4}$, respectivamente. Pode-se 
observar que qualquer que seja o potencial de pré-tratamento, os voltamogramas das soluções de etanol e de eletrólito são similares por todo o intervalo de estabilidade da água. Entretanto, em potenciais acima de $1,8 \mathrm{~V}$, as densidades de corrente são aproximadamente $50 \%$ mais altas no eletrodo em soluçấo de etanol.

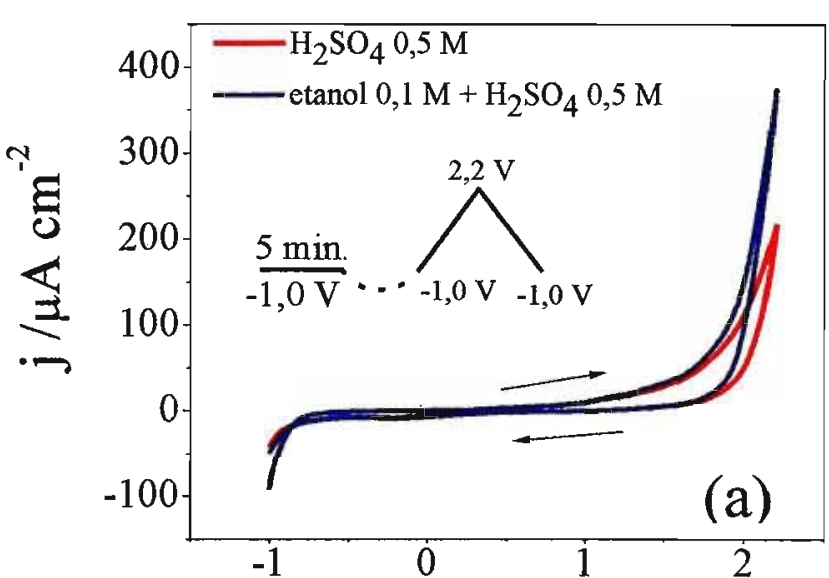

$\mathrm{E} / \mathrm{V}$

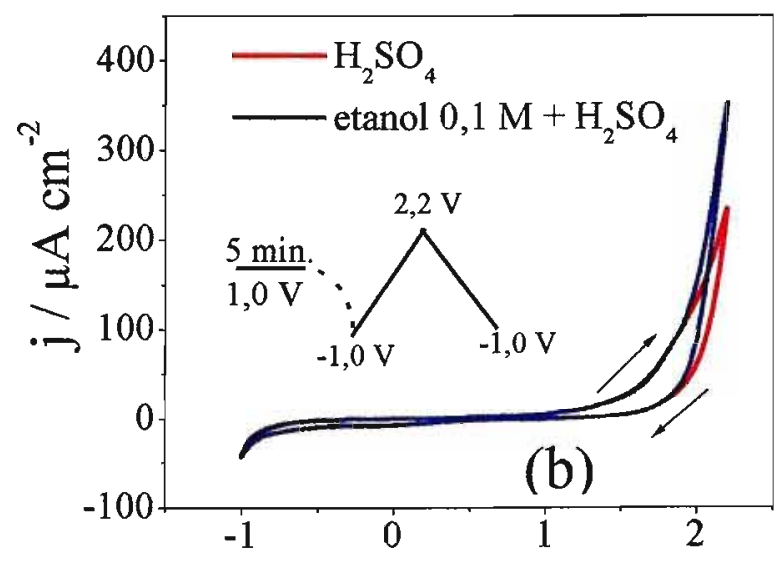

$\mathrm{E} / \mathrm{V}$

FIGURA 5.8: Voltamogramas do filme tratado no branco, $\mathrm{H}_{2} \mathrm{SO}_{4} 0,5 \mathrm{MT}$ ) e em soluções de etanol $0,1 \mathrm{M}+\mathrm{H}_{2} \mathrm{SO}_{4}$ 0,5 M ( ). Nivel de dopagem do filme: 20000 ppm. (a) é eletrodo tratado em $-1,0 \mathrm{~V}$ (5 minutos) em solução de $\mathrm{H}_{2} \mathrm{SO}_{4} 0,5 \mathrm{M}$. (b) é eletrodo tratado em 1,0 V na mesma solução. Velocidade de varredura: $100 \mathrm{mVs}^{-1}$.

É sabido que em potenciais de oxidação da água, etanol é oxidado a acetaldeído e $\mathrm{CO}_{2}$, sobre eletrodos de diamante ${ }^{94}$. Essa oxidação, com já mencionado, foi considerada como sendo devida à reação de etanol com peróxidos provenientes da oxidação da água sobre a superfície do eletrodo. Deste ponto de vista, os voltamogramas do eletrodo em solução de etanol e sem etanol (figura 5.8) deveriam ser similares, visto que o eletrodo não participaria diretamente da reação. Deste resultado, portanto, pode-se dizer que a superfície do eletrodo de diamante participa da reação de oxidação de etanol. Pode-se especular que a molécula de etanol se adsorva via átomo de oxigênio, da mesma forma que adsorvem-se espécies -OH sobre a superficie do diamante na reação de geração de $\mathrm{O}_{2}{ }^{32}$. Entretanto, essas especulações devem ser baseadas em uma investigação mais profunda sobre esse aspecto, com o intuito de confirmar e de se identificar que espécies 
são adsorvidas sobre o diamante, estando fora portanto esse estudo do escopo do presente trabalho.

\subsection{Modificação com Platina}

\subsection{1 - Eletrodeposição de Platina: Estudos Preliminares}

Com o intuito de se verificar o potencial de deposição de platina no eletrodo de diamante, foram efetuados voltamogramas cíclicos em solução de $\mathrm{H}_{2} \mathrm{PtCl}_{6}$ e na solução contendo somente o eletrólito-suporte $(\mathrm{KCl})$. Foram escolhidas condições de mínima cogeração de $\mathrm{H}_{2}$ (em pH alto) em que não houvesse risco de hidrólise do complexo $\mathrm{PtCl}_{6}{ }^{2-} \mathrm{o}$ que poderia causar aumento no potencial de deposição do metal. Por isso, o pH escolhido foi aproximadamente 3 .

$\mathrm{Na}$ figura 5.9, são apresentados os voltamogramas lineares referentes a este experimento. A curva (a) é voltamograma do eletrodo de diamante sem platina, em solução de $\mathrm{KCl}$, $1 \mathrm{M}$. No programa aplicado, o potencial foi variado de 0,8 a $-2,0 \mathrm{~V}$ a uma velocidade de varredura de $50 \mathrm{mV} \mathrm{s}^{-1}$. A curva (c) na Figura 5.9 é o voltamograma característico do eletrodo de DDB em solução de $\mathrm{H}_{2} \mathrm{PtCl}_{6} 3,8 \mathrm{mM}+\mathrm{KCl} 0,1 \mathrm{M}$. Nenhuma corrente é observada desde o início da varredura em $0,8 \mathrm{~V}$ até c.a. $-0,1 \mathrm{~V}$ onde aparece uma onda catódica que se estende até $-0,9 \mathrm{~V}$. Em potenciais mais negativos que - 0,9 V , inicia-se um perfil típico da geração de $\mathrm{H}_{2}$ (caracterizado também pelo aparecimento de bolhas na superfície no filme). A curva (b) é um voltamograma do eletrodo já platinizado, em solução de $\mathrm{KCl} 0,1 \mathrm{M}$. Na ampliação da curva (b) na região de c.a. $-0,7$ a $0,7 \mathrm{~V}$ (inserto na Figura 5.9) podem ser observados os picos característicos da adsorção de íons $\mathrm{H}^{+}$sobre a superfície platinizada do diamante. Como o pico catódico observado na curva (c) só aparece no eletrodo em solução de ácido hexacloroplatínico, pode-se inferir que este pico seja devido à redução de íons $\mathrm{PtCl}_{6}{ }^{2-}$ sobre a superfície do diamante. Observando-se a diferença de inclinação das curvas catódicas j (E) da região 1,0 e $-2,0 \mathrm{~V}$ das curvas (b) e (c), conclui-se que há a redução de íons $\mathrm{PtCl}_{6}{ }^{2-}$ paralela à geração de $\mathrm{H}_{2}$ quando o eletrodo é polarizado em potenciais de $\mathrm{RGH}$ na solução de $\mathrm{Pt}$ (IV). A carga anódica do eletrodo em solução de íons $\mathrm{PtCl}_{6}{ }^{2-}$ (curva (a)) é maior que a 
carga obtida na varredura do eletrodo platinizado em solução de eletrólito-suporte (curva (b)).

Estes resultados mostram que nas condições experimentais empregadas, a platina começa a ser depositada em c.a. - $0,2 \mathrm{~V}$ e este processo se confunde com o de geração de $\mathrm{H}_{2}$ em c.a. $-1,0 \mathrm{~V}$.

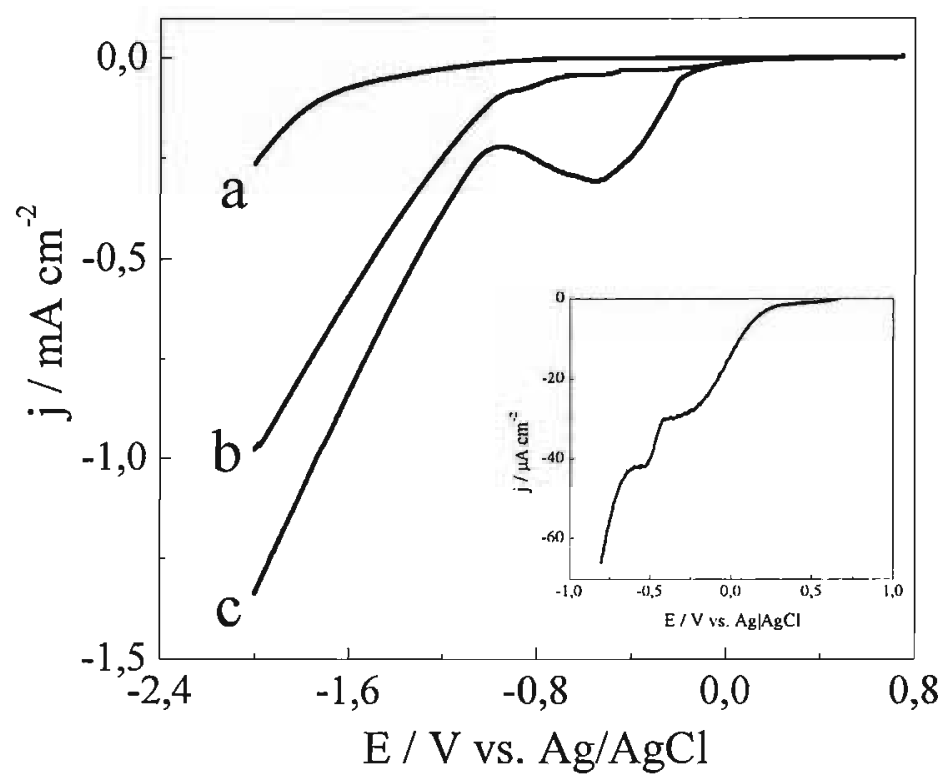

FIGURA 5.9: Voltamogramas de varredura linear registrados com o eletrodo de diamante. Curva $a$ para o eletrodo de $\mathrm{DDB}$ em solução de $\mathrm{KCl} 0,1 \mathrm{M}$. Curva $b$ : eletrodo platinizado em solução de $\mathrm{KCl} 0,1 \mathrm{M}$. Curva $c$ : eletrodo DDB em solução de $\mathrm{H}_{2} \mathrm{PtCl}_{6} 3,8$ $\mathrm{mM}+\mathrm{KCl} 0,1 \mathrm{M}$. Inserto: curva $b$ na região de adsorção de íons $\mathrm{H}^{+}$. $\mathrm{pH}$ das soluções: 3,4. Nível de dopagem do filme de diamante: $10000 \mathrm{ppm}, \mathrm{B} / \mathrm{C}$. Área (geométrica) do eletrodo: $0,071 \mathrm{~cm}^{2}$. Velocidade de varredura: $50 \mathrm{mV} . \mathrm{s}^{-1}$.

\subsection{2 - Influência do potencial de eletrodeposição}

De acordo com o relatado no item anterior, na voltametria registrada com eletrodo de diamante em solução de ácido hexacloroplatínico é observada uma onda catódica na região compreendida entre $-0,2$ e $-1,0 \mathrm{~V}$. Por isso, nesta etapa do trabalho foram realizados experimentos de eletrodeposição potenciostática em $-0,2$ e em $-0,9 \mathrm{~V}$ sobre eletrodos de diamante, a fim de se verificar a atividade eletrocatalítica da platina depositada em diferentes potenciais, frente à reação de oxidação anódica de etanol. 
Normalmente, na literatura, a quantidade de Pt depositada é apresentada em função da massa de Pt calculada a partir da carga de deposição, assumindo-se eficiência de corrente de $100 \%$. Nesse trabalho, para se determinar a eficiência de corrente no processo de eletrodeposição da platina, foram realizadas várias tentativas no sentido de se analisar quimicamente a Pt depositada. Entretanto, a baixa quantidade de Pt nos filmes analisados originou soluções com concentração de Pt abaixo do limite de deteç̧ão do aparelho. Por isso, nesta Dissertação, referir-nos-emos às quantidades de $\mathrm{Pt}$ em função da carga de deposição por $\mathrm{cm}^{-2}$ (área geométrica do eletrodo) e não da sua massa, assumindo-se que haja correlação direta entre a carga de deposição e a massa de Pt depositada no intervalo de cargas de deposição estudadas neste trabalho.

$\mathrm{Na}$ Figura 5.10 são apresentadas micrografias de amostras de diamante com diferentes quantidades de $\mathrm{Pt}$ depositada em $-0,9 \mathrm{~V}$. Com um exame qualitativo das micrografias, observa-se que em baixas cargas de deposição, Pt não foi depositada, ou houve a deposição de pequenos núcleos, os quais podem ter sido removidos quando a amostra foi cuidadosamente lavada na preparação para a micrografia. Não se pode também descartar a hipótese da formação de núcleos cujas dimensões estivessem além do limite de resolução do microscópio. Com o aumento do tempo de deposição, há a formação núcleos com um tamanho definido (aproximadamente $290 \mathrm{~nm}$ ), que aumentam em número, até a formação de aglomerados, em maiores cargas de $\mathrm{Pt}$.

Na Figura 5.11 são apresentadas micrografias de eletrodos em cuja superfície foi depositado $\mathrm{Pt}$ a - 0,2 V. Ao contrário do observado na deposição de Pt a - 0,9, não se observa a mesma tendência de crescimento dos núcleos de Pt com a carga elétrica aplicada ao eletrodo. Há entretanto a formação de partículas de maior tamanho (c.a 400 $\mathrm{nm}$, Figuras $5.11 \mathrm{a} \mathrm{e} \mathrm{b).} \mathrm{Na} \mathrm{amostra} \mathrm{de} \mathrm{DDB-Pt} \mathrm{com} \mathrm{991,9} \mathrm{mC} \mathrm{cm}{ }^{-2}$, (Figura $5.11 \mathrm{c}$ ), observa-se a presença de uma maior quantidade de partículas de tamanho visivelmente menor. Essa diminuição no tamanho das partículas com o aumento da carga de deposição (aumento do tempo de deposição a $-0,2 \mathrm{~V}$ ) sugere um processo de crescimento de núcleos de Pt até um ponto em que há seu desprendimento da superfície do filme e formação de Pt coloidal, similarmente ao observado na eletrodeposição de ouro sobre eletrodos DDB recém-depositados ${ }^{73}$. Isso daria lugar então ao crescimento de novas partículas de Pt sobre a superfície de DDB. 

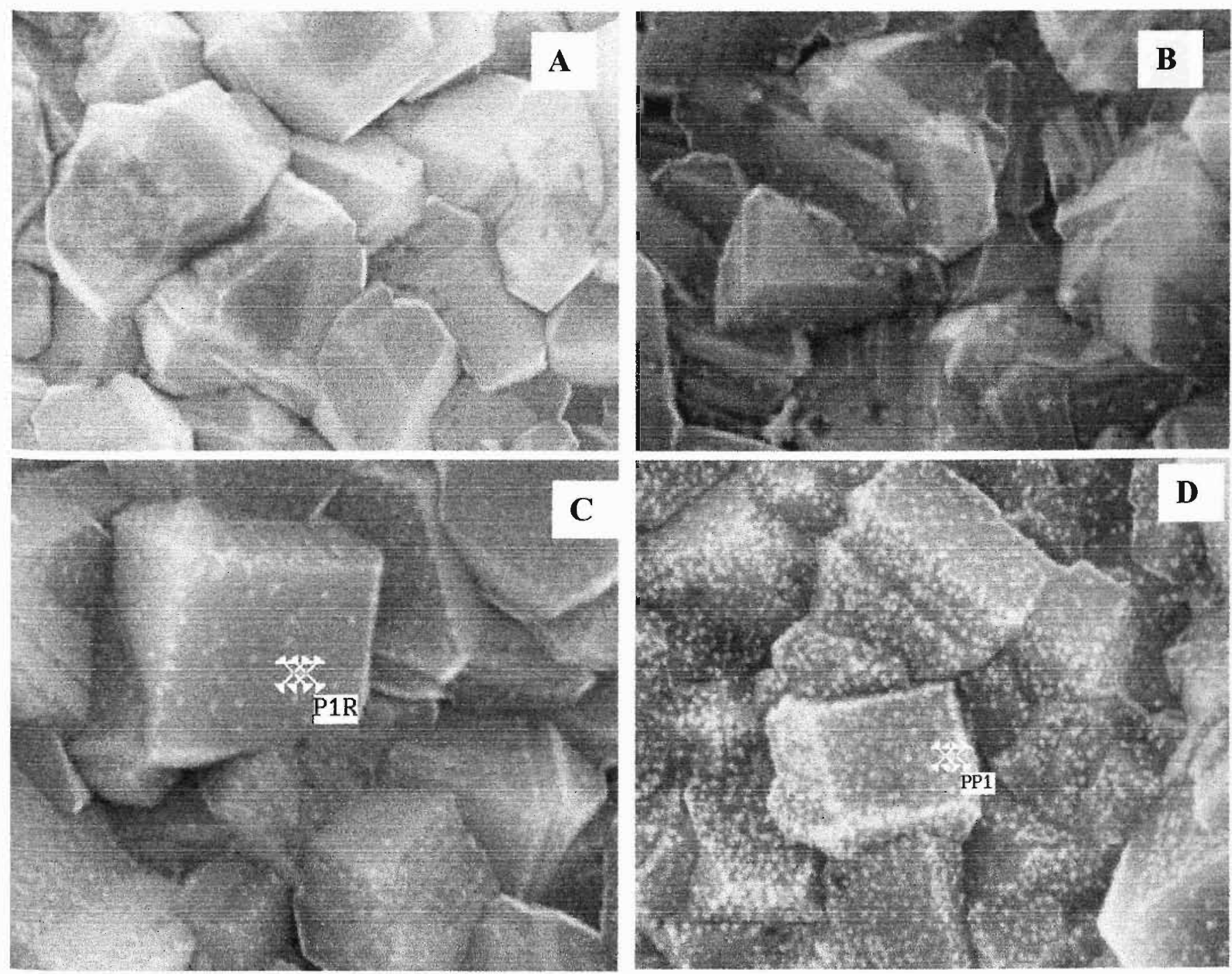

FIGURA 5.10: Micrografias de amostras de BDD com diferentes quantidades de Pt. Potencial de deposição: $-0,9 \mathrm{~V}$. Solução $\mathrm{H}_{2} \mathrm{PtCl}_{6} 3,8 \mathrm{mM}+\mathrm{KCl} 0,1 \mathrm{M}, \mathrm{pH}$ 3,4. A: 2,9 $\mathrm{mC} \mathrm{m} \mathrm{m}^{-2}, \mathbf{B}: 22,9 \mathrm{mC} \mathrm{m}^{-2} . \mathbf{C}: 98,8 \mathrm{mC} \mathrm{m}^{-2}$, D: $788,2 \mathrm{mC} \mathrm{m}^{-2}$. Nível de dopagem do filme: $20000 \mathrm{ppm} \mathrm{B/C}$. Magnificação: $15000 \mathrm{X}$. 

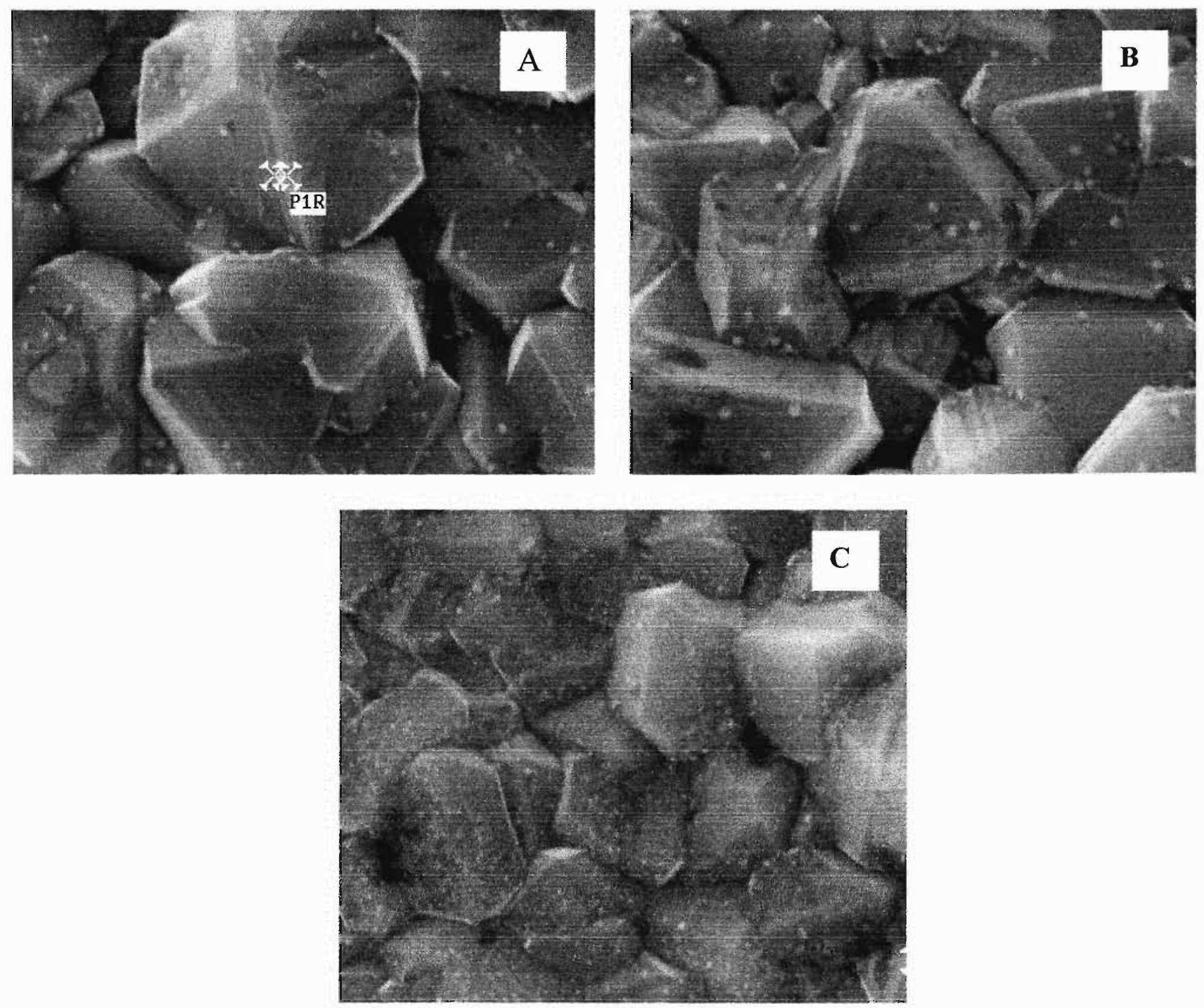

FIGURA 5.11: Micrografias de filmes de diamante com Pt. $E_{\text {deposicão: }}-0,2 \mathrm{~V}$. Imagens A: $18,4 \mathrm{mC} \mathrm{cm}^{-2}, \mathbf{B}: 59,4 \mathrm{mC} \mathrm{cm}^{-2}, \mathbf{C}: 991,9 \mathrm{mC} \mathrm{cm}^{-2}$. Solução: $\mathrm{K}_{2} \mathrm{PtCl}_{6} 3,9 \mathrm{mM}+\mathrm{KCl}$ $0,1 \mathrm{M}, \mathrm{pH}=3,4$. Nivel de dopagem do filme: $20000 \mathrm{ppm}$.

$\mathrm{Na}$ Figura 5.12 são apresentados os voltamogramas do eletrodo com diferentes cargas de deposição de platina, depositada em $-0,9 \mathrm{~V}$, feitos em solução de $\mathrm{H}_{2} \mathrm{SO}_{4} \quad 0,5 \mathrm{M}$. Nestes experimentos foram feitas varreduras de potenciais iniciando de $-0,5 \mathrm{~V}$, até $1,6 \mathrm{~V}$ e depois voltando a $-0,5 \mathrm{~V}$, com velocidade de varredura de $50 \mathrm{mV} \cdot \mathrm{s}^{-1}$ até obtenção de resposta reprodutível. 
Em baixas quantidades de platina $\left(6,7 \mathrm{mC} \mathrm{cm}^{-2}\right)$ observa-se que o voltamograma não apresenta densidades consideráveis de corrente na região de potenciais compreendida entre $0,5 \mathrm{~V}$ e $1,5 \mathrm{~V}$, onde a RGO começa a ocorrer. À medida em que se aumenta a carga de platina, a resposta voltamétrica do eletrodo aproxima-se da resposta de um eletrodo de platina policristalina em meio ácido, com três regiões bem definidas:

- a região de adsorção reversível de hidrogênio (-0,25 V a 0,25 V);

- $\quad$ a região de formação de óxidos superficiais, seguida pela oxidação da água $(0,8$ a $1,5 \mathrm{~V})$

- a região de redução catódica dos óxidos superficiais do depósito de platina $(0,5 \mathrm{~V}$ a $0,2 \mathrm{~V})$.

Na Figura 5.13 apresenta-se a região de adsorção de hidrogênio, ampliada da Figura 5.12. A região anódica, que corresponde à dessorção de hidrogênio adsorvido, apresenta densidade de corrente de pico que varia pouco em função da densidade superficial de platina, assumindo valores em torno de $170 \mu \mathrm{A} \cdot \mathrm{cm}^{-2}$.

$\mathrm{Na}$ região catódica, em $6,7 \mathrm{mC} . \mathrm{cm}^{-2}$ de platina observa-se baixas densidades de corrente $\left(-40 \mu \mathrm{A} . \mathrm{cm}^{-2}\right)$, que aumentam com a carga de platina. A partir de $31,8 \mathrm{mC} . \mathrm{cm}^{-2}$ aparece uma onda catódica em $-0,06 \mathrm{~V}$ que tem a densidade de corrente aumentada com $o$ aumento da densidade superficial de platina.

Contudo, deve-se dizer que o comportamento voltamétrico da platina depositada sobre a superfície do eletrodo de DDB, especialmente na região de adsorção de íons $\mathrm{H}^{+}$é muito distante do que é observado tipicamente em um eletrodo de Pt metálica (ver item 2.2 do capítulo 2). Mesmo em altas cargas de deposição de Pt, observa-se que os picos característicos deste processo têm baixa densidade e ocorrem em potenciais mais negativos, quando comparados ao voltamograma da platina metálica. Em estudos envolvendo eletrodos platinizados, é usual o seu pré-tratamento com vários ciclos entre potenciais de RGH e de RGO. Isso faz com que a resposta do eletrodo fique mais parecida com a de um eletrodos de Pt policristalina ${ }^{15}$. Entretanto, neste trabalho optou-se por não se empregar esse tipo de pré-tratamento extremo por que isso poderia contribuir para a aglutinação das partículas, com diminuição da área superficial da dispersão de Pt. 


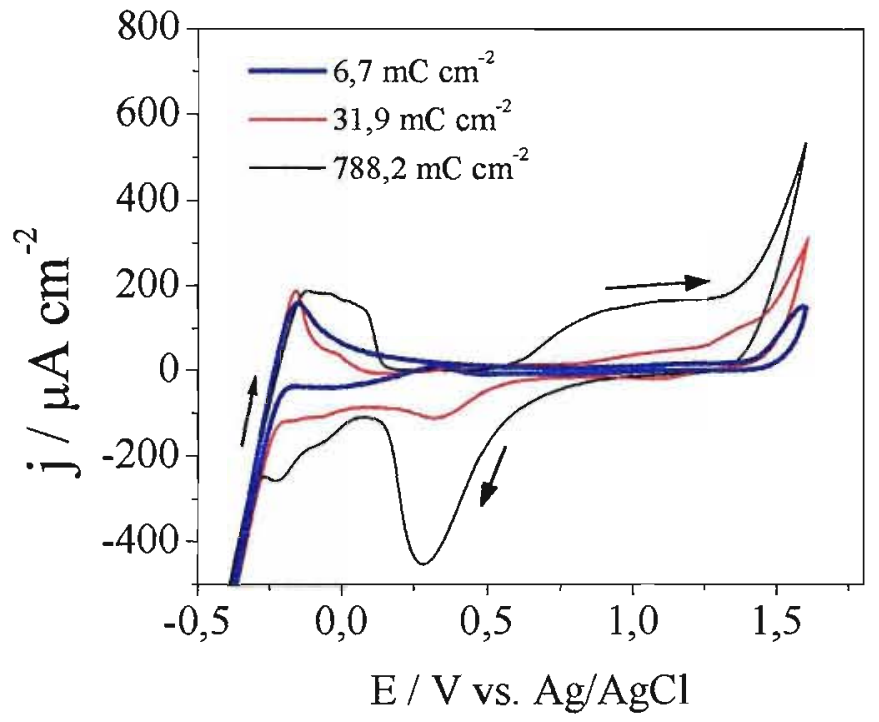

FIGURA 5.12: Voltamogramas sobrepostos do eletrodo platinizado com diferentes densidades superficiais de platina. Velocidade de varredura: $50 \mathrm{mV} \mathrm{s}^{-1}$. Potencial de eletrodeposição: - 0,9 V. Solução: $\mathrm{H}_{2} \mathrm{SO}_{4} \quad 0,5 \mathrm{M}$, velocidade de varredura $50 \mathrm{mV} \mathrm{s}^{-1}$. .Nível de dopagem do filme de diamante: $20000 \mathrm{ppm} \mathrm{B/C}$. Área geométrica do eletrodo: $0,19 \mathrm{~cm}^{2}$.

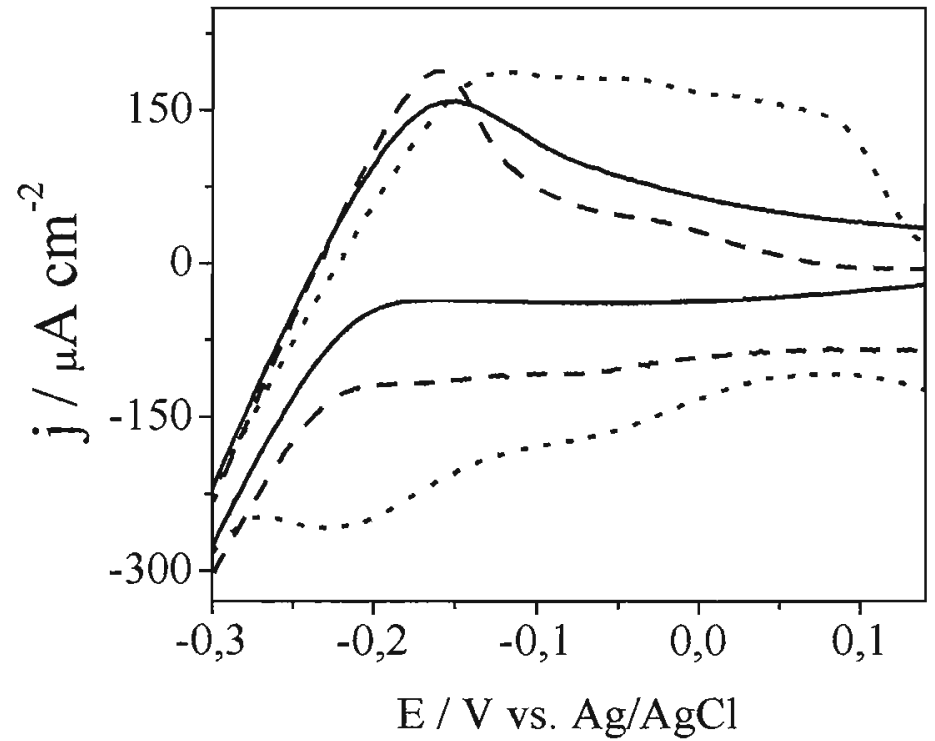

FIGURA 5.13: Voltamogramas da Figura 5.10 ampliados na região de adsorção reversível de hidrogênio. Cargas de deposição de Pt: $-6,7 \mathrm{mC} \mathrm{cm}^{-2},-31,9 \mathrm{mC}$ $\mathrm{cm}^{-2}, \quad \ldots \ldots .788,2 \mathrm{mC} \mathrm{cm}^{-2}$. Velocidade de varredura: $50 \mathrm{mV} \mathrm{s}^{-1}$. Área geométrica do eletrodo: $0,19 \mathrm{~cm}^{2}$. 
Com os eletrodos de diamante com partículas de platina depositada a $-0,9 \mathrm{~V}$ e a - 0,2 V foram efetuadas voltametrias cíclicas em solução de etanol $0,1 \mathrm{M}$ (eletrólitosuporte $\mathrm{H}_{2} \mathrm{SO}_{4} 0,5 \mathrm{M}$ ) a fim de se avaliar a atividade do eletrodo para a oxidação de etanol.

$\mathrm{Na}$ figura 5.14 são apresentados os voltamogramas referentes a este experimento. Foi aplicado um programa no qual o potencial elétrico era variado crescentemente desde $-0,5 \mathrm{~V}$ até $1,6 \mathrm{~V}$, e depois decrescia até - $0,5 \mathrm{~V}$ novamente. A velocidade de varredura foi de $50 \mathrm{mV} \mathrm{s}^{-1}$. Na Figura 5.14 é omitido o pico referente à geração de $\mathrm{H}_{2}$ em potenciais abaixo de $-0,3 \mathrm{~V}$ a fim de se evidenciar os picos referentes aos outros processos eletroquímicos que ocorrem sobre o eletrodo de diamante modificado com platina. Observa-se que para cargas de Pt inferiores a $19,2 \mathrm{mC} \mathrm{cm}^{-2}$, há basicamente duas regiões anódicas bem distintas: a região de dessorção de hidrogênio (de - 0,2 a 0,2 V) e uma região anódica (de 0,9 a 1,5 V). À medida em que a carga superficial do eletrocatalisador aumenta, observa-se o aumento da carga anódica na região de 0,9 a 1,5 V.

Isto equivale a dizer que a eletroatividade para a oxidação de etanol aumenta com a quantidade de platina eletrodepositada, o que seria de se esperar. No entanto, para cargas superficiais de platina maiores que $19,2 \mathrm{mC} \mathrm{cm}^{-2}$, surge um outro pico anódico em $0,7 \mathrm{~V}$. Como o pico em 1,2 V não desaparece com o surgimento deste último pico, pode-se dizer que a partir de uma certa quantidade de platina, são formados dois tipos de superfície de eletrocatalisador sobre os quais o etanol pode ser oxidado: uma superfície sobre a qual o etanol adsorve-se e oxida-se mais facilmente e uma superfície em que o etanol oxida-se em potenciais mais altos. O voltamograma cíclico de um eletrodo de Pt em solução ácida de um álcool ${ }^{15}$ apresenta usualmente um pico menor localizado na região de 0,6 a $0,9 \mathrm{~V}$ (vs. $\mathrm{Ag} / \mathrm{AgCl}$ ), seguido de uma região anódica que se estende por um largo intervalo de potenciais (c.a. 0,9 a 1,2 V), confundindo-se com a RGO. O primeiro pico, de menor intensidade é resultado da oxidação de moléculas do álcool, que se adsorveram, dissociativamente ou não, sobre a superfície do catalisador, em presença da crescente concentração de óxidos de Pt presentes, que começam a se formar sobre a Pt nesta região de potenciais. No caso do etanol, esta oxidação leva à geração de $\mathrm{CO}_{2}$ ou ao ácido acético. A proporção entre estes produtos dependerá da concentração de etanol e do potencial anódico aplicado, sendo que a oxidação do álcool a $\mathrm{CO}_{2}$ em maior quantidade é 
obtida em baixas concentrações de etanol ${ }^{95}$. A segunda região anódica é resultado da oxidação incompleta de moléculas do álcool, originando o aldeído correspondente.

No sentido catódico da varredura, observa-se um pico catódico em c.a. 0,4 V, referente à redução de óxidos superficiais da platina $^{15}$ e um pico anódico de grande intensidade em $0,3 \mathrm{~V}$ o qual corresponde à oxidação de etanol em uma superfície livre de espécies adsorvidas, quer seja oxigênio, quer sejam intermediários de oxidação do próprio etanol.

Foram também efetuados estes mesmos experimentos utilizando eletrodos cuja platina foi eletrodepositada em um potencial de $-0,2 \mathrm{~V}$. Na figura 5.15 são apresentados os voltamogramas referentes a este experimento. Pode-se observar que, assim como no eletrodo platinizado a $-0,9 \mathrm{~V}$, a carga anódica referente à oxidação de etanol cresce com o aumento da carga superficial de platina. No entanto não é observado o pico em $0,7 \mathrm{~V}$ mesmo em cargas de platina acima de $277 \mathrm{mC} \mathrm{cm}^{-2}$.

Na Figura 5.16 são apresentadas micrografias de amostras de filmes de diamante com $59,4 \mathrm{mC} \mathrm{cm}^{-2}$ de platina depositada potenciostaticamente em - 0,2 V (imagem A) e em $0,9 \mathrm{~V}$ (imagem B). Pode-se observar que em geral uma maior quantidade de Pt é depositada a $-0,9 \mathrm{~V}$.

Na Figura 5.17 são apresentadas micrografias de filmes de diamante, com alta carga de platina. A imagem $\mathrm{E}$ é de um filme com uma carga de platina de $991,8 \mathrm{mC} \mathrm{cm}^{-2}$, eletrodepositada em $-0,2$ V. A imagem $\mathrm{F}$ é de um filme com $787,6 \mathrm{mC} \mathrm{cm} \mathrm{cm}^{-2}$ eletrodepositada em $-0,9 \mathrm{~V}$. Seguindo a tendência observada nas amostras com menores cargas de platina (Figura 5.16), uma maior quantidade de platina é obtida na deposição em $-0,9 \mathrm{~V}$ e esta amostra apresentou bem maior atividade eletroquímica do que a amostra com $991,8 \mathrm{mC} \mathrm{cm}^{-2}$, depositada em - 0,2 V (Figuras $5.17 \mathrm{G} \mathrm{e} \mathrm{H}$ ). 


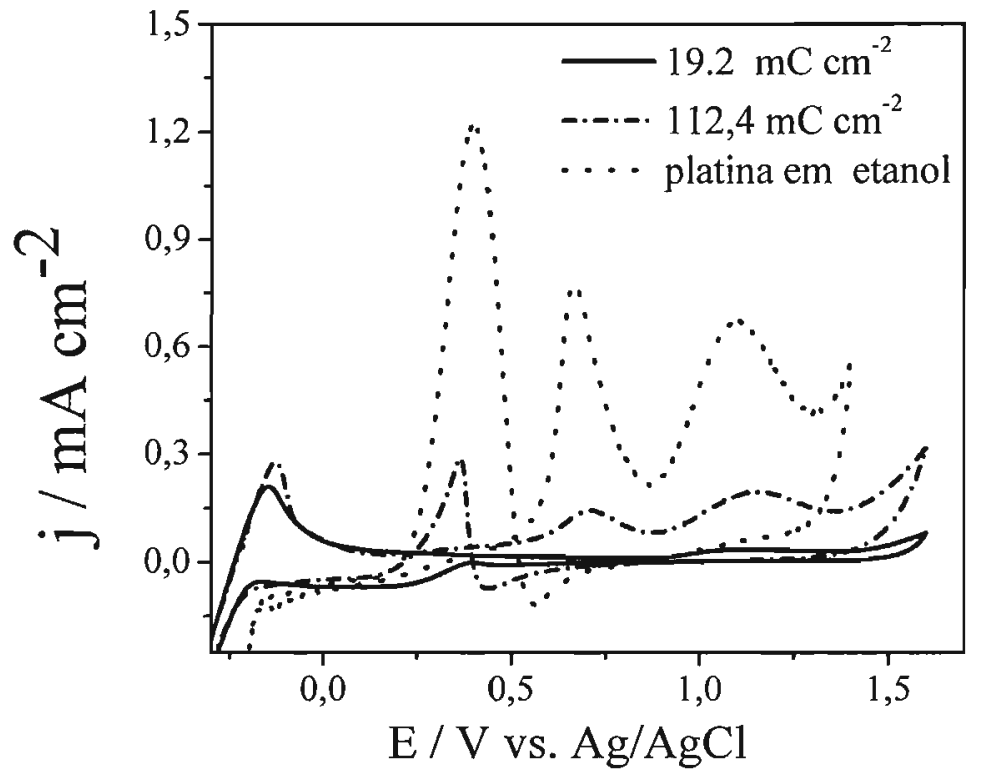

FIGURA 5.14 - Voltamogramas do eletrodo de diamante modificado com diferentes cargas superficiais de platina. Velocidade de varredura: $50 \mathrm{mV} \mathrm{s}^{-1}$. Solução: etanol $0,1 \mathrm{M}$, $\mathrm{H}_{2} \mathrm{SO}_{4} \quad 0,5 \mathrm{M}$. Condições de eletrodeposição: $\mathrm{pH}=3,3, \mathrm{E}=-0,9 \mathrm{~V}$, banho: $\mathrm{K}_{2} \mathrm{PtCl}_{6}$ $3,9 \mathrm{mM}+\mathrm{KCl} 0,1 \mathrm{M}$. Nível de dopagem do filme de diamante: $20000 \mathrm{ppm} \mathrm{B/C}$.

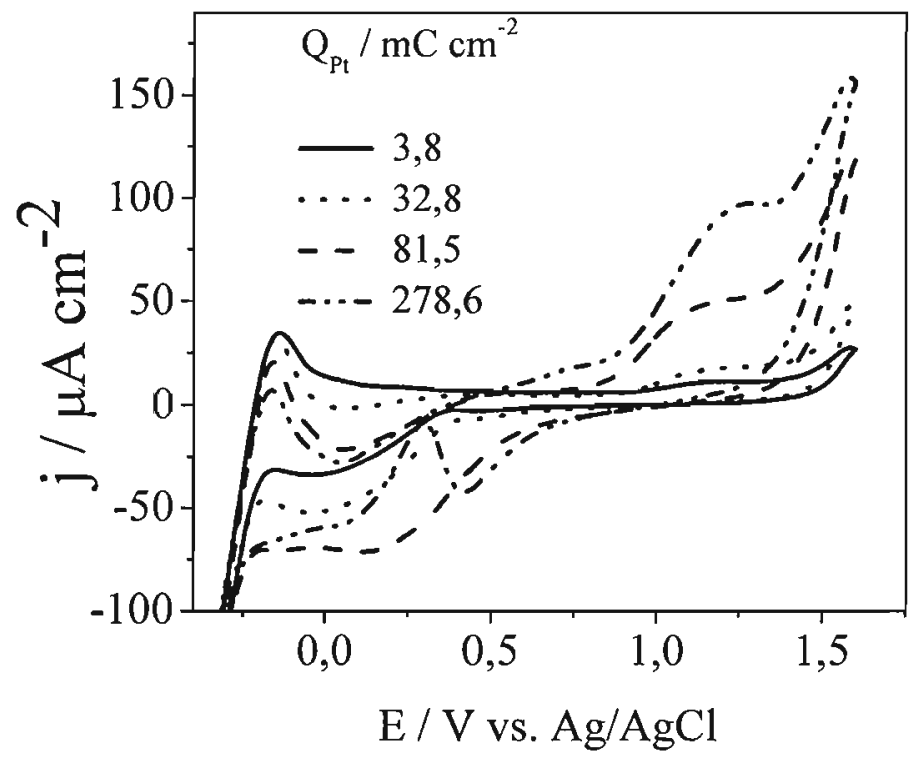

FIGURA 5.15: Voltamogramas do eletrodo de diamante modificado com diferente cargas superficiais de platina. Velocidade de varredura: $50 \mathrm{mV} \mathrm{s}^{-1}$. Solução: etanol $0,1 \mathrm{M}$ $+\mathrm{H}_{2} \mathrm{SO}_{4}$ 0,5 M. Condições de eletrodeposição: $\mathrm{pH}=3,3, \mathrm{E}=-0,2 \mathrm{~V}$, banho: $\mathrm{K}_{2} \mathrm{PtCl}_{6}$ $3,9 \mathrm{mM}+\mathrm{KCl} \mathrm{0,1} \mathrm{M}$. Nível de dopagem do filme de diamante: $20000 \mathrm{ppm} \mathrm{B/C}$. 

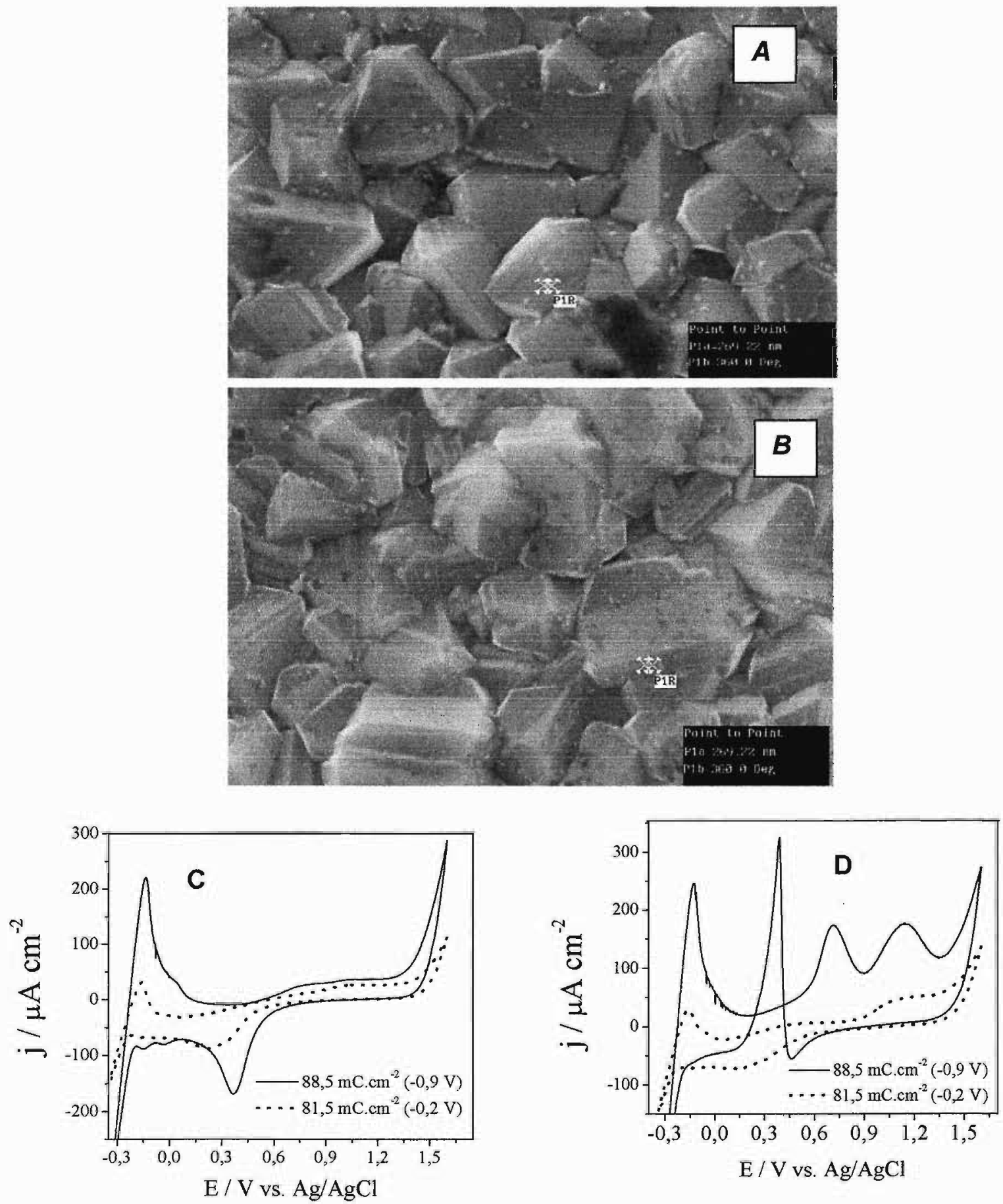

FIGURA 5.16: Micrografias dos eletrodos de diamante (Nível de dopagem $10000 \mathrm{ppm}$, $\mathrm{B} / \mathrm{C})$. Imagem A: $59,4 \mathrm{mC} \mathrm{cm}$ de Pt $(-0,2 \mathrm{~V})$. Imagem $\mathrm{B}: 59,43 \mathrm{mC} \mathrm{cm}^{-2} \mathrm{de} \mathrm{Pt}$ $(-0,9 \mathrm{~V})$. Solução de eletrodeposição: $\mathrm{H}_{2} \mathrm{PtCl}_{6} 3,9 \mathrm{mM}+\mathrm{KCl} 0,1 \mathrm{M}, \mathrm{pH} 3,4$. Amostras sem pré-tratamento. Magnificação: 15000 vezes. Voltamograma $\mathrm{C}$ e $\mathrm{D}$ : eletrodo de diamante platinizados em solução de $\mathrm{H}_{2} \mathrm{SO}_{4} \quad 0,5 \mathrm{M}$ e de etanol $0,1 \mathrm{M}+\mathrm{H}_{2} \mathrm{SO}_{4} \quad 0,5 \mathrm{M}$, respectivamente. Velocidade de varredura: $50 \mathrm{mV} \mathrm{s}^{-1}$. 

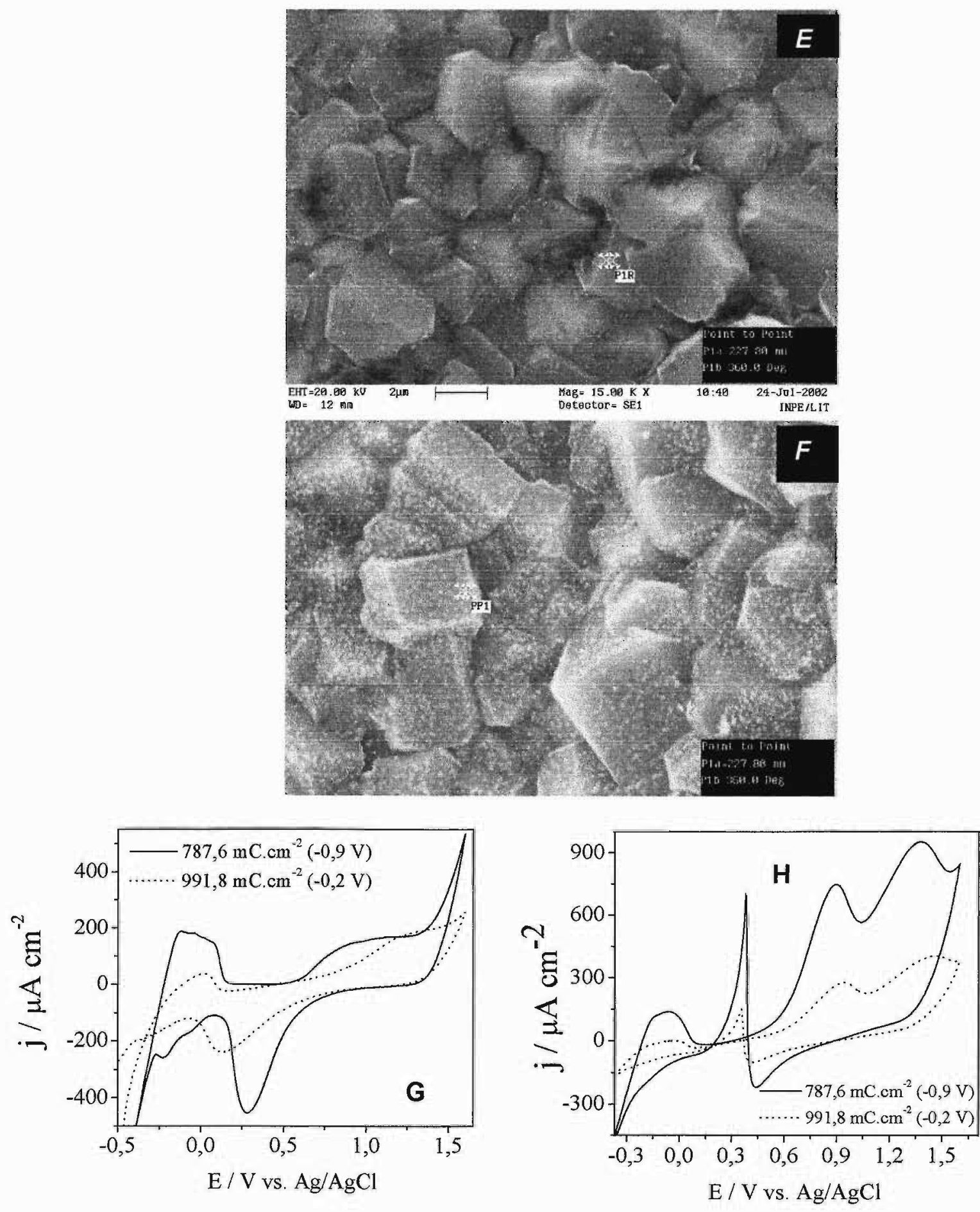

FIGURA 5.17: Imagens de MEV dos eletrodos de diamante (Nível de dopagem: 10000 ppm, B/C). Imagem E: $991,8 \mathrm{mC} \cdot \mathrm{cm}^{-2}$ de Pt $(-0,2 \mathrm{~V})$. Imagem F: $788,2 \mathrm{mC} \cdot \mathrm{cm}^{-2}$ de Pt $(-0,9 \mathrm{~V})$. Solução de eletrodeposição: $\mathrm{H}_{2} \mathrm{PtCl}_{6} 3,9 \mathrm{mM}+\mathrm{KCl} 0,1 \mathrm{M}, \mathrm{pH} 3,4$. Amostras sem pré-tratamento. Magnificação: 15000 vezes. $\mathrm{G}$ e $\mathrm{H}$ são os voltamogramas em solução de $\mathrm{H}_{2} \mathrm{SO}_{4}$ 0,5 M (G) e de etanol $0,1 \mathrm{M}+\mathrm{H}_{2} \mathrm{SO}_{4} \quad 0,5 \mathrm{M}(\mathrm{H})$. Velocidade de varredura: $50 \mathrm{mV} \mathrm{s}^{-1}$. 


\subsection{3- Eletrodeposição de Platina: Efeito do tratamento superficial do substrato.}

Para investigar o efeito do pré-tratamento do substrato na eletrodeposição de Pt no filme de diamante, o eletrodo foi polarizado em potenciais de $\mathrm{RDO}$ em solução de $\mathrm{H}_{2} \mathrm{SO}_{4}$ 0,5 M antes da deposição de Pt. A figura 5.18 apresenta os voltamogramas resultantes da aplicação de uma varredura linear de $0,3 \mathrm{~V}$ a $-2,0 \mathrm{~V}$ à velocidade de varredura de $50 \mathrm{mV}$ $\mathrm{s}^{-1}$, no eletrodo de DDB. Neste caso o filme de diamante foi pré-polarizado em $+2,0 \mathrm{~V}$ por diferentes tempos em solução de $\mathrm{H}_{2} \mathrm{SO}_{4} \quad 0,5 \mathrm{M}$. Pode-se observar que o sobrepotencial de deposição foi maior para a amostra anodizada, o que se pode constatar pelo deslocamento da região catódica de deposição do metal, no eletrodo anodizado (Fig. 5.18 b). Logo, a polarização anódica fornece uma superfície menos suscetível para a deposição de Pt. A figura 5.18 c mostra que após a polarização a $+2,0 \mathrm{~V}$ por 3 horas, menos Pt foi depositada e o pico da corrente de deposição quase que não é notado. Uma região catódica de baixa densidade de corrente é observada em c.a. $-1,3 \mathrm{~V}$ e a RDH parece ter início em potenciais mais negativos que $-2,0 \mathrm{~V}$. Desse voltamograma, conclui-se que uma menor quantidade de Pt é depositada sobre o filme anodizado. Este resultado é confirmado por micrografias de MEV das amostras (figura 5.19 a e b), nas quais se pode observar que a Pt praticamente não se depositou na amostra anodizada nestas condições. 


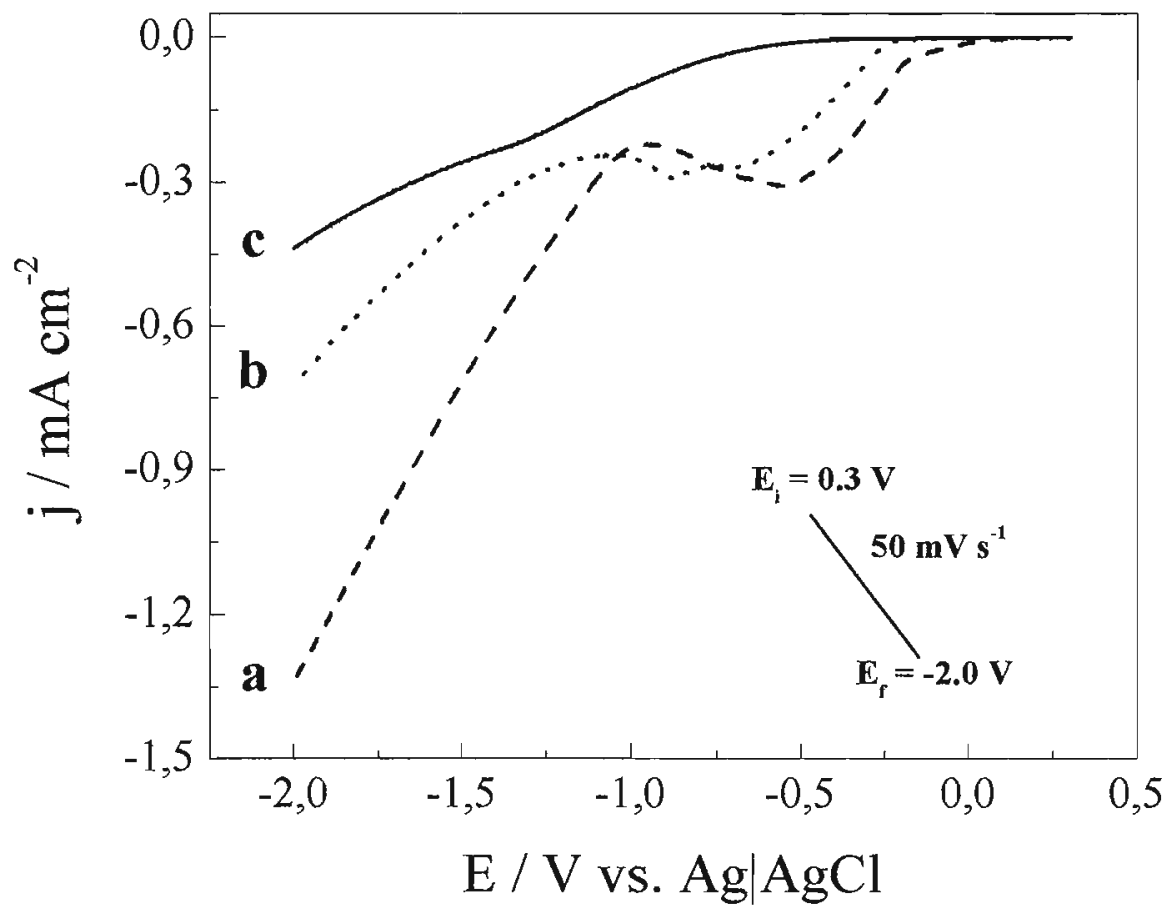

FIGURA 5.18 - Voltamogramas lineares registrados em solução de $\mathrm{H}_{2} \mathrm{PtCl}_{6} 3,9 \mathrm{mM}+$ $\mathrm{KCl} 0,1 \mathrm{M}, \mathrm{pH} 3,4$. (a) é eletrodo não polarizado, (b) e (c) pré-polarizado em $20 \mathrm{~min}$. e em $1 \mathrm{~h},+3,0 \mathrm{~V}$ em solução de $\mathrm{H}_{2} \mathrm{SO}_{4} 0,5 \mathrm{M}$, respectivamente. Velocidade de varredura: $50 \mathrm{mV} \mathrm{s}^{-1}$. Solução do branco: $\mathrm{KCl} 0,1 \mathrm{M}, \mathrm{pH} \mathrm{3,4}$. Nível de dopagem das amostras: $10000 \mathrm{ppm}, \mathrm{B} / \mathrm{C}$. Área (geométrica) do eletrodo: $0,071 \mathrm{~cm}^{2}$.
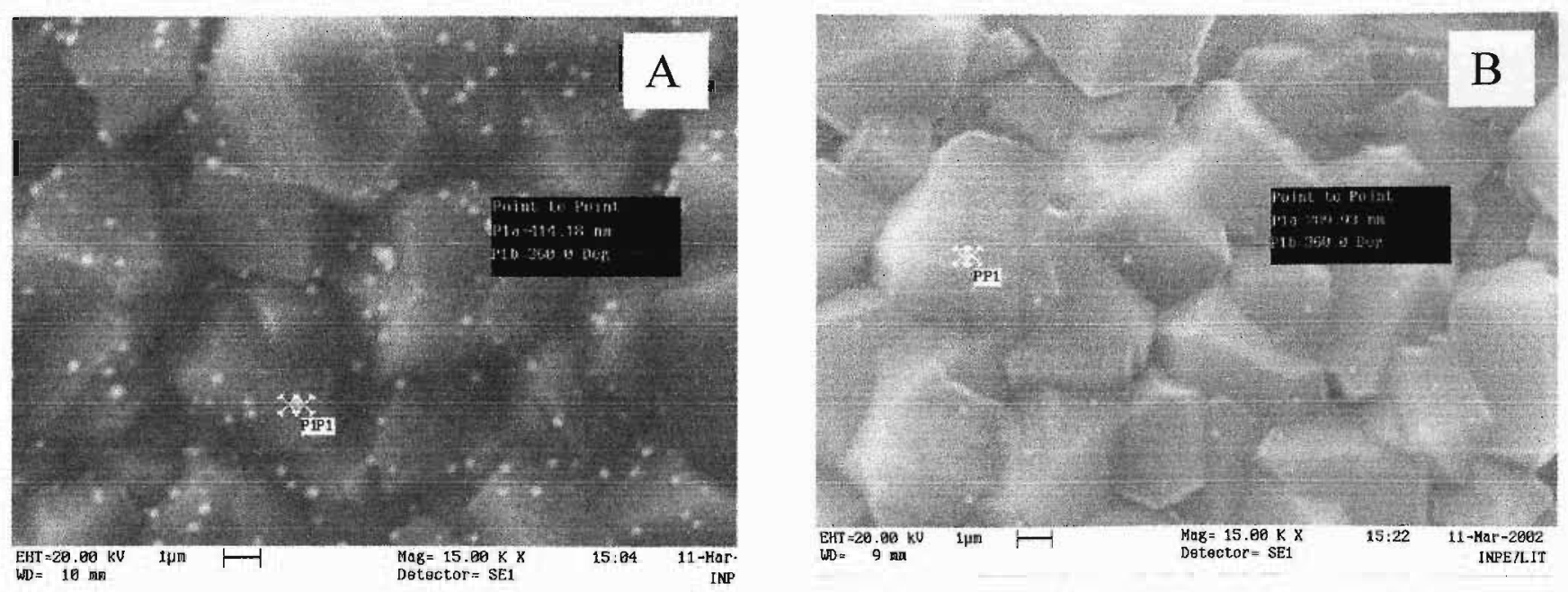

FIGURA 5.19: Micrografias de MEV dos eletrodos de diamante. Solução de $\mathrm{H}_{2} \mathrm{PtCl}_{6}$ 3,9 $\mathrm{mM}+\mathrm{KCl}$ 0,1 M. Magnificação: 15000 vezes. Micrografia (A) é eletrodo pré-tratado em $10 \mathrm{~s},+3,0 \mathrm{~V}$. Micrografia (B): eletrodo pré-tratado em $1 \mathrm{~h},+3,0 \mathrm{~V}$. 
Embora este resultado tenha concordado com outros autores que relatam a inibição da deposição de metais sobre superfícies anodizadas de diamante, é também unânime a idéia de que a deposição mais eficiente de metais ${ }^{77}$ e de óxidos ${ }^{80-84}$ podem ser obtidos através de um leve tratamento oxidativo do filme de DDB, que contribui para o aumento da hidrofilicidade do filme. Segundo esses autores, a superfície hidrofóbica do diamante recém-depositado dificulta o contato da solução com a superfície, inibindo a deposição do metal.

Neste experimento, discutido anteriormente, a amostra de DDB que não foi polarizada em $+3,0 \mathrm{~V}$ não era necessariamente recém-depositada, mas havia sido ciclada algumas vezes em meio ácido (sem RGH ou RGO) para obtenção de resposta voltamétrica reprodutível, antes de ser colocada na solução de ácido hexacloroplatínico para o registro do voltamograma (figura 5.18). Neste caso, não se poderia saber se a maior eficiência de deposição obtida foi devida ao fato de o filme não ter sido polarizado em $+3,0 \mathrm{~V}$, ou se essas poucas ciclagens já terem contribuído para a diminuição da hidrofobicidade do filme. Por isso, repetiu-se o experimento, utilizando-se cinco amostras recém-depositadas de mesmo nível de dopagem (10000 ppm, B/C). Quatro destas amostras foram polarizadas em $+3,0 \mathrm{~V}$ por $10,20,30$ e 60 minutos, respectivamente, em meio de $\mathrm{H}_{2} \mathrm{SO}_{4}$ 0,5 M. Então, sobre estas amostras foi depositada Pt por voltametria cíclica. O programa de potenciais utilizado foi a variação de potenciais de $1,0 \mathrm{~V}$ a $-1,0 \mathrm{~V}$, com velocidade de varredura de $50 \mathrm{mV} \mathrm{s}^{-1}$. (figura 5.18). O potencial mínimo escolhido foi de $-1,0 \mathrm{~V}$ (e não de $-2,0 \mathrm{~V}$, como no experimento anterior) para se evitar um possível desprendimento de Pt metálica do filme pela geração turbulenta de bolhas de $\mathrm{H}_{2}$.

Como não foi possível a análise química, pelo fato de a quantidade de Pt nos filmes ter sido abaixo do limite de detecção por Espectrometria de Absorção Atômica, as amostras de BDD-Pt depositadas neste experimento foram analisadas por EDS, afim de avaliar as concentrações superficiais de $\mathrm{Pt}$, em função do tempo de anodização do eletrodo em meio ácido. Na Figura 5.20 são apresentados os espectros de EDS das amostras de BDD-Pt, com diferentes tempos de pré-tratamento anódico. Podemos observar que no eletrodo sem pré-tratamento não foi possível a detecção de $\mathrm{Pt}$ no filme. $\mathrm{Na}$ amostra tratada com $10 \mathrm{~min}$. de polarização anódica, há um substancial aumento na concentração de $\mathrm{Pt}$, que diminui, para as outras amostras, à medida em que o tempo de 
anodização aumenta. Entretanto, como se pode observar na figura 5.21, da concentração superficial de oxigênio inferida das porcentagens em massa apresentadas pelos espectros de EDS, não se pode inferir um padrão desta variável com o tempo de anodização da amostra. Observando as tabelas contidas nos espectros (figura 5.20), pode-se inferir que em todas as amostras, os ZAF's referentes ao oxigênio estão na faixa de 5, o que mostra que essas medidas da concentração de oxigênio são apenas qualitativas ${ }^{19}$. Isso é decorrente do fato de que a energia do feixe, sendo necessariamente alta (10 keV) para a detecção apropriada da $\mathrm{Pt}$, fez com que o feixe penetrasse na amostra. O detector então, recebeu uma maior quantidade de emissões por parte do carbono do interior da amostra e portanto não foi capaz de discernir entre esse elemento e o oxigênio, que têm números atômicos similares. No caso da Pt, todas as medidas apresentaram um ZAF da ordem de 1,5. Isso embora torne as medidas apenas semiquantitativas, mostra ser possível o uso destes resultados para se comparar as diferentes concentrações de Pt nas amostras, em função do tempo de polarização anódica do substrato. 

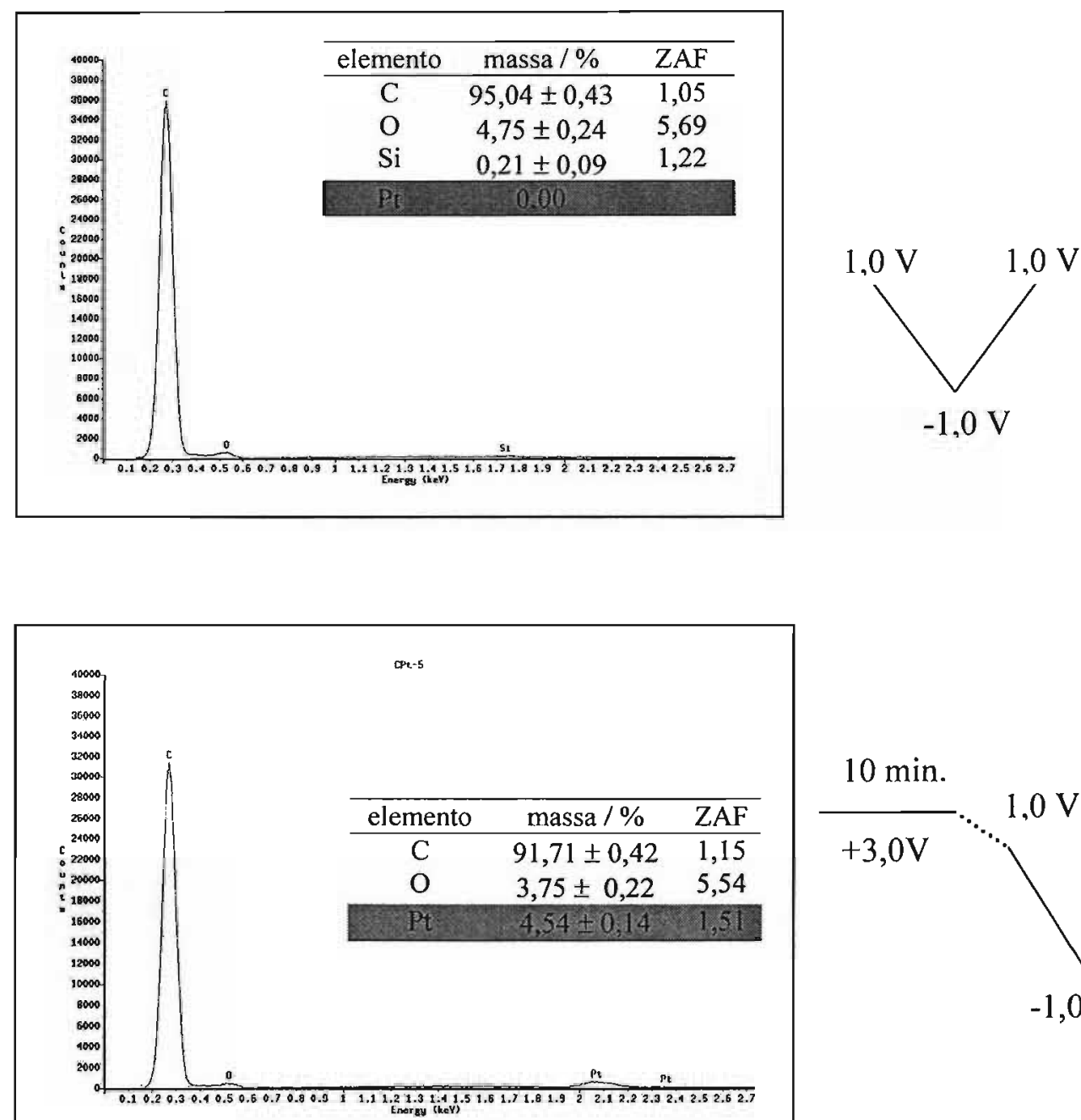

$10 \mathrm{~min}$.

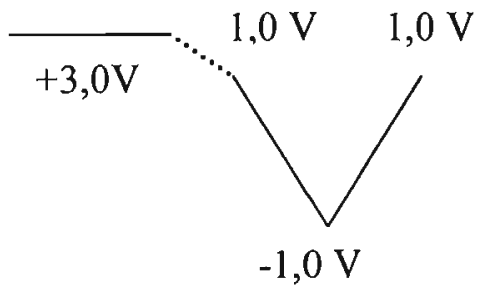

$20 \mathrm{~min}$

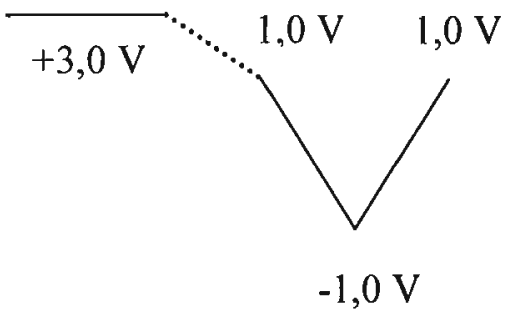




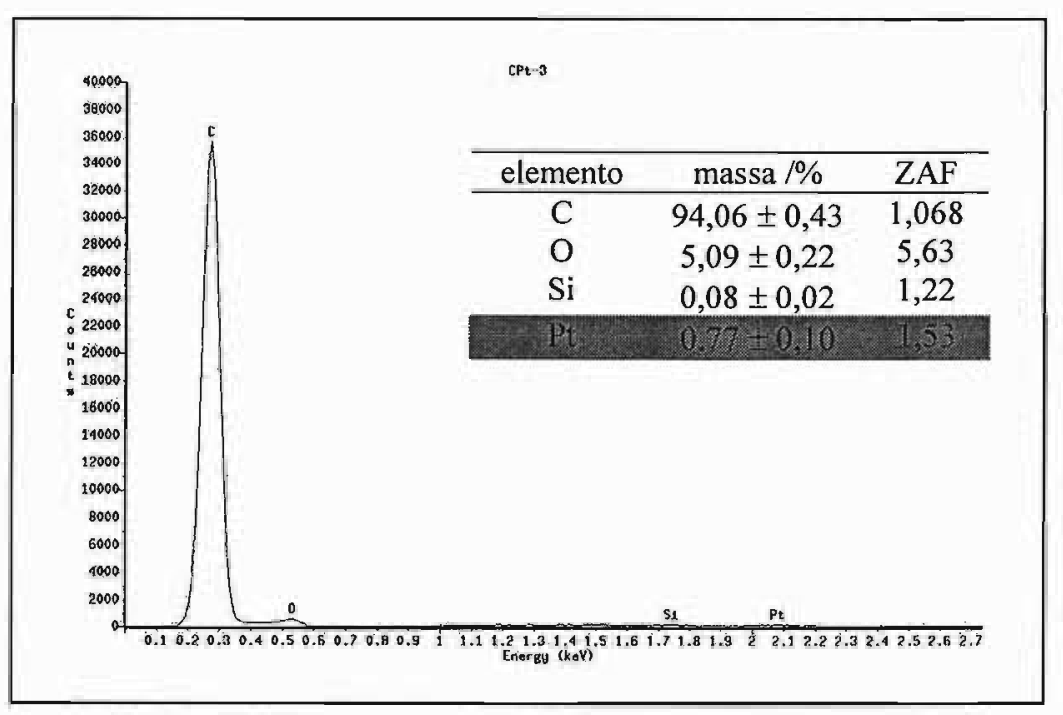

$30 \mathrm{~min}$.
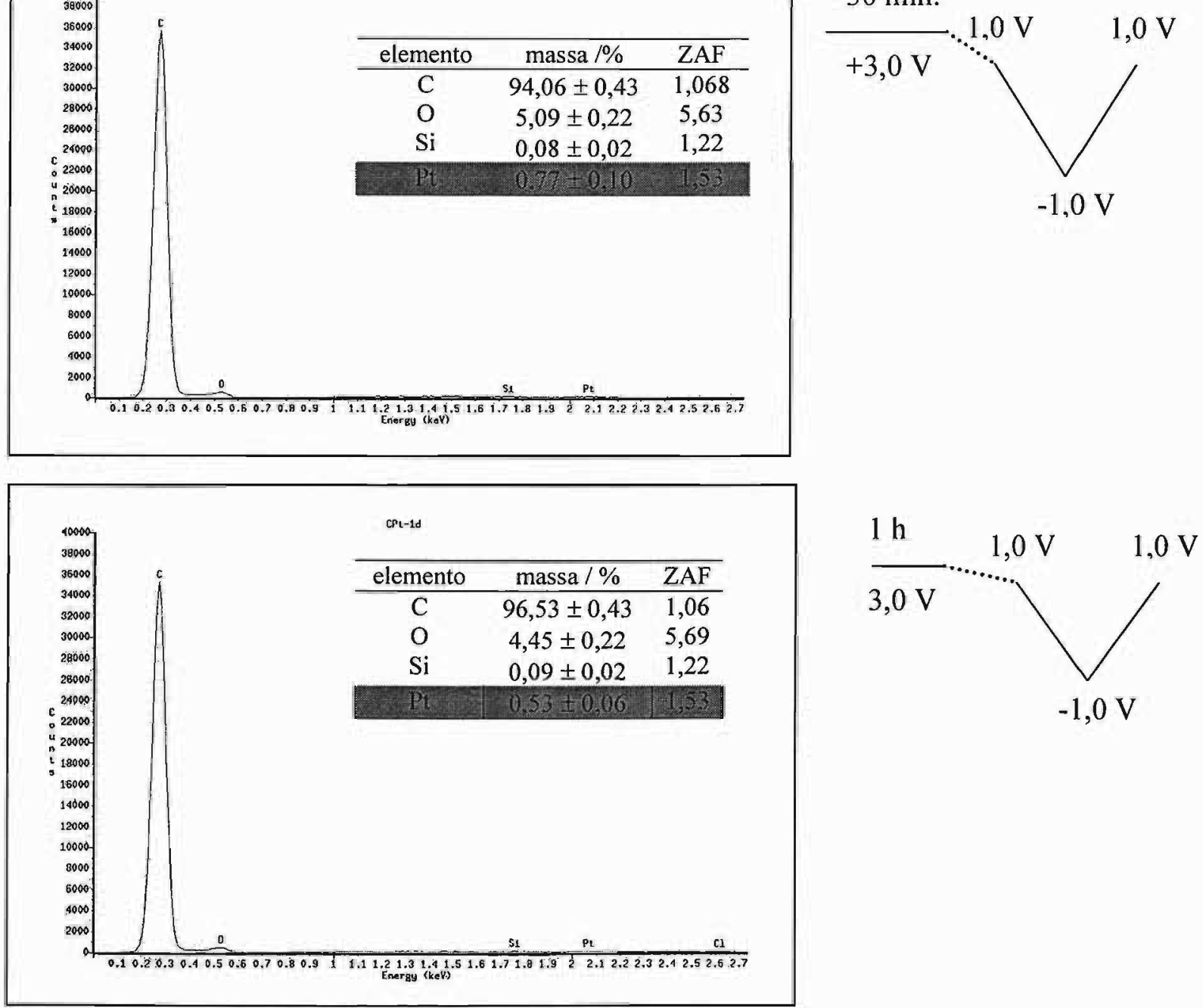

FIGURA 5.20: Espectros de EDS para as amostras oxidadas em diferentes tempos de anodização em $+3,0 \mathrm{~V}, \mathrm{H}_{2} \mathrm{SO}_{4}$ 0,5 M. Energia do feixe $10 \mathrm{keV}$. Ampliação de 100 vezes. Pt depositada de solução $\mathrm{H}_{2} \mathrm{PtCl}_{6} 3,8 \mathrm{mM}+\mathrm{KCl} 0,1 \mathrm{M}$. 


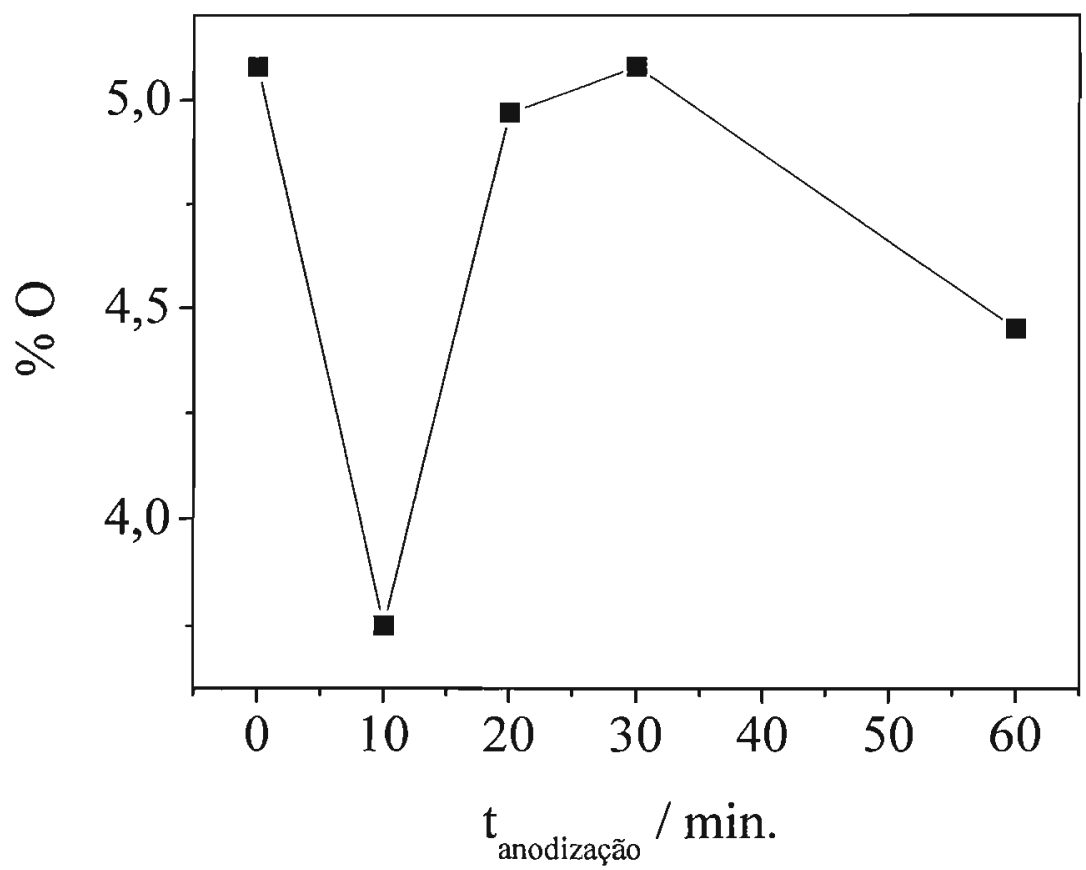

FIGURA 5.21: Concentrações superficiais de oxigênio nos filmes de BDD em função do tempo de pré-tratamento

$\mathrm{Na}$ figura 5.22a é mostrada a porcentagem de Pt depositada, obtida por EDS, em função do tempo de pré-anodização. Na Figura 5.22b, é mostrada a carga catódica em função do tempo de pré-anodização. Da comparação das figuras 5.22 a e b, pode-se concluir que há uma correlação entre a carga de deposição de $\mathrm{Pt}$ e a porcentagem deste metal presente na amostra de DDB. Esse comportamento é contrário à diminuição da eficiência de corrente (quantidade de metal efetivamente depositado por unidade de carga elétrica de deposição) quando o filme de DDB é oxidado, observada na deposição de Au e de $\mathrm{Cu}^{42,71,74}$.

Na figura 5.22 pode-se observar dois tipos de comportamento. Primeiro, na amostra não-tratada, a deposição de Pt parece ser fortemente inibida. Entretanto, logo depois de 10 minutos de tratamento em potenciais de $\mathrm{RGO}(+3,0 \mathrm{~V})$, a porcentagem de $\mathrm{Pt}$ depositada no diamante aumentou para um valor máximo, decrescendo com a progressiva oxidação anódica da superfície do filme. Este aumento na eficiência de deposição é 
confirmado por Fujishima e col. ${ }^{77}$ que afirmaram que depósitos de Pt mais dispersos e ativos podem ser obtidos sobre diamante que sofreu tratamento oxidativo, antes da deposição do catalisador. Eles atribuíram este fato à perda da hidrofobicidade devido à oxidação da superfície do diamante, que inicialmente é hidrogenada e hidrofóbica. Isto contribuiria para o aumento da superfície de contato filme de diamante/solução, facilitando a chegada do íon complexo de Pt à superfície do eletrodo. Por outro lado, uma queda similar na eficiência de eletrodeposição foi já observada anteriormente na deposição de $\mathrm{Cu}^{42}$ e de $\mathrm{Au}^{74}$ em superfícies de diamante oxidadas tanto anodicamente quanto quimicamente. Além disso, como já foi visto na primeira parte desta Dissertação, foi mostrado que a polarização faz com que os sobrepotenciais de RGH e de RGO sejam deslocados para valores mais altos, o que mostra que a superfície oxidada do diamante se torna mais inerte para estes processos. Estudos sobre o efeito do tratamento eletroquímico da superfície do diamante mostram que possivelmente haja a formação de grupos $\mathrm{C}=\mathrm{O}$ ou $\mathrm{C}-\mathrm{O}-\mathrm{C}^{39,44}$. Estes grupos poderiam formar uma camada de óxidos que poderia exercer um efeito eletrostático repulsivo. Por causa da repulsão eletrostática, a distância entre o íon metálico e a superfície do eletrodo aumenta, diminuindo a taxa de transferência eletrônica entre estas duas partes. Entretanto, o fato desta inibição poder ser observada com a deposição de metais a partir tanto de íons positivos quanto negativos $\left(\mathrm{Cu}^{2+}, \mathrm{AuCl}_{4}{ }^{2-}\right.$, $\mathrm{PtCl}_{6}{ }^{2-}$ ), faz com que o argumento baseado na repulsão eletrostática seja pouco provável. Por outro lado, a inibição da deposição do metal sobre a superfície anodizada do diamante poderia ser mais razoavelmente atribuída ao bloqueio, por parte do oxigênio, de sítios ativos para deposição do metal. A superfície hidrogenada do diamante recémsintetizado seria muito hidrofóbica para ter um contato apropriado com os íons de Pt, que estão solubilizados em água. Contudo em uma superfície completamente oxidada, esperase que a concentração de sítios ativos para deposição do catalisador seja reduzida, inibindo a redução completa da $\mathrm{Pt}$, bem como a sua adesão à superfície do filme, com possivel formação do metal em forma de colóide, ou de um íon com menor carga. Além disso, através da Fig. 5.22 pode-se ver que há uma correlação entre a carga de deposição e a quantidade de Pt presente no filme de DDB, independentemente do tempo de anodização do filme. 


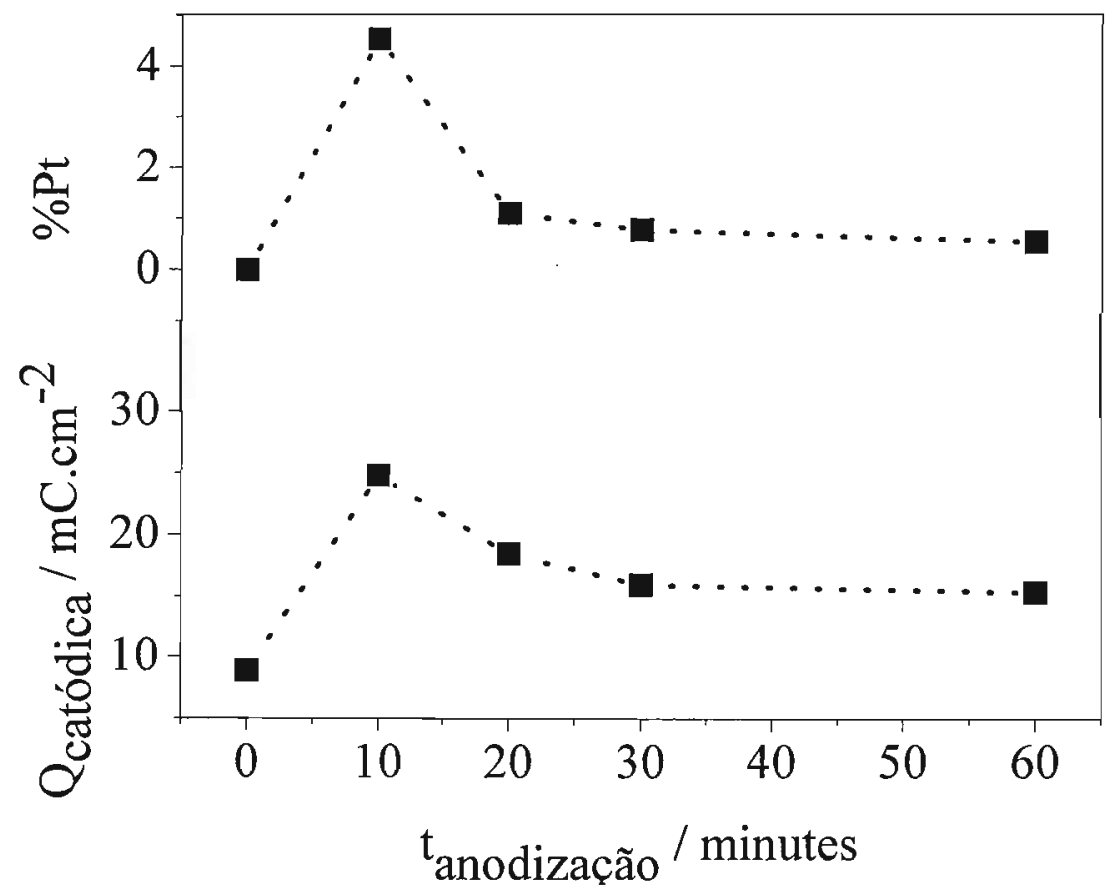

FIGURA 5.22 - Dependência (a) da concentração de Pt (\%Pt em massa -inferida por EDS) e (b) da carga catódica de deposição de Pt no tempo de anodização do BDD em meio ácido (+3,0 V/ $\mathrm{H}_{2} \mathrm{SO}_{4}$ 0,5 M). Solução de deposição: $\mathrm{H}_{2} \mathrm{PtCl}_{6} 3,8 \mathrm{mM}+\mathrm{KCl} 0,1$ $\mathrm{M}, \mathrm{pH} 3,4$.

\subsubsection{1 - Área eletroquímica dos depósitos de $\mathbf{P t}$}

Para esses estudos, foram efetuados voltamogramas cíclicos utilizando as amostras de DDB-Pt obtidas no experimento anterior. O programa utilizado foi a repetição de varreduras cíclicas de potenciais de $-0,1 \mathrm{~V}$ a $1,0 \mathrm{~V}$ até obtenção de um voltamograma reprodutível. A velocidade de varredura foi de $50 \mathrm{mV} \mathrm{s}^{-1}$. O meio utilizado foi de $\mathrm{H}_{2} \mathrm{SO}_{4}$ $0,5 \mathrm{M}$.

As áreas eletroquímicas dos depósitos foram inferidas da carga anódica da formação de óxidos superficiais sobre a platina, que no caso dos voltamogramas do BDD-Pt corresponderam à região anódica entre c.a $0,6 \mathrm{~V}$ e 1,0 V (Figura 5.23). Assumiu-se que a 
carga de formação de uma camada de óxidos sobre a platina foi de $420 \mu \mathrm{C} . \mathrm{cm}^{-2}$ $[12,13,14]$. Esta região do voltamograma foi escolhida ao invés da região de adsorção de $\mathrm{H}^{+}$porque nas pequenas quantidades de Pt depositadas, não foi possível determinar bem onde essa região se confundia com a RGH ou com a redução de óxidos sobre a Pt (ver Figura 5.23). A figura 5.24 mostra a dependência da área eletroquímica por \% $\%$ (estimada da análise de EDS - figura 5.20) no tempo de pré-anodização do eletrodo em solução de $\mathrm{H}_{2} \mathrm{SO}_{4} \quad 0,5 \mathrm{M} /+3,0 \mathrm{~V}$. Podemos observar nesta figura que quanto maior o tempo de anodização da superfície do BDD, maior é a área eletroquímica do depósito. Este resultado surpreendente mostra que depósitos mais dispersos de $\mathrm{Pt}$ podem ser obtidos quando o substrato de diamante é pré-oxidado em potenciais de RGO.

Destes resultados de deposição potenciodinâmica de Pt sobre filmes de BDD pôde-se observar que em tratamentos anódicos:

a- o $E_{\text {deposição }}$ é deslocado para potenciais mais negativos

b- menos Pt é depositada

c- São obtidos depósitos mais dispersos, ou seja, com maior área superficial por quantidade de Pt depositada.

Na deposição de Pt por um processo potenciodinâmico, há a alteração do potencial a que o sistema está sendo submetido, assim como há também a alteração da própria superfície do eletrodo, em virtude da quantidade cada vez maior de Pt presente. Com o intuito de se estudar a causa dos resultados obtidos, fez-se necessária comparação destes resultados de deposição potenciodinâmica discutidos nesta seção, com os resultados da deposição de Pt a potencial constante, já apresentados na seção 5.2.2. Nesta discussão serão apresentados os resultados de área eletroquímica e de rendimento para a oxidação de etanol. 


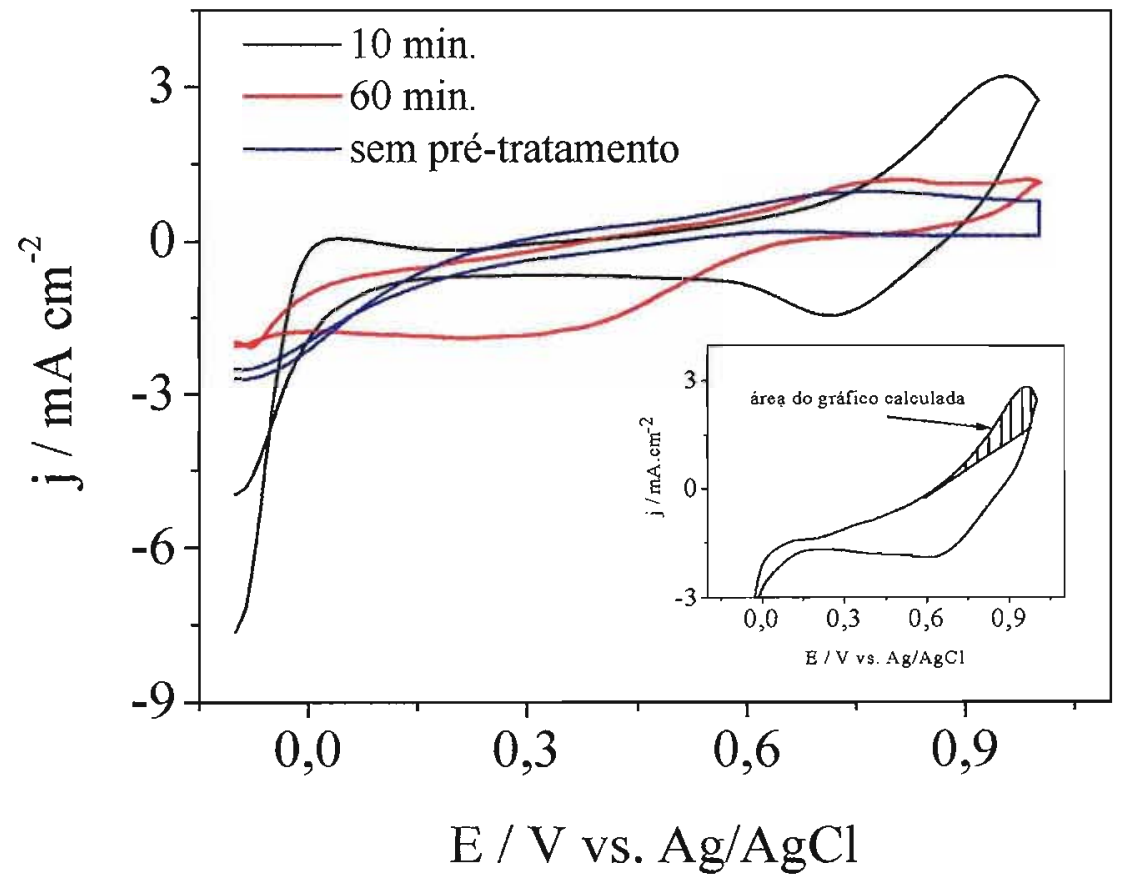

FIGURA 5.23: Voltamogramas do BDD-Pt. Condições de pré-tratamento do BDD: $+3,0 \mathrm{~V} / \mathrm{H}_{2} \mathrm{SO}_{4} 0,5 \mathrm{M}$. Velocidade de varredura: $50 \mathrm{mV} \mathrm{s}^{-1}$.

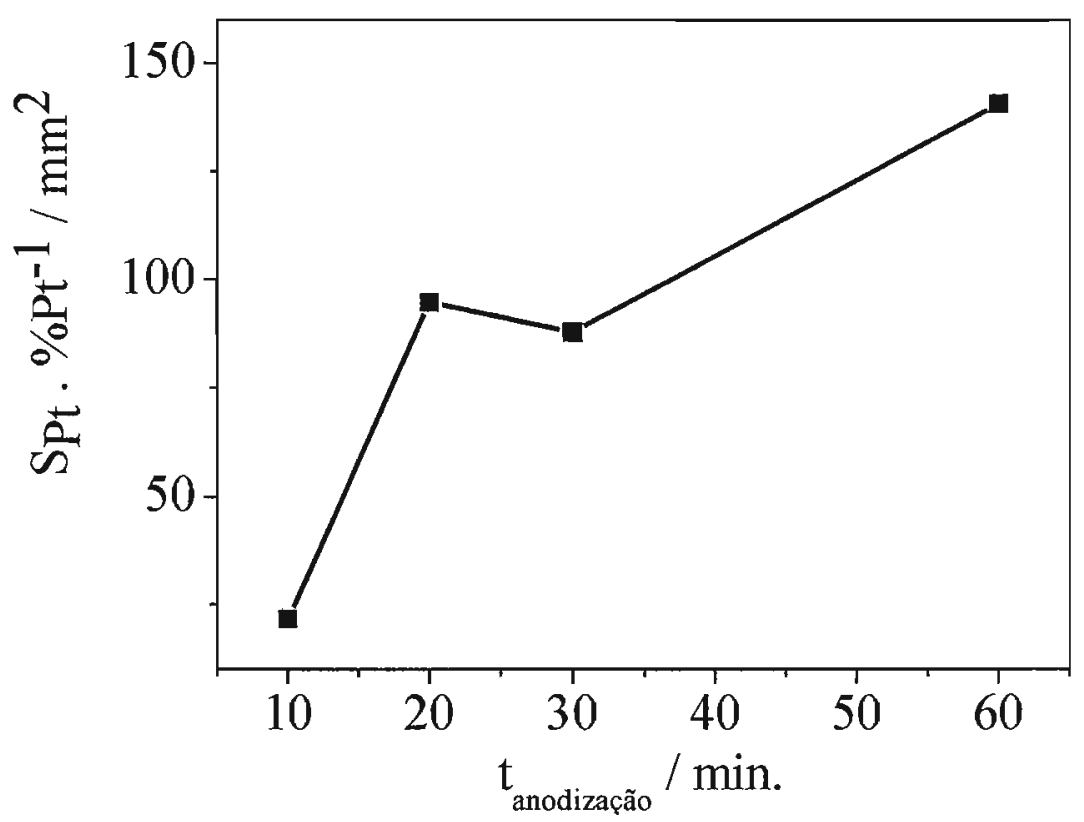

FIGURA 5.24: Dependência da área eletroquímica $\left(\mathrm{S}_{\mathrm{Pt}}\right)$ por $\% \mathrm{Pt}$ no tempo de préanodização do $\mathrm{BDD} \mathrm{em}+3,0 \mathrm{~V} / \mathrm{H}_{2} \mathrm{SO}_{4} 0,5 \mathrm{M}$. 


\subsubsection{2 - Área Eletroquímica e carga de oxidação de etanol}

Nestes experimentos, o tratamento anódico dos filmes de DDB consistiu em polarizar o eletrodo em um potencial de $+2,0 \mathrm{~V}$ por $3100 \mathrm{~s}$. A posterior deposição de Pt foi feita a potencial constante (- 0,9 V), em diferentes tempos de deposição. Após a deposição, os filmes foram ciclados voltametricamente entre $-0,1 \mathrm{~V}$ e $1,7 \mathrm{~V}$ a $50 \mathrm{mV} \mathrm{s}^{-1}$ em soluções de $\mathrm{H}_{2} \mathrm{SO}_{5} \quad 0,5 \mathrm{M}$ (eletrólito suporte) e em etanol $0,1 \mathrm{M}+\mathrm{H}_{2} \mathrm{SO}_{4} \quad 0,5 \mathrm{M}$. A discussão referente a esses experimentos encontra-se na seção 5.2.2 - Influência do potencial de eletrodeposição.

Dos voltamogramas obtidos da solução de eletrólito suporte, as cargas de adsorção de íons $\mathrm{H}^{+}$foram obtidas, para a determinação da área eletroquímica dos depósitos $\left(\mathrm{S}_{\mathrm{H}}{ }^{+}\right)$, assumindo que a carga de adsorção de uma monocamada de $\mathrm{H}^{+}$corresponde a 210 $\mu \mathrm{C} . \mathrm{cm}^{-2}[12,13]$. As cargas de oxidação anódica de etanol foram obtidas ciclando o eletrodo em solução ácida de etanol. Na Figura 5.25 é apresentada a dependência da área eletroquímica normalizada, ou seja, a área eletroquímica da $\mathrm{Pt}\left(\mathrm{S}_{\mathrm{H}}{ }^{+}\right)$dividida pela carga de deposição de $\mathrm{Pt}$, na carga de deposição $\left(\mathrm{Q}_{\mathrm{Pt}}\right)$, para os filmes anodizados e sem prétratamento. Pode ser visto que quanto maior a carga de Pt no filme, menor a sua área normalizada. Este comportamento é esperado quando se tem quantidades de catalisador inferiores à quantidade necessária para a formação de uma monocamada, depositadas sobre substratos inertes ${ }^{16}$. Neste caso, a inicialmente grande área normalizada dos depósitos de Pt tende a diminuir, tornando-se constante em quantidades maiores de metal depositado, indicando que a área superficial não mais pode ser efetivamente alterada pela adição do metal.

Outra característica interessante observada na figura 5.25 é que em comparação com o eletrodo sem pré-tratamento, a deposição na superfície de BDD origina depósitos com maior área superficial, especialmente em pequenas quantidades de catalisador depositado. (c.a. $1-7$ C. $\mathrm{cm}^{-2}$ ). Uma possível explicação para esse fato é que simplesmente poder-seia depositar menos Pt no eletrodo sem pré-tratamento. Entretanto, através da inspeção qualitativa das imagens de MEV (figura 5.26), ocorre o contrário: a deposição no filme anodizado mostrou-se menos eficiente, com menos Pt. Tanto o fenômeno da inibição causada pela anodização do filme, quanto o aumento da área eletroquímica do eletrodo, 
ambos observados em eletrodos anodizados, corroboram os resultados obtidos através dos experimentos potenciodinâmicos, discutidos no item anterior.

Lembramos que o nível de dopagem das amostras utilizadas nos experimentos potenciostáticos $(20000 \mathrm{ppm})$ foi diferente das amostras dos experimentos potenciodinâmicos (10000 ppm). Contudo, para fazer essa comparação, considerou-se que o comportamento do filme de diamante frente a pré-tratamentos anódicos não se altere consideravelmente em função do nível de dopagem do filme de diamante.

Na Figura 5.27 é apresentada a carga normalizada (por carga de deposição de Pt) de oxidação de etanol em função da carga de deposição de Pt. Desta figura, pode ser estimada e comparada a eficiência real das dispersões de catalisador tanto no eletrodo sem pré-tratamento quanto no eletrodo anodizado. Pode ser visto que a carga de oxidação de etanol maior no BDD-Pt anodizado. Ao mesmo tempo, a atividade de depósito é bem maior em cargas de deposição abaixo de $2 \mathrm{C} \mathrm{cm}^{-2}$, seguindo o mesmo padrão apresentado pela área superficial dos depósitos (fig. 5.25). Este comportamento é esperado, visto que a densidade de corrente (e portanto a carga elétrica) de um processo eletroquímico é diretamente proporcional à área superficial do eletrodo ${ }^{1}$.

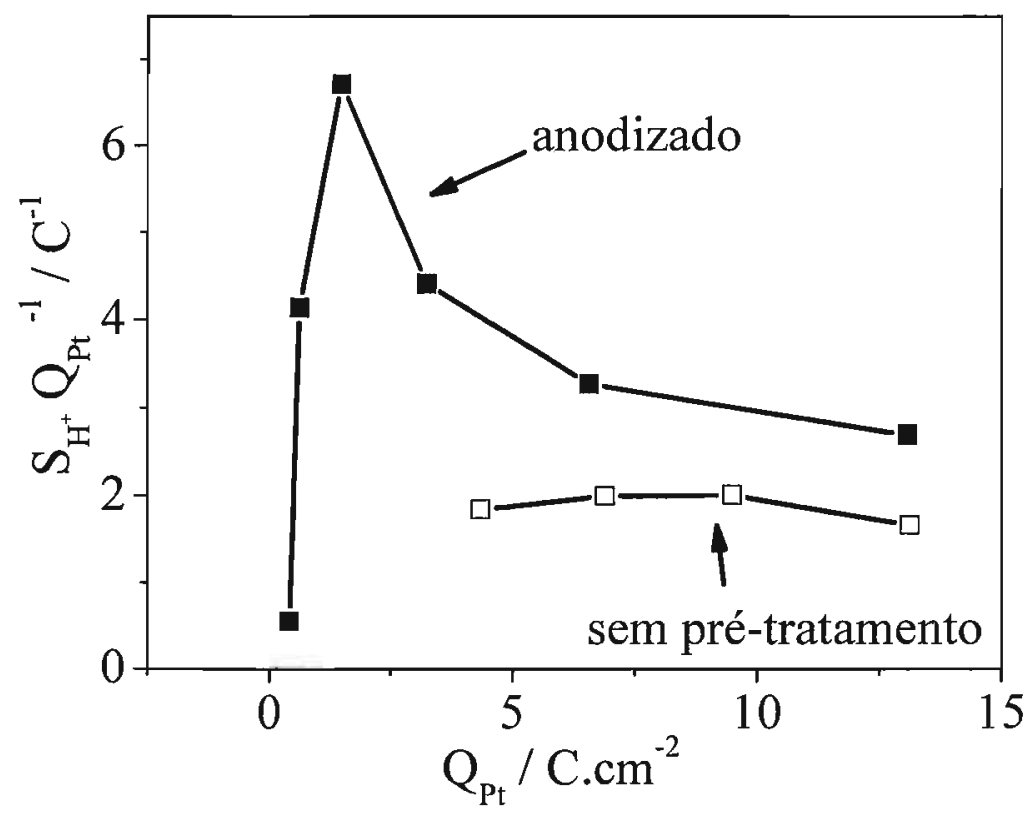

FIGURA 5.25: Área eletroquimica (A) e área eletroquímica por unidade de carga de Pt depositada (B), em função da carga catódica de deposição de Pt. $E_{\text {deposição: }}-0,9 \mathrm{~V}$. Tratamento anódico: $3100 \mathrm{~s}$ em $+2,0 \mathrm{~V}$. Tratamento catódico: $2 \mathrm{~h} 10 \mathrm{~min}$. em $-2,0 \mathrm{~V}$. 

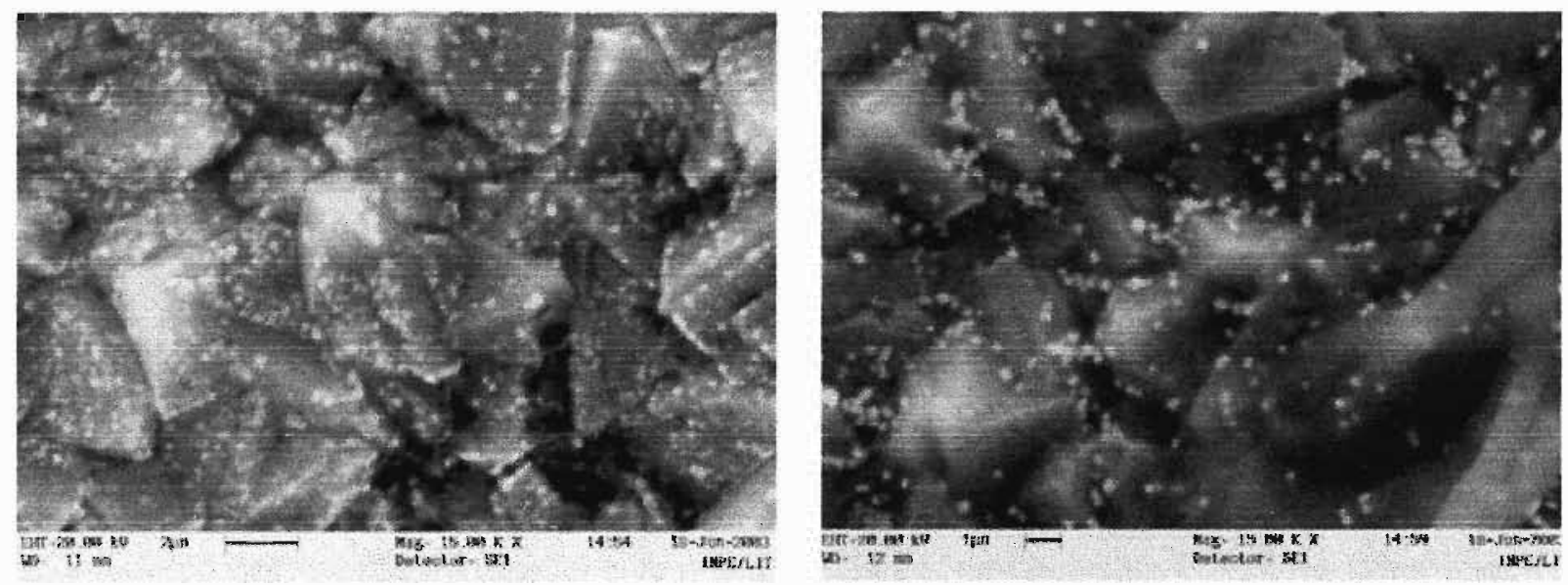

FIGURA 5.26: Micrografias de MEV dos filmes de BDD-Pt depositados potenciostaticamente. (a) sem pré-tratamento, $Q_{\mathrm{Pt}}=279,5 \mathrm{mC} \cdot \mathrm{cm}^{-2}$. (b) tratamento anódico $\mathrm{QPt}_{\mathrm{Pt}}: 250,9 \mathrm{mC} . \mathrm{cm}^{-2},\left(3100 \mathrm{~s},+2,0 \mathrm{~V} / \mathrm{H}_{2} \mathrm{SO}_{4}\right.$ 0,5 M). Edeposição: $-0,9 \mathrm{~V}$. Solução: $\mathrm{H}_{2} \mathrm{PtCl}_{6} 3,8 \mathrm{mM}+\mathrm{KCl} \mathrm{0,1} \mathrm{M}, \mathrm{pH} \mathrm{3,4}$. Magnificação: 15000 vezes.

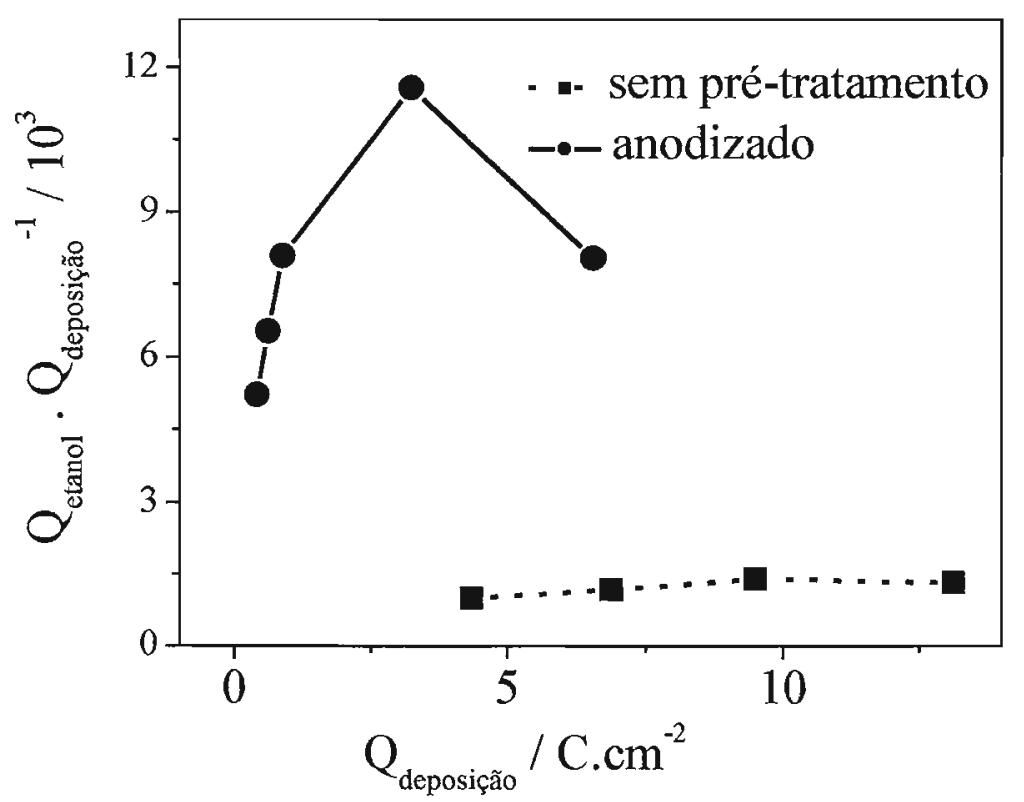

FIGURA 5.27: Carga de oxidação de etanol normalizada em função da carga de deposição de Pt sobre eletrodos de diamante submetidos a diversos pré-tratamentos em $\mathrm{H}_{2} \mathrm{SO}_{4} 0,5 \mathrm{M}$. 
Foi visto então que a deposição de Pt sobre a superfície anodizada do diamante é menos eficiente, devido à já esperada dificuldade para nucleação de um metal sobre a sua superfície oxidada ${ }^{21}$ enquanto que a deposição de Pt sobre uma superfície hidrogenada do diamante catodizado e sem pré-tratamento pareceram ser mais eficientes. Por outro lado, estes depósitos de $\mathrm{Pt}$ feitos sobre o eletrodo anodizado apresentaram uma maior área eletroquímica e são mais eficientes para a oxidação anódica de etanol. Estes fatos sugerem que a deposição de Pt sobre superfícies de diamante terminadas em oxigênio resultam em depósitos mais dispersos. Provavelmente, essa diferença de comportamento entre eletrodos oxidados e hidrogenados seja atribuída à influência exercida pelo oxigênio superficial nas etapas de fixação e de coalescência das partículas de Pt sobre a superfície do diamante ${ }^{65-67,96}$, segundo os mecanismos já explicados no parágrafo anterior. Como já mencionado, esse fato foi também observado por Fujishima e col. ${ }^{77}$ que depositaram Pt sobre filmes de diamante nanoestruturados. Os autores propuseram uma explicação baseada no fato de que óxidos superficiais presentes no diamante poderiam ancorar íons de $\mathrm{PtCl}_{6}^{2-}$ e impedir a coalescência das partículas de Pt dispersa, contribuindo para um aumento no grau de dispersão do catalisador.

Destes resultados, é sugerido o seguinte modelo para a influência do tratamento superficial do eletrodo de diamante na deposição de Pt (Figura 5.28). Basicamente, a deposição de Pt comportar-se-ia diferentemente em duas situações: deposição de Pt em baixos e em altos potenciais. Em baixos potenciais, o processo de deposição tende a ser mais difícil porque nesta situação, a influência do tipo de pré-tratamento (e por isso, da presença ou não de óxidos superficiais) é mais intensa e a deposição de Pt é mais sensivelmente impedida pela presença de óxidos na superfície do diamante, que ocupam sítios ativos para este processo. Entretanto, em altos potenciais de deposição, a influência do nível de oxidação do filme de diamante não é mais determinante, por causa do alto potencial de deposição do metal. Nesta situação, os óxidos superficiais poderiam inibir a etapa de coalescência dos núcleos de $\mathrm{Pt}^{66,96}$, o que poderia resultar em Pt mais dispersa sobre a superfície do substrato. Isto poderia explicar as dispersões de Pt mais ativas para a oxidação de etanol, na Pt depositada em $-0,9 \mathrm{~V}$ sobre a superfície anodizada do diamante. 


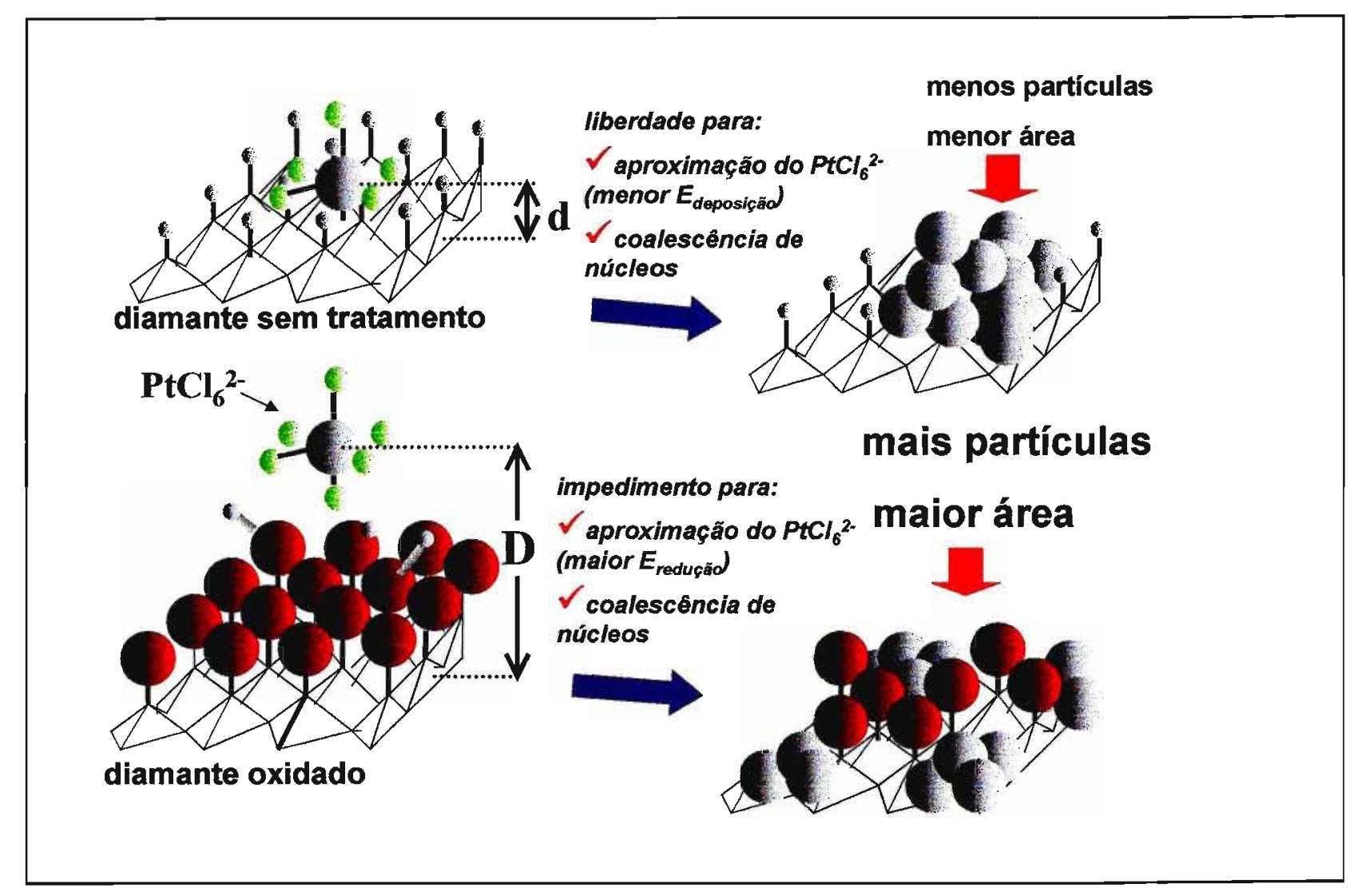

FIGURA 5.28 - Modelo proposto para a influência do tratamento superficial do diamante sobre a atividade catalítica da dispersão de platina. 


\section{6 - CONCLUSÕES}

- Polarizações em potenciais de RGH e de RGO influenciam no intervalo de estabilidade da água. Polarizações anódicas aumentam este intervalo e polarizações catódicas o diminuem (ativam o filme), embora este efeito de ativação não seja constante, mas diminua à medida em que o filme é usado. Acredita-se que este efeito de ativação seja devido à inserção de $\mathrm{H}_{2}$ nos interstícios que existem no filme recém sintetizado. Quando estes interstícios são decompostos por longos períodos de oxidação anódica, o efeito de ativação devido à polarização catódica diminui.

- Polarizações em potenciais de RGO inibem a deposição potenciodinâmica de Pt. Contudo, quando Pt é depositada a potencial constante próximo à RGH, o pré-tratamento anódico gera depósitos de $\mathrm{Pt}$ mais dispersos, aumentando a eficiência da Pt para a oxidação anódica de etanol. 


\section{7 - SUGESTÕES PARA TRABALHOS FUTUROS}

- Estudar a influência de outros pré-tratamentos oxidativos (anodização em meio básico, ataque químico com oxidantes tais como $\mathrm{HNO}_{3}, \mathrm{H}_{2} \mathrm{O}_{2}$ ) nas características dos eletrodepósitos de catalisador.

- Estudar a eletrodeposição de outros metais (Ni, Co) ou ligas de Pt (Pt-Ru, PtSn).para fins eletrocatalíticos.

- Alterar a geometria do eletrodo de DDB com o intuito de aumentar sua área superficial.

- Verificar influência do nível de dopagem dos filmes na mudança de comportamento do filme frente aos pré-tratamentos eletroquímicos em potenciais de $\mathrm{RGH}$ e de RGO. 


\section{8- REFERÊNCIAS BIBLIOGRÁFICAS}

1. J. M. Bockris, A. K. N. Reddy, Modern Electrochemistry $2 B, 2^{\text {nd }}$ edition, chapter 13 , (1789-1888).

2. M.L. Perry, T.F. Fuller, J.Electrochemical Society, 149, S59, (2002).

3. S.C. Roy, P.A. Christensen, A. Hamnett, K.M. Thomas, V. Trapp, J. Electrochemical Society, 143, 3073, (1996).

4. P. Stonehart, Berichte Bunsengesellschaft, Physical Chemistry, 94, 913, (1990).

5. R. F. Davis, Diamond Films and Coatings, Noyes, 1998.

6. K.E. Spear, J.P. Dismukes (ed.), Synthetic Diamond Emerging CVD Science and Technology, Wiley, (1994).

7. Q. Chen, M.C. Granger, T.E. Listen, G.M. Swain, J. Electrochemical Society 143, L238, (1996).

8. S. R. Vatcha, Colloids \& Surfaces A, 133, 99, (1998).

9. L.L.G. Silva, "Eletrodos em Diamante CVD para Estudos Eletroquimicos", Tese de Doutoramento, Instituto Tecnológico da Aeronáutica, (2001).

10. Ciência e Engenharia de Matérias: uma Introdução, W.D. Callister, Jr., LTC, $5^{\text {a }}$ ed., p.418-420.

11. R. Kalish, Applied Surface Science, 117/118, (1997), 558.

12. S. Gilman, The Anodic Film on Platinum Electrodes in A.J. Bard (ed.), “Electroanalytical Chemistry”, Marcel Dekker Inc., New York, 1967, vol. 2, p. 112.

13. R. Woods, "Chemisorption at Electrodes: Hydrogen and Oxygen on Noble Metals and Their Alloys" in: A.J. Bard (ed), "Electroanalytical Chemistry", Marcel Dekker, Inc., New York, 1976, vol. 9, p. 1.

14. T. Biegler, D.A.J. Rand, R. Woods, J. Electroanalytical Chemistry, 29, 269, (1971).

15. P.T.A. Sumodjo, "Oxidação Eletrocatalítica do Etanol sobre Eletrodo de Platina Platinizada", Tese de Doutoramento, Universidade de São Paulo - SP, 1985.

16. L.M. Pletcher et. al., Instrumental Methods in Electrochemistry, Ellis Horwood Lmtd., (1985), p. 283.

17. K.B. Oldham, J.C. Myland, Fundamentals of Electrochemical Science, Academic Press, Inc., (1998). 
18. D.C. Joy, "Scanning Electron Microscopy" in R.W. Cahn, P. Haasen, E.J.Kramer (eds.), Materials Science and Technology, VCH, vol. 2, p. 230.

19. D. Newbury, D. Joy, P. Echlin, C.Fiori, J.Goldstein, Advanced Scanning Electron Microscopy and X-Ray Microanalysis, Plenum Press, New York, 1986.

20. Y.V. Pleskov, A.Y. Sakharova, M.D. Krotova, J. Electroanalytical Chemistry, 228, (1987), 19.

21. I. Yagi, D. Tsunozaki, D.A. Tryk, A. Fujishima, Electrochemical \& Solid State Letters, 2, (9), (1999), 457.

22. H.J. Looi, L.Y.S. Pang, A.B. Molloy, F. Jones, J.S. Foord. R.B. Jackman, Diamond \& Related Materials, 7, (1998), 550.

23. O. Nishikawa, K. Maeda, Y. Ohtani, M. Watanabe, K. Tanaka, T. Sekine, M. Iwatsuki, S. Aoki, J. Itoh, K. Yamanaka, Applied Surface Science, 146, (1999), 398.

24. G. M. Swain, R. Ramesham, Analytical Chemistry, 345, 65, (1993).

25. H. B. Martin, A. Argoitia, J.C. Angus, U. Landau, J. Electrochemical Society 146, 8, 2959, (1999).

26. H.B.Martin, A. Argoitia, U. Landau, A. B. Anderson, J. C. Angus, J. Electrochemical Society 143, 6, L 133, (1996).

27. S. Alehashem, F. Chambers, J. W. Strojek, G. M. Swain, Analytical Chemistry, 67, 2812 , (1995).

28. R.M. Torresi, O R. Câmara, C.P. de Pauli, Electrochimica Acta, 32, (1987), 1357.

29. Y.S. Kang, H. Y. Kim, J.Y. Lee, J. Electrochemical Society, 147, (12), 4625, (2000).

30. S. Yoshihara, K. Shinozaki, T. Zenbayashi, S. Morino, T. Shirakashi, K. Hashimoto, D.A. Tryk, A. Fujishima, Electrochimica Acta, 45, 3375, (2000).

31. I. Yagi, K. Ogai, T. Kondo, A. Fujishima, K. Ueda, K. Uosaki, Chemistry Letters, 32, $11,1050,(2003)$.

32. H.B. Suffredini, S. Machado, L. A. Avaca, J. Brazilian Chemical Society, 15, 1, 16, (2004).

33. Yu. V. Pleskov, M.D. Krotova, V.G. Ralchenko, A.V. Khomich, R.A. Khmelnitskiy, Electrochimica Acta, 49, 41, (2003).

34. G.M. Swain, J. Electrochemical Society, 141, (1994), 3383. 
35. T. Ando, S. Inoue, M. Ishii, M. Kamo, Y. Sato, O. Yamada, T. Nakano, J. Chemical Society, Faraday Transactions, 89,(4), 749, (1993).

36. T. Ando, M. Ishii, M. Kamo, Y. Sato, J. Chemical Society, Faraday Transactions, $89,(9), 1383,(1993)$.

37.T. Ando, K.Yamamoto, M. Ishii, M. Kamo, Y. Sato, J. Chemical Society, Faraday Transactions, 89,(19), 3635.

38. I. Yagi, H. Notsu, T. Kondo, D.A. Tryk, A. Fujishima, J. Electroanalytical Chemistry, 473, 173, (1999).

39. H. Notsu, I. Yagi, T. Tatsuma, D.A. Tryk, A. Fujishima, Electrochemical \& SolidState Letters, 2 (10), 522, (1999).

40. M. C. Granger, G.M. Swain, J. Electrochemical Society, 146, (12), 4551, (1999).

41. C. H. Goeting, F. Marken, A. Sosa, R.G. Compton, J.S. Foord, Diamond \& Related Materials, 9, 390, (2000).

42. N. Ohta, S. Nakabayashi, A. Fujishima, Chemistry Letters, 1147, (1999).

43. S. Yoshihara, K. Shinozaki, T. Shirakashi, K. Hashimoto, D.A. Tryk, A. Fujishima, Electrochimica Acta, 44, 2711, (1999).

44 - H. Notsu, I. Yagi, T. Tatsuma, D.A. Tryk, A. Fujishima, J. Electroanalytical Chemistry, 492, 31, (2000).

45 - H. Notsu, T. Fukazawa, T. Tatsuma, D.A. Tryk, A. Fujishima, Electrochemical \& Solid-State Letters, 4, (3), H1, (2001).

46- J. Lin-Cai, D. Pletcher, J. Electroanalytical Chemistry, 149, 237, (1983).

47- V.S. Bagotzky, L.S. Kanevsky, V.S.Palanker, Electrochimica Acta, 473, (1973).

48 -V.S. Bagotzky, A.M. Skundin, Electrochimica Acta, 757, (1984.

49- V.S. Bagotzky, A.M. Skundin, Electrochimica Acta, 951, (1984).

51- V.S. Bagotzky, A.M. Skundin, Electrochimica Acta, 485. (1985).

52- V.S. Bagotzky, A.M. Skundin, Electrochimica Acta, 899, (1985).

53- P. Garrido, E. Gomez, E. Vallés, J. Electroanalytical Chemistry, 441, (1998), 147.

54- Y. Nakato, H. Tsubomura, Electrochimica Acta, 37, (1992), 897.

55- K. Shimazu, D. Weisshaar, T. Kuwana, J. Electroanalytical Chemistry, 223, 223, (1987). 
56- L. Zubimendi, L. Vázquez, P. Ocón, J.M. Vara, W.E. Triaca, R.C. Salvarezza, A.J. Arvía, J. Phys. Chem. 5095, (1993).

57- P. Bindra, E. Yeager, Proceedings of The Symposium on Electrcrystallization, The Electrochemical Society, Pennington, 233, (1985).

58- V.P.Santos, G.T. Filho, Química Nova, 856, 24, 6,(2001).

59- P. Allongue, E. Souteyrand, J. Electroanalytical Chemistry, 286, 217, (1990).

60- S. Yae, M. Kitagaki, T. Hagihara, Y. Miyoshi, H. Matsuda, B. A. Parkinson, Y. Nakato, Electrochimica Acta, 345, (2001).

61- A. Malinauskas, Synthetic Metals, 107, 75, (1999).

62- Y.M. Maksimov, B.I. Podlovchenko, T.L. Azarchenko, Electrochimica Acta, 1053, (1998).

63- A.A. Mikhaylova, O. A. Khazova, V. S. Bagotzky, J. Electroanalytical Chemistry, $480,225,(2000)$.

64- McCreery R.L., Electroanalytical Chemistry, 221, vol. 9, p.221.

65. Yi-Fu Yang, Yun-Hong Zhou, J. Electroanalytical Chemistry, 415, 143, (1996).

66. C.P.Burguete, A.L. Solano, F.R. Reinoso, C.S.M. Lecea, J. Catalysis, 115, (1989).

67. K. Amine, M. Mizuhata, K. Oguro, H. Takenaka, J. Chemical Society Faraday, 91, 4451, (1995).

68. F. Bouamrane, A. Tadjeddine, R. Tenne, J.E. Butler, R. Kalish, C. Clément, J.Physical Chemistry B, 102, 134, (1998).

69- R. Sato, T. Kondo, K. Shimizu, K. Honda, Y. Shibayama, K. Shirahama, A. Fujishima, Y. Einaga, Chemistry Letters, 32, (2003), 972.

70- B. Miller, R. Kalish, L.C. Feldman, A. Katz, N. Moriya, K. Short, A. White, J. Electrochemical Society, 141, (1994), L41.

71- S. Nakabayashi, D.A. Tryk, A. Fujishima, N. Ohta, Chemical Physics Letters, 300, 409, (1999).

72- O. Enea, B. Riedo, G. Dietler, Nanoletters, 241, 2, (2002).

73- Y. Zhang, S. Asahina, S. Yosihara, T. Shirakashi, Electrochimica Acta, 48, 741, (2003).

74- K. B. Holt, G. Sabin. R.G. Compton, J. S. Foord, F. Marken, Electroanalysis, 14, (2002), 797. 
75- J. Wang, G. M. Swain, Electrochemical \& Solid-State Letters, 5, (2002) E4.

76- J. Wang, G. M. Swain, J. Electrochemical Society, 150, (2003), E24.

77- K. Honda, M. Yoshimura, T.N. Rao, D.A. Tryk, A.Fujishima, K.Yasui, Y. Sakamoto, K. Nishio, H.Masuda, J. Electroanal. Chem., 35, 514, (2001)

78- N.M. Markovic, H.A. Gasteiger, P.N. Ross, J. Phys. Chem., 100, 6715, (1996).

79- S. Trasatti (Ed.), Electrodes of conductive metallic oxides, Part B, 11, Elsevier, 1981.

80- I. Duo, P.A. Michaud, W. Haenni, A. Perret, C. Comninellis, Electrochem. Solid St. Lett., 325, (2000).

81- C. Terashima, T.N. Rao, B.V. Sarada, N. Spataru, A. Fujishima, J. Electroanalytical Chem., 65, 544, (2003)

82- S. Ferro, A. De Battisti, J. Physical Chemistry B, 2249, 106, (2003).

83- K. J. McKenzie, F. Marken, Electrochemical \& Solid-State Letters, E47, 5 (2002).

84- N. Spataru, C. Terashima, K. Tokuhiro, I. Sutanto, D.A.Tryk, S.M. Park, A. Fujishima, J. Electrochemical Society, E337, 150, (2003).

85- K. Nakagawa, C. Kajita, N. Ikenaga, T. Suzuki, T. Kobayashi, M. Gamo, T. Ando, J. Phys. Chem. B, 4048, (2003).

86- Y. Yuan, L. Wang, L. Feng, K. Xu, J. Shen, European Polymer Journal, 38, 2125, (2003).

87- T. Yano, E. Popa, D.A. Tryk, K. Hashimoto, A. Fujishima, J. Electrochemical Society, 146, (1999), 1081.

88. E. Popa, H. Notsu, T. Miwa, D.A.Tryk, A.Fujishima, Electrochemical \& Solid State Letters, 2, (1999), 49.

89. C. Terashima, T.N. Rao, B.V. Sarada, D.A. Tryk, A. Fujishima, Analytical Chemistry, $74,(2002), 895$.

90. J.W. Strojek, M. C. Granger, G.M. Swain, Analytical Chemistry, 68, (1996), 2031.

91. N. Vinokur, B. Miller, Y. Avyigal, R. Kalish, J. Electrochemical Society, 146, (1999). 
92. A. Fujishima, T.N. Rao, E. Popa, B.V. Sarada, I. Yagi, D.A. Tryk, J. Electroanalytical Chemistry, 473, 179, (1999).

93- I. Yagi, K. Tsunozaki, D. A. Tryk, A. Fujishima, Electrochemical \& Solid State Letters, 2, 9, 457, (1999).

94- G. Fóti, D.Gandini, C. Comninellis, A. Perret, W.Haenni, Electrochemical \& Solid State Letters, 2, (5), (1999), 228.

95- T. Iwasita, B. Rasch, E. Cattaneo, W. Vielstich, Electrochimica Acta, 1073, (1989).

96- C. Ehlers, U. König, G. Staikov, J.W. Schultze, Electrochimica Acta, 47, (2001), 379. 